THE INTERNATIONAL

REVIEW OF RESEARCH IN

OPEN AND DISTANCE LEARNING

\title{
Frontiers in Open and Distance Learning in the North
}

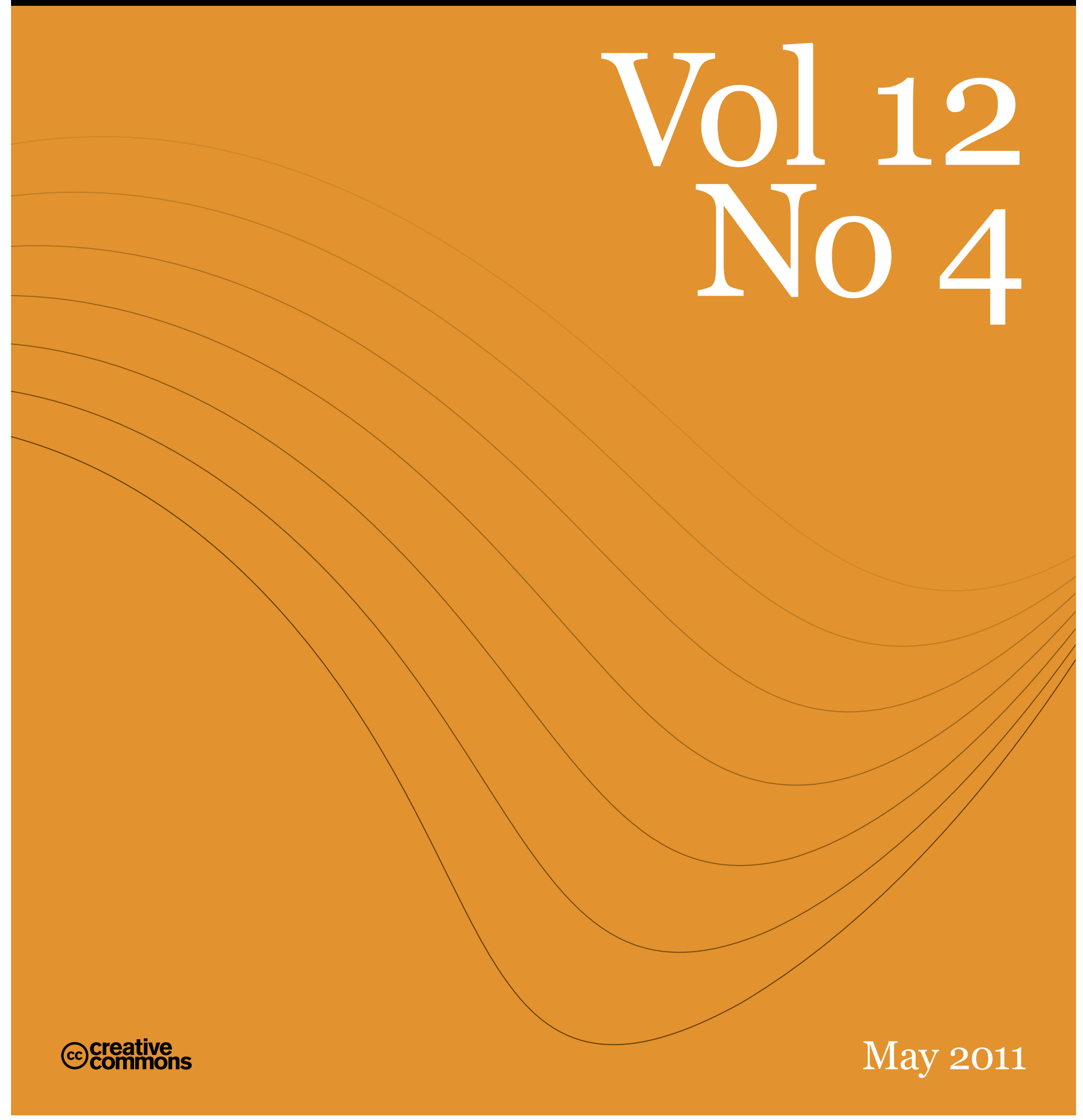




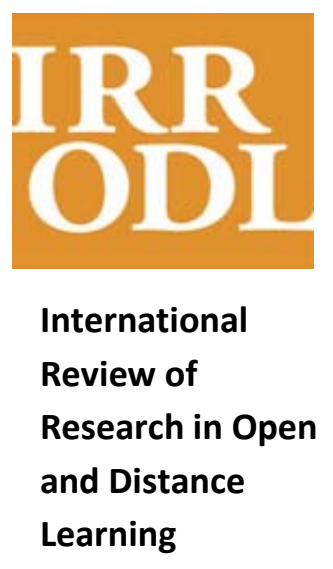

Vol. 12.4

May - 2011

\section{Special Issue Editorial}

\section{Some Frontiers in Open and Distance Learning in the North}

\author{
Steinar Thorvaldsen \\ University of Tromsø, Norway \\ Griff Richards \\ Athabasca University, Canada
}

The high North is a vast area with huge contrasts and strong seasonal variations. The situation in the North is special because the region for many years has been impressed by closed borders - a border that separated the East from the West and that represents great language, economic, technological, and social differences. However, the peoples in the high North have much in common, such as their closeness to nature and its seasons.

Some years ago the concept of the digital divide was used to describe the East-West situation of the North. The digital divide refers to the gap between people or nations with effective access to digital and information technology and those with very limited access (Compaine, 2001). It includes the imbalance in physical access to technology and in the resources and skills needed to effectively participate as a digital user. The term was introduced in the 1990s to describe the gap in ownership of computers between ethnic groups, but later it was also utilized to refer to differences in access between countries.

Education is one area where the digital divide makes an impact. And by bridging the digital divide, it is possible for regions to enhance communication with other countries and therefore to offer better educational and social opportunities.

The University of the Arctic (UArctic) started in 2001 as a virtual university with the mission to "Empower the residents of the Circumpolar North, by building human capital through higher education.” The realities of the Arctic region with its vast distances, great cultural diversity, and small communities and institutions called for a common effort by the involved nations and universities. UArctic is a cooperative network of universities, colleges, and other organizations committed to higher education and research in the North. UArctic has developed innovative courses offered in the classroom and in the field or delivered online, including north2north student exchange programs. 
The University of the Arctic Thematic Network on Distance Education and E-learning was started in 2008 with funding received from the Norwegian Ministry of Education and Research. University of Tromsø, Faculty of Education, is the lead and the host institution in the network, with participating institutions from Russia and Canada. In 2009 the thematic network arranged a conference in Murmansk in the Russian Federation on flexible learning, together with Murmansk State Pedagogical University (Levites et al., 2009).

The Arctic Frontiers conference is organized as an independent network and a leading meeting place for pan-Arctic issues. For the last five years annual conferences have been arranged in Tromsø.

On January 27-28, 2010 the UArctic Thematic Network on Distance Education and E-learning met at the University of Tromsø as part of the Arctic Frontiers conference, Part IV: Frontiers in E-learning of the High North. Here 18 papers were presented (see http://www.arcticfrontiers.com/).

The aim of the e-learning part of the conference was to exchange knowledge and research about e-learning and to host a discussion of the methodology of the field. It was centred on the learning processes, pedagogy, and appropriate information technologies necessary to deliver content to and support distant learners. The sessions had their main focus on education in the Arctic communities and regions. Particular emphasis was placed on technology-enhanced learning, and the pedagogic and creative use of learning management systems (LMS) were discussed, together with issues related to teacher training and digital resources from the Arctic region. Five of the presentations were from Russia, three from Canada, one from Denmark, and nine from Norway. A book of abstracts is available online for download (Arctic Frontiers, 2010).

After the conference, IRRODL made an open call for papers on Arctic issues, and we are happy to publish seven research articles and field notes in this special issue. The broad span of northern interests is evident in the collection of articles and field notes.

Alexander McAuley and Fiona Walton write under the title "Decolonizing Cyberspace: Online Support for the Nunavut MEd” and report results from a master's of education program offered between 2006 and 2009 among Inuit peoples of northern Canada. This program made significant use of an online component, and their paper situates the online component within the program, explores the pragmatic and theoretical reasons for its inclusion and design, and summarizes its contribution to the program as a whole.

From the opposite side of the North Pole, Lena Zamorshchikova, Olga Egorova, and Marina Popova of the Faculty of Foreign Languages at Yakutsk State University in Siberian Russia write about their bachelor's level project on foreign language called Net-Based Course Development: English through Digital Storyline.

Mariann Solberg at the University of Tromsø, Norway writes about "Educating the Citizen of Academia Online,” where experiences with the use of the tool Elluminate Live are presented, and 
the extent to which this tool has turned out to be helpful in developing the quality of online courses is discussed. Elluminate Live is a real-time application that enables synchronous oral dialogue, simultaneous sharing of texts, and so on.

Ronald Macintyre and Janet R. Macdonald from the Open University in Scotland discuss in their paper perspectives of distance learning students in remote rural areas of Scotland. They show that remote students in Scotland exhibit differences from urban students in terms of gender balance, age profile, previous educational qualifications, and income.

Nancy Steel and Patrick J. Fahy address better ways of attracting, preparing, and retaining underrepresented populations in northern Alberta communities for participation in adult education.

Peter Øhrstrøm at Aarhus University is leading and coordinating an EU-financed research project called HANDS, Helping Autism-Diagnosed Teenagers Navigate and Develop Socially. Ten partners from six countries are involved in this project, and the purpose is to improve the quality of life for teenage students with an autism diagnosis by providing an e-learning toolset to support the teenager's social development. The paper addresses the system design of HANDS as seen from the user's perspective and the results of the evaluation of the first prototype of the toolset.

Finally, Frank Rennie, Sigurbjörg Jóhannesdóttir, and Stefania Kristinsdottir report on "ReThinking Sustainable Education Systems in Iceland: The Net-University Project.” This report is written in light of the recent economic crisis in Iceland, which has raised issues of the sustainability of Icelandic Higher Education, but it may be sensible for other countries to be prepared for hard times too. There is a particular focus on the practical use of open educational resources for course design and the sharing of these course modules across university partners.

In summary, the tally of research and field note topics comprises an assorted mix. What is indisputable, however, is the consistent connection to sound and locally situated learning practice. This pedagogical approach must not only be observed but also shared and discussed, and we hope that IRRODL's special issue on Frontiers in Open and Distance Learning in the North will contribute to the discussion.

\section{References}

Arctic Frontiers (2010). Book of abstracts. Retrieved from http://www.arcticfrontiers.com/index.php?option=com_docman\&task=cat_view\&gid=138\&Itemid=306\&l $\underline{\text { ang }=\text { en }}$

Compaine, B. M. (Ed.) (2001). The digital divide: Facing a crisis or creating a myth? Cambridge, Massachusetts: MIT Press.

European Commission (2010). ICT for all: Technology supporting an inclusive world. Retrieved

from 
http://cordis.europa.eu/ictresults/pdf/policyreport/INF\%207\%200100\%20IST-

R\%20policy\%20report-eInclusion_final\%20studio.pdf

Levites, D.G., Mescherova, I., \& Savrasova, A.N. (Eds.) (2009). Quality of education and flexible learning: Problems of management. Murmansk: Murmansk State Pedagogical University. Mostly in Russian.

\section{Athabasca University $\mathbf{I}$}

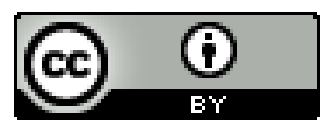




\section{ODR \\ International \\ Review of \\ Research in Open \\ and Distance \\ Learning}

Vol. 12.4

May- 2011

\section{Remote from What? Perspectives of Distance Learning Students in Remote Rural Areas of Scotland}

\author{
Ronald Macintyre and Janet Macdonald \\ The Open University in Scotland
}

\begin{abstract}
Distance learning is seen as the obvious answer for remote learners, and the use of online media is expected to overcome any access difficulties imposed by geographical distance. However, this belief may be obscuring our understanding of the role that location and individual circumstances have in shaping student experience. This paper explores the variation in experiences of remote rural students who study with the Open University (UK). The researchers found that perceptions of remoteness depended on geography, but were also relative to individual circumstances. With respect to students' sense of connection with university staff and peers, most mentioned their contact with their personal tutor. Networks with peers were less common, a matter of concern if peer networks are integral to fostering improved retention and progression. In this particular context, distance education may be playing an important and distinctive role for remote students by providing opportunities for connections with like-minded people.
\end{abstract}

Keywords: Distance learning; remote students; learning communities

\title{
Introduction
}

Distance learning is often seen as an obvious choice for many students with access limitations because it can provide higher education without the necessity for attendance at a campus, and geographically remote students are a case in point. However, little is known about the ways students in remote areas experience study, which could indicate their levels of satisfaction and show strategies to increase retention rates.

This may be because a focus on online learning within distance education as the best solution for all learners is obscuring our understanding of the range of contexts in which distance learning is experienced. This paper focuses on remote learners to illustrate this variation. The relationship between spatial remoteness and inclusion is often seen as an infrastructure and access issue with frequent reference to roads and broadband access (see, for example, Mason \& Rennie, 2004). 
While this technical and location focus is important - as poor infrastructure within remote locales stifles development - the theory that students' learning experiences will be the same wherever they live if they can study online is unproven (Warren, 2007).

This paper describes a case study of students in the North West Highlands of Scotland. The researchers use the experience of remote rural students as a way to explore the variation in students' experiences of learning with the Open University, UK (OU). The researchers explore those experiences in relation to the students' sense of being remote and of being a student.

\section{Academic Communities, Inclusion, and Access}

Rural educational research is often based on particular sectors with a prominent focus on compulsory education and ongoing professional development for teachers or health care professionals. For example, the schools literature primarily from Australia and North America describes the experience of pupils that engage in blended or distance learning (for example, Lowrie, 2007; Hannum, Irvin, Lei, \& Farmer, 2008), or in Northern Europe, the experience of pupils within small rural schools and policy innovation for community schools (Kvansland, 2004). The other main theme within the literature is ongoing professional development for teachers (Engestrom, Santo, \& Yost, 2008; McQuaide, 2009). Recent research within Iceland has studied the balance of online and face-to-face interactions within a postgraduate distance (blended) learning programme for rural teachers (Jakobsdóttir, 2008). Policy and academic discourses on rural health converge on problems associated with the delivery of education in rural areas to promote recruitment and retention and to maintain appropriate professional standards. Academic interest within this area is most pronounced within Australia, North America, and Scandinavia (Godden, Heaney, \& Farmer, 2007), shown, for example, in the role of mentors helping to support the maintenance of skills and ongoing professional development for rural nurses (Mills, Lennon, \& Francis, 2007).

The bulk of literature on distance learning for remote students focuses primarily on instructional design and user experience (Ritzhaupt, Stewart, Smith, \& Barron, 2010; Mason \& Rennie, 2004; Rennie \& Mason, 2005). Overall, there is a sense that the development of fixed and mobile Internet infrastructure has meant that since distance learning has adopted online media, there is less need to be engaged with location or rurality. The tendency to see the Internet as something that offers equality of access regardless of location is ever-present in the literature (see, for example, Rennie, 2003). A co-word analysis of North American distance learning journals with articles from Europe, North America, and Australia (Ritzhaupt et.al, 2010) found that computers have dominated distance learning literature since the late 1990s.

In Scotland, the government has invested heavily in the provision of digital infrastructure to improve Internet access within rural areas (Primrose \& Fawcett, 2007). In the early phase, Internet uptake in rural Scotland was higher than it was in urban Scotland (Scottish Executive, 2000). However, the idea of broadband as an enabler that offers equality of access is questionable, and it may be the case that differences in uptake and infrastructure between locations accentuate exclusion (Galloway, 2007). The result is that rather than leading to the 
“death of space,” ubiquitous broadband reconfigures spatial relations (Rye, 2009). Some parts of the economy and society become more integrated while others become more excluded, and this pattern is accentuated in rural areas (Grimes, 2003). The unevenness of uptake between locations even where infrastructure is present implies that a more subtle approach to understanding "access" is required.

Rural communities are increasingly being recognized as complex and heterogeneous places, particularly in relation to the lives of "hidden rural others" and to questions of exclusion (Philo, 1992; Cloke \& Little, 1997; Agyeman \& Neal, 2006). The hiddenness partly relates to the dispersed nature of comparative disadvantage within rural populations. The apparent hiddenness of rural deprivation, coupled with a perception of close social relations, can lead to situations where individuals are unable to access or are reluctant to seek help or advice. This means that educational outreach work and interventions suitable in an urban context, such as drop-in centers, may be less applicable and effective in a rural context (Shucksmith, 2000).

Debates around exclusion often center on accessibility. Inherently geographic, they ask us to think about the location of individuals and of services (Gray, Shaw, \& Farrington, 2006). However, in rural areas the solution is not simply a matter of road improvements and subsidized bus services (Farrington \& Farrington, 2005). Access is spatial, but it is also relative to the individual (Farrington, 2007). We must account for how accessible education is for different individuals as well. This understanding of access as relating to the individual and the individual's location reflects an increasing awareness within rural literature of the idea that rurality itself is subjective. This suggests that despite the apparent "evenness" of access afforded by a move toward online delivery, location is probably an oversimplification for distance learning provision.

The idea to conduct the research reported here was born out of concerns that the variations in student experience related to individuals' circumstances, and their locations may be overlooked. We use the context of rurality to explore this variation, and we apply a subtle understanding of what rurality is and what access means to rural students in distance learning. This case study of remote rural students set out to establish what factors influenced remote students' understanding and experience of studying with the OU.

\section{Characterizing Rural Scotland}

Scotland is one of the four nations that make up the United Kingdom. Although Scotland has always maintained an independent education sector, it has only had its own parliament since 1999. While Scotland contains only some 9\% of the UK population, it is dispersed over an area which amounts to more than one-third of the total UK land mass, including four major clusters of inhabited islands. Over 90\% of Scotland's landmass is predominantly rural. And while overall population density is low, it is highly urbanized with over two-thirds of the population living in urban areas. Figure 1 illustrates the distribution of urban and rural populations in Scotland. 


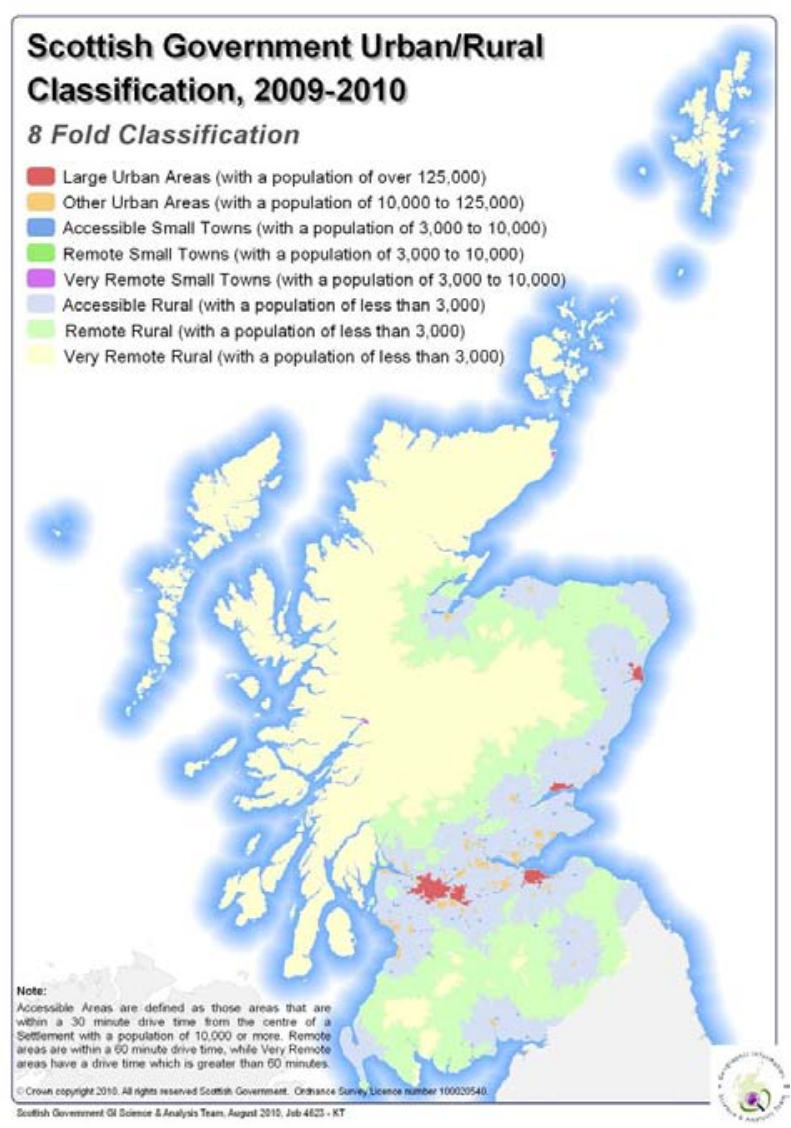

Figure 1. Scottish Government 8-Fold Urban Rural Classification (Scottish Government, 2010).

Scottish Government data on school leavers in rural areas show a relatively high percentage with Higher Education-level entry qualifications and a high percentage entering education or employment, but low participation in Further Education (technical and vocational) (Scottish Funding Council, 2009; Scottish Funding Council, 2010).

While a relatively high percentage of people in rural areas have Higher Education qualifications (Scottish Government, 2009), there are significant variations associated with migration. Key drivers of out-migration are limited local employment, limited local training, and participation in Further and Higher Education (Highlands and Island Enterprise, 2009). The idea that you have to "get away to get on" is supported by data collected in remote rural island communities, which show that $78 \%$ of those who leave will gain Higher Education qualifications, compared to $29 \%$ of those who stay. These leavers are primarily in the 16-24 age range. The report finds in-migrants' (including returners') households have higher incomes and tend to have higher educational qualifications than those who remain in the area (Hall Aitken, 2007). 


\section{Supporting Remote Students at the OU in Scotland}

The provision of support to remote students has been a concern of the university since its inception because of its mission to be open to all students, regardless of their situation. Catering to remote students is particularly relevant in Scotland, where approximately $20 \%$ of Scottish OU students are geographically remote.

Online systems have the potential to enable better access to a wider range of services for all as the systems themselves do not appear to differentiate between remote students and students elsewhere. These include administrative and operational systems governing applicant enquiries and course choice as well as access to Open Library services and online teaching systems.

Tutorial provision is both virtual and face-to-face, varying with the module and level of module. For example, on large population modules at entry, or level one (first year undergraduate), tutors are assigned geographically and may have a group of rural and remote students. Higher level (second and third year undergraduate) modules tend to have lower student numbers, which means tutor groups must cover a larger geographic area, so tutors can support remote and urban students in one group; some will hold face-to-face tutorials at study centers in the major cities where the majority of students are situated. Tutorial attendance is not compulsory, although students are required to travel to access exam centers at the end of most modules. However, in Scotland remote exam centers are provided for any students who live on the islands.

As the university moves away from face-to-face tuition, other forms of support are becoming more important. Telephone tuition has always been provided either one-to-one on demand or by arrangement with a group of students. However, online forums are increasingly used by tutors to keep in touch with their tutor groups of up to 25 students, and these complement the provision of plenary forums that provide course-wide discussion for several hundred students. Most recently, synchronous web conferencing via Elluminate is being adopted for the provision of online group tuition because it has the advantage of supporting common whiteboard and break-out rooms in addition to verbal communication and text chat options.

\section{Research Methods}

In order to gain a rich picture of the experience of remote and rural students, we chose a qualitative approach, including semi-structured telephone interviews followed by focus groups, with the intention of providing an in-depth understanding of the perspectives of remote rural students on their experience of study with the OU.

\section{Sample Selection}

An initial remote rural cohort within a unitary local authority area was identified using the Scottish Government's 8-fold indices of rurality (Scottish Government, 2010). Using postcodes, 
we were then able to extract quantitative data about the cohort from information already held by the Open University in Scotland.

The area selected was a "very remote" rural area in the Highlands and Islands of Scotland. It is over 70 miles from the nearest study center for tutorial provision and urban facilities. Currently the OU has 62 students residing in the area. They were studying at a wide range of levels and discipline areas. We sought permissions from the OU to approach these students, and after an initial email contact and a subsequent mailing to 42 students, a sample of 20 students took part in the research (see Table 1).

Table 1

Profile of Sample and OU Students in Study Area in Relation to Study Area and OU Students in Scotland

\begin{tabular}{|c|c|c|c|c|c|c|c|c|}
\hline & \multicolumn{2}{|c|}{$\begin{array}{l}\text { Gender ratio } \\
(\%)\end{array}$} & \multicolumn{2}{|c|}{$\begin{array}{l}\text { Fee waiver } \\
(\%)\end{array}$} & \multicolumn{4}{|l|}{$\begin{array}{l}\text { Age } \\
(\%)\end{array}$} \\
\hline & Male & Female & Yes & No & Under 25 & 25-44 & 45-64 & 65 \\
\hline $\begin{array}{l}\text { All OU } \\
\text { students in } \\
\text { Scotland }\end{array}$ & 40 & 60 & 28 & 72 & 9 & 60 & 27 & 3 \\
\hline Study area $^{1}$ & 49 & 51 & N/A & N/A & 28 & 26 & 28 & 17 \\
\hline $\begin{array}{l}\text { OU } \\
\text { students in } \\
\text { study area }\end{array}$ & 32 & 68 & 35 & 65 & 10 & 44 & 40 & 5 \\
\hline $\begin{array}{l}\text { Interview } \\
\text { sample }\end{array}$ & 25 & 75 & 45 & 55 & 0 & 60 & 30 & 10 \\
\hline
\end{tabular}

The demographic details included in Table 1 show that in relation to OU students in general and very remote rural students, the sample profile is slightly older and is more likely to be female, though gender ratios at the OU already tend toward female students (60/40). In terms of age, urban OU students peak in the 25-29 age group, whereas rural students peak in the 40-44 age group. This needs to be read in relation to the fact that remote rural residents themselves tend to be older; as noted earlier, many people migrate to access education and employment. However, in terms of numbers, the sample size is too small for qualitative analysis. We should also note that the profile of the sample is an accentuated version of the pattern observed when we compare all OU students in the study area with all OU students in Scotland. One final item to note is that 95\% of the sample consisted of migrants to the area; high percentages of in-migrants are characteristic of this part of Scotland. 


\section{Data Collection}

Once students had responded to the initial email or letter, they were contacted and a time and date was set for a short, semi-structured telephone interview. Twenty interviews were recorded, each typically lasting 20-30 minutes. In the interviews and the focus groups, students were asked to comment on different aspects of their OU experience. Students were asked about their sense of being remote and how they felt about being described as remote. They were asked whether they felt like students, who they had contact with at the OU, and how they had made those connections. In addition to the recordings, interviewers took handwritten notes. The interviews took place in May and June 2009. Interviewees were invited to attend one of two focus group sessions held in the study area. Four people took part in these. Informed by an initial reading of the interview material, the focus groups were centered on the activities that made people feel like students and explored peer networks in more detail. Student responses were recorded by the researchers in note form.

\section{Data Analysis}

The taped interviews were reviewed immediately after recording and the interviewers took note of the major themes that emerged. Once all the interviews had been conducted, the tapes were reviewed and coded by each interviewer then compared to identify dominant themes (Baxter \& Eyles, 1997). These informed a partial transcription of the data where specific examples were identified to illustrate the coded themes (Punch, 2005).

By reading the transcripts iteratively, it was possible to identify a number of common trends in students' perceptions. We describe these trends in the Findings section below and illustrate them with quotes from student responses. The aim was to paint as full a picture as possible of the variations in perspectives of respondents based on the principles of constant comparison (Glaser \& Strauss, 1967).

The relative openness of the coding in relation to the semi-structured nature of the collection methods employed led to a meaning-oriented analysis that could account for emergent themes. The use of specific examples to illustrate generic themes was also used as a way to focus on developing student-led narratives (Punch, 2005). Overall, while the initial theoretical perspectives informed and framed the questions and responses, we felt that this open approach to coding meant that the researchers mapped the emergent themes from the data rather than onto the data (Dingwall, 1997).

\section{Findings}

In this section, we describe the main themes arising from the coding under two headings: participants' perceptions of remoteness and their connections with the academic community of the university. 


\section{Remote from What?}

We were interested in investigating students' understanding and experience of their location, especially their sense of being remote. The title of this paper and the beginning of this section reflect the initial response of many students to our question about whether they recognized themselves as living in a remote area: "[I] do not think of myself as remote, [name of place] is a big place, bigger services, lots of access, online shopping for clothes and education online.”

Many of the respondents were keen to present remote rural life as a positive choice (95\% of the sample had moved to the area from elsewhere). However, when we began to explore those perceptions in greater detail, a more subtle pattern emerged. Participants described access in relation to lack of choice in employment, economic, and educational opportunities.

I am long-term unemployed and there are not a lot of job prospects.

I know what is available on the doorstep. Most of the things I would be interested in doing [studying] would have to be done via distance learning.

A sense of remoteness was apparent to participants when they had to access services that were geographically remote from them. For example, participants spoke about the difficulty of using public transport to access specialist health care or to visit relatives in hospital. This was also reflected in comments about accessing OU services that are delivered face-to-face.

I do, once I had gone to a tutorial, accessing that is a nightmare for someone without a car, I attended one in Glasgow, it meant an overnight stay ... [I] missed last hour in order to get the bus back home ... I realized just how remote I was [emphasis added].

The provision of a remote service or poor road networks and public transport contribute to the learner's sense of being remote. However, that sense of remoteness is accentuated by individual circumstances (such as lack of personal transport). While many remote rural students do access face-to-face sessions, they are not compulsory, and the main way that people access education is in their homes through study materials and in interactions with their tutor or fellow students on the Internet or the telephone.

Everyone within the sample had access to home broadband. It is clear that communication technology plays an important role in participants' understanding of remoteness because they were able to use online tools to access goods and services, and use of these is assumed to be integral to their way of life. Indeed, online tools are arguably more important in this context, where conventional alternatives are costly and time-consuming. 
.... depends what you are remote from ... I don't see myself as remote at all. ... I have telephone broadband all the services ... what you are looking at is simply distance from your tutor or other learners .... in terms of access to usual communication channels, you are not [emphasis added].

In the examples, distance within distance education is subjective. It is a relational concept where accessibility is relative to an individual's location, their personal circumstances, and the means they employ to gain access. Distance is mediated by "the usual communication channels," or access to "online shopping."

In this section we explored how location and individual circumstances changed the way that students experienced blended learning at the OU. In this context, the students' sense of being remote depended not just on their geography and the physical character of places but also on what they were trying to access, on how they tried to access it, and on their individual circumstances. This illustrates the wide range of influences affecting students' experience of study and the need to understand access relationally. In the next section we consider the nature of student interactions and the different ties that students in this study have with the OU.

\section{Networks, Ties, and Academic Communities}

Our interest in students' interactions relates to the idea that developing a sense of belonging to an academic community is important to a university's retention and progression strategy (Yorke, 2004; Longden, 2006). The value of this sense of community has been accepted among mainstream scholars, but establishing conditions that encourage it presents unique challenges to distance learning providers (Thomas, 2002). In this study we wanted to establish what ties the participants had with different individuals at the university and how they were maintained. Haythornthwaite (2004) has described the factors influencing the development of strong and weak ties within online communities, and we have chosen to use his terminology here. In addition, we are interested in networks within rural development; for our purposes, networks are referred to as horizontal (local or between peers) and vertical (extra-local or within a hierarchical organization) (Arnason, Shuckmsith, \& Vergunst, 2009). We use the term horizontal networks to refer to student peer networks and the term vertical networks to refer to the degree of integration with university staff.

The main tie that participants mentioned was their contact with and access to their personal tutors. Connections were made and ties maintained using online forums, email, group and individual telephone calls, and face-to-face meetings.

Tutor is always at the end of an email.

... using Elluminate and emails to keep in touch. 
[I] have tutors who have been very keen to telephone tutorials . . . I had one-to-one [consultations by telephone] and I found them very useful.

The range of communication channels used reflects the strength of this tie (Haythornthwaite, 2005). Participants reported infrequent communications with centrally based staff and stated that limited communication channels were available (among these, email dominates). These reports support other research in this area that suggests two distinct networks or academic communities exist within distance learning: course teams and office-based staff being one, and tutors and students the other (Correia \& Davis, 2008).

So far we have discussed vertical ties, which are connections between students and employees of the university, such as tutors and OU support staff. The tie with the tutor was seen as the main tie with the institution, and though the nature of the tie did vary, location did not seem to be a factor. When participants talked about being students or members of an academic community, they referred to connections with their peers, or horizontal ties. While contact with peers was a feature of campus-based study which some had experienced, it was unlikely to be a common feature in distance learning: "student life ... [distance learning is a] different social experience. ... I guess the same applies even if you are studying in a non-rural area."

Participants had established ties with their peers through forums, although the extent of their involvement varied considerably. The range of responses and involvement with forums within the sample was very similar to the involvement in online academic forums reported elsewhere (Paz Dennen, 2005). However, their reflections on the content of forum discussions also indicate that discussions within the forums themselves can be overtly geographic.

The fact that I live 80 miles away from a big town. . . . and I am studying with the OU. . . . When I miss tutorials, I cant "nip," well, on the forums you have people talking about "nipping" into the local bookshop.

Some students told us that they rarely felt like students, while for others their identity as a student was important.

...if you live in a small village and everyone knows what you are doing, and because I am not out working everyday at a certain job, people are always asking me what I do, all the time. Well, I have got lots to do. ... you end up mentioning that you are studying. ... .

Some felt most like OU students when they were attending exams, tutorials, and residential courses. Despite the issues around face-to-face connections, they were still seen as an important part of the student experience for many of the students. At the same time, these were experiences 
that made students feel different and reminded them of their remote locations: "[I've] got an exam coming up and that makes me feel like a student."

Some students have no desire to interact with their peers or their tutor, and some may even select distance learning for that very reason. Others do want contact with their tutors and peers. Participants spoke about the lack of like-minded people in their rural communities and wanted to get in touch with people who shared similar interests. The wish to connect with other like-minded people seemed to relate to a shared sense of being a student and the ability to learn about being a distance learning student from peers.

...[you experience] rural isolation as a learner, very few people like you, very few places to meet like-minded people.

In rural areas [you are] less likely to find other students studying your course.

In this context, distance education may be playing an important and distinctive role for remote students by providing opportunities for connections with like-minded people. These discussions were of interest because they reflected individuals' experience of their location. However, the benefits they saw were not course-specific; rather; they were social and related to learning how to be a distance learning student in what appears to be an implicit recognition of the additional emotional and cognitive demands of distance education.

\section{Conclusions}

This case study of remote rural distance learning students explores perceptions of remoteness in relation to two themes: access and accessibility as related to location and the individual and networks and ties within academic communities. Our findings indicate that it is difficult to characterize remote rural students as having uniform needs or requirements in terms of support from the university because of the variety and range of perspectives represented here. It is probably also true to say that many of the access challenges faced by remote students are common to urban students as well.

Participants understood remoteness in relation to what they were trying to access, to how they accessed it, and to their personal circumstances. This is in keeping with research that explores social inclusion and access in rural areas where geographic exclusion (remote rurality) may overlap and be accentuated by some forms of social exclusion (Shucksmith, 2000), such as low income and lack of access to personal transport.

We explored the different ways in which the student experience was mediated through the various ties and connections between the university and the student. We found that the students' main connection was with their individual tutor, though the strength of these ties varied between modules, tutors, and individual students. This connection is a common experience with most distance students. Networks with peers were less common, which is a matter of concern as some 
have argued that horizontal peer networks may be integral to fostering academic communities to improve retention and progression (Thomas, 2002).

Some participants reported feeling most like students (and thus members of an academic community) when attending face-to-face events like exams with fellow students, even though accessing distance services could make them feel remote. This emphasizes the role that maintenance of a range of contacts has in developing a sense of belonging (Haythornthwaite, 2005; Fuller \& Paton, 2008). However, location may be an important consideration if individuals experience other barriers that affect access (like income, work or caring responsibilities, and personal mobility) as location can accentuate exclusion.

It is important to bear in mind that education is just one of the services remote rural dwellers access, and distance learning for most students is a solitary, self-directed domestic activity. However, this case study suggests that for remote learners, place still matters. In the context explored here, individual understanding of remoteness depends on what students were attempting to access, on how they attempted to access it, and on individual circumstance. Online tools are part of the solution. Nevertheless, we must take care that a focus on availability and infrastructure does not obscure the importance of individual circumstances in shaping peoples' experience of place.

Further research is required to understand how we might account more fully for the role location and individual circumstances have in creating variations in student experience within our institution.

In relation to the context of this research, we have three recommendations for good practice in supporting remote rural distance students:

- provide induction and make students aware of the availability and value of online peer groups;

- consider further developments in non-subject-based online networks for study support and the maintenance of community with fellow students; and

- promote and maintain the use of locally based exam centers to alleviate accessibility issues. 


\section{References}

Agyeman, J., \& Neal, S. (2006). The new countryside? Ethnicity, nation and exclusion in contemporary rural Britain. Bristol, UK: Policy Press.

Arnason, A., Shucksmith, M., \& Vergunst, J. (2009). Comparing rural development: Continuity and change in the countryside of Western Europe. Aldershot, UK: Ashgate, UK.

Baxter, J., \& Eyles, J. (1997). Evaluating qualitative research in social geography: Establishing "rigour" in interview analysis. Transactions of the Institute of British Geographers, 22, 505-525.

Cloke, P., \& Little, J. (1997). Contested countryside cultures: Otherness, marginalisation and rurality. London, UK: Routledge.

Correia, A. P., \& Davis, N. (2008). Intersecting communities of practice in distance education: The programme team and the online course community. Distance Education, 29(3), 289306.

Dingwall, R. (1997). Accounts, interviews, observations. In G. Miller \& R. Dingwall (Eds.), Context and method in qualitative research (pp. 51-65). London, UK: Sage Publications.

Engstrom, M. E., Santo, S. A., \& Yost, R. M. (2008). Knowledge building in an on-line cohort. The Quarterly Review of Distance Education, 92(2), 151-167.

Farrington, J. H. (2007). The new narrative of accessibility: Its potential contribution to discourses in (transport) geography. Journal of Transport Geography, 15(5), 319-330.

Farrington, J. H., \& Farrington, C. (2005). Rural accessibility, social inclusion and social justice: Towards a conceptualisation. Journal of Transport Geography, 13(1), 1-12.

Fuller, A., \& Paton, K. (2008). "Barriers" to participation in higher education? Depends who you ask and how. Widening Participation and Lifelong Learning, 10(2), 6-17.

Galloway, L. (2007). Can broadband access rescue the rural economy? Journal of Small Business and Enterprise Development, 14(4), 641-653.

Glaser, B. G., \& Strauss, A. L. (1967). The discovery of grounded theory: Strategies for qualitative research. Chicago, IL: Aldine Publishing.

Godden, D., Heaney, D., \& Farmer, J. (2007). Contemporary issues in Scottish rural health care. Health and Rurality Digest, $12 . \quad$ Retrieved from http://www.abdn.ac.uk/crh/uploads/files/heard12.pdf 
Gray D., Shaw J., \& Farrington J. (2006). Community transport, social capital, and social exclusion in rural areas. Area, 38(1), 89-98.

Grimes, S. (2003). The digital economy challenge facing peripheral rural areas. Progress in Human Geography, 27(2), 174-193.

Hall Aitken (2007). Outer Hebrides migration study (Final report). Retrieved from http://www.cne-siar.gov.uk/factfile/population/documents/OHMSStudy.pdf

Hannum, W. H., Irvin, M. J., Lei, P. W., \& Farmer, T. W. (2008). Effectiveness of using learnercentred principles on student retention on distance education courses in rural schools. Distance Education, 29(3), 211-229.

Haythornthwaite, C. (2005). Social networks and Internet connectivity effects. Information Communication and Society, 8(2), 125-147.

Highland Council (2001). Highland Council 2001 Census homepage. Retrieved from http://www.highland.gov.uk/plintra/iandr/cen/cen.htm

Highlands and Islands Enterprise (2009). Young people in the Highlands and Islands: Understanding and influencing the migration choices of young people to and from the Highlands and Islands of Scotland (Final report). Retrieved from http://www.hie.co.uk/2009/Young\%20People\%20in\%20the\%20Highlands\%20and\%20Is lands\%20_\%20Final\%20Report\%20August\%202009.pdf

Jakobsdóttir, S. (2008). The role of campus sessions and face-to-face meetings in distance education. The European Journal of Open, Distance, and E-Learning, II. Retrieved from http://www.eurodl.org/index.php?p=archives\&year=2008\&halfyear=2\&article=348

Kvalsund, R. (2004). Schools as environments for social learning-shaping mechanisms? Comparisons of smaller and larger rural schools in Norway. Scandinavian Journal of Educational Research, 48(4), 347-371.

Longden, B. (2006). An institutional response to changing student expectations and their impact on retention rates. Journal of Higher Education Policy and Management, 28(2), 173-187.

Lowrie, T. (2007). Learning engagement in distance and rural settings: Four Australian cases. Learning Environment Research, 10, 35-51.

Mason R., \& Rennie, F. (2004). Broadband: A solution for rural e-Learning. International Review of Research in Open and Distance Learning, 5(1), 1-19. 
McQuaide, S. (2009). Making education equitable in rural China through distance learning. International Review of Research in Open and Distance Learning, 10(1), 1-21.

Mills J., Lennon, D., \& Francis, K. (2007). Contributing to a culture of learning: A mentor development and support project for Australian rural nurses. International Journal of Nursing Practice, 13, 393-396.

Paz Dennen, V. (2005). From message posting to learning dialogues: Factors affecting learner participation in asynchronous discussion. Distance Education, 26(1), 127-148.

Philo, C. (1992). Neglected rural geographies: A review. Journal of Rural Studies, 8(2), 193-207.

Primrose, D., \& Fawcett, J. (2007). Evaluation of the Scottish Executive's "Broadband for Scotland" intervention. Retrieved from http://www.scotland.gov.uk/Resource/Doc/212800/0056576.pdf

Punch, K. F. (2005). Introduction to social research: Quantitative and qualitative approaches (2nd ed.). London, UK: Sage Publications.

Rennie, F. (2003). The use of flexible learning resources for geographically distributed rural students. Journal of Distance Education, 24(1), 25-39.

Rennie, F., \& Mason, R. (2005). Bits or baubles: The opportunities for broadband to add value to education and learning. Scottish Affairs, 53, 31-47.

Ritzhaupt, A. D., Stewart, M., Smith, P., \& Barron, A. E. (2010). An investigation of distance education in North American research literature using co-word analysis. International Review of Research in Open and Distance Learning, 11(1), 37-60. Retrieved from http://www.irrodl.org/index.php/irrodl/article/view/763/1502

Rye, S. A. (2008). Exploring the gap of the digital divide: Conditions of connectivity and higher education participation. GeoJournal 71(2-3), 171-184.

Scottish Executive (2000). Digital inclusion: Connecting Scotland's people. Retrieved from http://www.scotland.gov.uk/Resource/Doc/158435/0042935.pdf

Scottish Funding Council (2009). Measures of success. Retrieved from http://www.sfc.ac.uk/web/FILES/ReportsandPublications/Learning_for_all_measures_of _success_March_09.pdf.

Scottish Funding Council (2010). SFC facts \& figures. Retrieved from http://www.sfc.ac.uk/web/FILES/UnusedFiles/SFC_Facts_Figures2010.pdf 
Scottish Government (2009). Rural Scotland key facts 2009: People and communities, services and lifestyle, economy and enterprise. Retrieved from http://www.scotland.gov.uk/Resource/Doc/285755/0087036.pdf

Scottish Government (2010). 2010 urban rural classification. Retrieved from http://www.scotland.gov.uk/Publications/2010/08/2010UR

Shucksmith, M. (2000). Exclusive countryside? Social inclusion and regeneration in rural areas. Joseph Rowntree Foundation. Retrieved from http://www.jrf.org.uk/sites/files/jrf/1859351271.pdf

Thomas, L. (2002). Student retention in higher education; the role of institutional habitus. Journal of Education Policy, 17(4), 423-442.

Yorke, M. (2004). Retention, persistence and success in on-campus higher education, and their enhancement in open and distance learning. Open Learning, 19(1), 19-32.

Warren, M. (2007). The digital vicious cycle: Links between social disadvantage and digital exclusion in rural areas. Telecommunications Policy, 31(6-7), 374-388.

\section{Athabasca University $\mathbf{A}$}




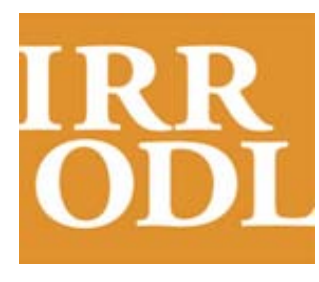

International

Review of

Research in Open

and Distance

Learning

Vol. 12.4

May-2011

\title{
Decolonizing Cyberspace: Online Support for the Nunavut MEd
}

\author{
Alexander McAuley and Fiona Walton \\ University of Prince Edward Island, Canada
}

\begin{abstract}
Offered between 2006 and 2009 and graduating 21 Inuit candidates, the Nunavut Master of Education program was a collaborative effort made to address the erosion of Inuit leadership in the K-12 school system after the creation of Nunavut, Canada's newest territory, in 1999. Delivered to a large extent in short, intensive, face-to-face courses, the program also made extensive use of online supports. This paper outlines the design challenges - geographical, technological, pedagogical, and cultural - that faced the development and delivery of the online portion of the program. It highlights the intersection of the design decisions with the decolonizing principles that framed the program as a whole, the various and varying roles played by the online environment over the course of the program, and the program's contribution to student success.
\end{abstract}

Keywords: Inuit; Aboriginal; distance graduate program; decolonization; pedagogy; K-12; school administrator; Indigenous education; Nunavut; decolonizing; educational leadership; distance education; distance learning; blended learning; knowledge building

\section{Background: The Nunavut MEd and the Need for Online Support}

Nunavut, created in 1999, translates to our land in English. As its name suggests, the territory was the culmination of nearly three decades of lobbying and negotiation by the Inuit of northernmost Canada for recognition of their rights to the lands they had occupied for centuries. As well as being the most significant change to the map of Canada in 50 years, the process of creating Nunavut made the Inuit the largest group of private landowners in the world and established a de facto Aboriginal government by virtue of the territory’s 85\% Inuit demographic.

While satisfying the legal and political requirements for an Inuit homeland, the creation of Nunavut was problematic with respect to establishing such things as the new government and economic self-sufficiency. In terms of the education system, the challenges of establishing the 
new territory resulted in a significant reduction in the number of Inuit educators in schools as many moved to jobs in the new bureaucracy. Advances in local control were also undermined because the divisional boards of education were eliminated. The net result of these events was fewer Inuit educators in schools, especially in leadership positions, which caused feelings of isolation and disempowerment to develop among Inuit who remained in the education system (O’Donoghue et al., 2005).

A survey of all educators in the Nunavut regions during the mid-1990s identified the need for graduate studies to be offered in Nunavut for Inuit (Nunavut Boards of Education, 1995; O’Donoghue, 1998). A 2004 study (O’Donoghue et al., 2005) reaffirmed this finding and set in motion a chain of events that resulted in the creation of the Nunavut Master of Education (MEd) program, initially offered between 2006 and 2009 (Tompkins, McAuley, \& Walton, 2009). The program was based on highly successful MEd outreach programs developed by the University of Prince Edward Island (UPEI) for small communities in northern Alberta. Unlike its Alberta counterparts, however, the Nunavut MEd made significant use of an online component. The remainder of this paper will situate the online component within the MEd program, explore the pragmatic and theoretical reasons for its inclusion and design, and summarize its contribution to the program as a whole. The authors will conclude the paper with lessons learned and plans for the program to continue to be offered through 2010-2013.

\section{The Context of the Nunavut MEd}

From a geographic perspective, Nunavut seems like a natural candidate for distance learning programs. Its 30,000 residents live in 28 communities with populations ranging in number from 140 to 6,200 scattered across the northeastern portion of Canada's landmass. The territory constitutes one-fifth of the entire country, nearly 2 million square kilometers. There are no roads between communities or between Nunavut and southern Canada, and except for snowmobile trails and a brief shipping season from August to October, only transportation by air is available. Bringing people together is expensive at the best of times and is often impossible because of extreme weather conditions. Even so, all communities have satellite access to TV, radio, and the Internet.

The 27 candidates in the program came from eight of these communities - Igloolik, Iqaluit, Pangnirtung, Sanikiluaq, Kugluktuk, Cambridge Bay, Arviat, and Rankin Inlet (Figure 1). All were Inuit women with bachelor of education degrees who held leadership positions in education and their communities and who spoke Inuktitut or Inuinnaqtun as their mother tongue. While some were graduates of the northern high school system, several were survivors of the residential schooling model, a colonial legacy that existed into the 1980s. The candidates were therefore representative of $85 \%$ of the Inuit population of Nunavut and, more particularly, of the $50 \%$ of Inuit who still identify Inuktitut as their home language.

The restriction of the Nunavut MEd to Inuit candidates was regarded as a controversial policy at first, incurring charges of racism from some quarters. It was, however, based on the fact that Inuit educators and the linguistic and cultural capital they bring with them are severely 
underrepresented in the school system, particularly in leadership positions. Moreover, compared to non-Inuit educators, Inuit are more likely to find that family and community obligations make it difficult for them to take graduate programs at universities in the south. A graduate program offered to Inuit in Nunavut therefore fit within the stated goals of the Government of Nunavut for a public service that reflects the territory's demographics and is shaped by Inuit Qaujimajatuqangit, or traditional Inuit values.

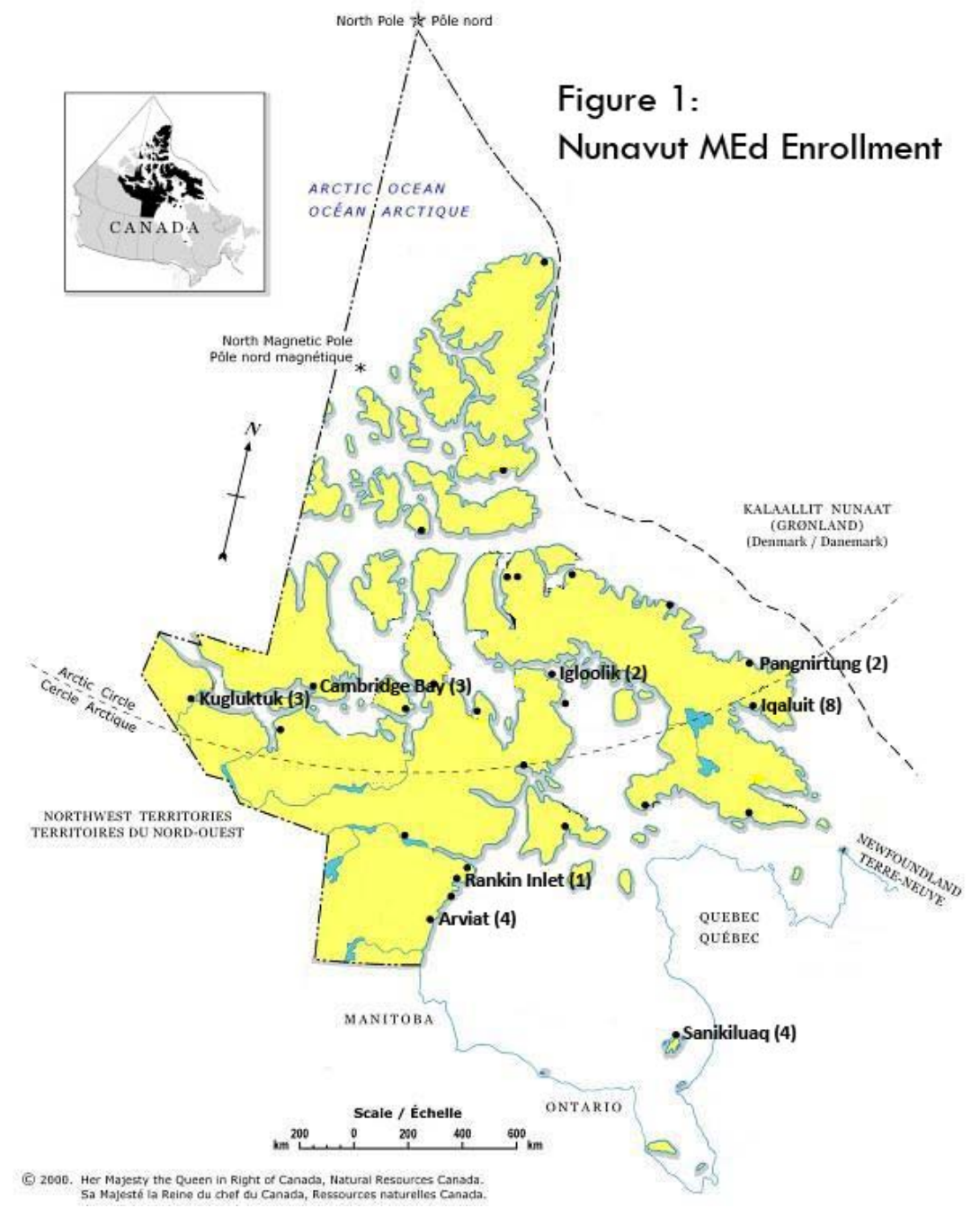

\section{Design Challenges}

Although geography and logistics argued for the potential of distance learning as a delivery mode for the MEd in Nunavut, other factors urged caution. As mentioned above, while Inuit educators in Nunavut had expressed an interest in starting an MEd program by distance education, they were only one-sixth as likely to wish to take courses or workshops by distance education as their non-Inuit peers (Nunavut Boards of Education, 1995, p. 6) and over twice as likely to "find it hard to take a distance education course” (p. 14). The choice of the typical ten-course, part-time outreach MEd program from UPEI partially addressed this issue with its emphasis on short, 
intensive, face-to-face courses. It did, however, require further adaptation to the Nunavut context. Most salient for this paper, given the distribution of the program candidates, a fully face-to-face program would have been prohibitively expensive and would have required unacceptably long absences from candidates' home communities. A blended program combining face-to-face meetings and distance learning was therefore necessary. How the blending would take place was the next issue.

Whether face-to-face or at a distance, the program had to respond to a number of fundamental concerns. All candidates were Inuit and spoke Inuit Uqausingit (Inuit languages) as their mother tongue and believed strongly in the importance of Inuit language and culture in the MEd program in particular and the school system in general. At the same time, many expressed the fear that the program might become "watered down," an accusation also leveled by a number of the program's critics. Because there were no Inuit with advanced degrees in education at the time, the decision was made to hire lead instructors with extensive experience in the North and to draw on the participation of Elders and guest speakers as adjunct instructors. A related decision was to encourage the use of written and spoken Inuit Uqausingit in courses wherever possible.

At a deeper level in terms of both program content and design, designers of the Nunavut MEd program intended to acknowledge and create a critical focus on the postcolonial context in which it existed. To what extent do the values and methods for creating and validating knowledge in a conventional academic program intersect, conflict with, or dominate those at the heart of Inuit society? To what extent and how could the MEd program provide access to the academic and economic capital of a graduate degree while questioning and reframing the underlying assumptions? As an initial step toward addressing this concern, an instructor with extensive northern Canadian experience and a background in cultural grief counselling became an integral member of the program team and a part of virtually every course. In addition, content that drew from Indigenous experience in the North and elsewhere was used extensively. Finally, several courses integrated presentations by Elders, and two of these individuals, Mariano Aupilardjuk and Meeka Arnakaq, received honorary degrees from the University of PEI at the end of the program (Tompkins, McAuley, \& Walton, 2009).

Smith’s "Indigenous Research Agenda” (1999, p. 117), with its emphasis on decolonizing, mobilization, and transformation through four "tides" (survival, recovery, development, and selfdetermination), provided an initial conceptual framework that situated the overall goals of the Nunavut MEd within the larger sociocultural, -political, -epistemological, and -ontological contexts. Reflected in various forms of writing explored by students throughout the program, her "Twenty-five Indigenous Projects" helped make explicit the connection between their individual and collective work and the wider project of decolonization.

A second, perhaps more diffuse conceptual framework permeating the Nunavut MEd, was that of Inuit Qaujimajatuqangit (IQ). A framework that "embraces all aspects of traditional Inuit culture including values, world-view, language, social organization, knowledge, life skills, perceptions and expectations” (Government of Nunavut, 2005, p. 5), Inuit Qaujimajatuqangit is being used to guide the development of all government initiatives in Nunavut, including education. The 
diffuseness of this framework with respect to the Nunavut MEd is a result of its being an emergent "work in progress," particularly at its intersection with the values and structures of contemporary governmental institutions and practices.

As Figure 2 illustrates, six of the eight Inuit Qaujimajatuqangit principles are relational, that is, they focus on connections between individuals and their sociocultural, psychosocial, and physical environments. Although all eight principles influenced the design of the distance learning portion of the MEd, relationality was particularly important.

\section{IQ Principles}

$$
\begin{aligned}
& \text { Inuuqatiglitsiarniq: } \\
& \text { respecting others, } \\
& \text { relationships, and caring } \\
& \text { for people. }
\end{aligned}
$$

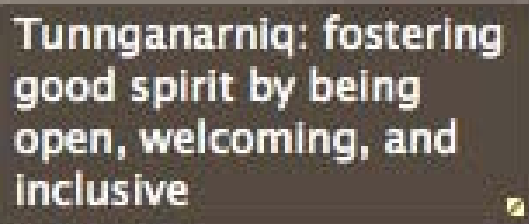

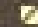

Piliriqatigiinniq/ Ikajuqtiglinniq: working together for a common cause

\section{Avatittinnik Kamatsiarniq: respect and care for the land, animals, and the environment}

Pijitsirniq: serving and providing for family and/or community a
Pilimmaksarniq/
Pijariuqsarniq: development
of skills through practice, effort, and action

\section{Qanuqtuurniq: being innovative and resourceful}

2

Figure 2. IQ Principles.

\section{Decolonizing Cyberspace: Design Choices for the Online Environment}

Based on this discussion, the ideal distance learning environment for the Nunavut MEd would support enduring relationships between widely distributed students and instructors over the threeyear program, bridging both geographic separation and the gaps between courses. As well as 
supporting program delivery, the goal was to create a sense of the persistence of the course content and student-student, instructor-student, and instructor-instructor relationships. Asynchronous text-based interaction in Inuit Uqausingit and English was the minimum necessary requirement; however, a synchronous audiovisual mode would have enhanced the sense of presence between participants and extended it to the participation of Inuit Elders and their knowledge, which is primarily oral. A final goal was to make the environment lend itself to student control, that is, not dependent solely on instructional or institutional impetus for use.

The explosion of multimodal web-based technologies over the past 10 years should have made possible all of these affordances. Two limiting factors intervened, however, the first being the erratic nature of broadband Internet connections within Nunavut and the second the desire for a consistent and coherent means of online support. Although all Nunavut communities have broadband Internet access and the quality of that access has improved since it first became available in the mid-1990s, it still lags far behind what is available in most of southern Canada in terms of both bandwidth and reliability. Experiments with iVocalize, Elluminate, and Skype quickly demonstrated that Internet-based synchronous audio and audio-video multipoint interaction were a greater source of frustration than facilitation as participants inevitably dropped offline unexpectedly, had difficulty connecting, or experienced garbled transmissions. NonInternet teleconferencing alternatives might have been possible, but were generally much more expensive, less flexible, and less open to student-initiated ad hoc use. Synchronous multipoint interaction was therefore reduced to scheduled teleconference calls, and even these were handicapped by having to coordinate four time zones. Yet despite its shortcomings, Skype did find a very useful role for casual, point-to-point contact because its contact list readily displayed the online status of program participants.

Although the results of experiments with synchronous multimedia environments were disappointing, they had been anticipated, and the decision to rest most of the distance learning component of the program on an asynchronous web-based system was made well before the program began. Abundant alternatives meet these criteria, ranging from open source learning management systems (LMS) such as Moodle and Sakai to commercial products such as Blackboard and Desire2Learn. Because its use had been intrinsic to a longitudinal study of network-supported knowledge building in the Northwest Territories/Nunavut and because that research had documented a knowledge building framework relevant to and effective within the cross-cultural northern context (McAuley, 1998; McAuley, 2001; McAuley, 2004; McAuley, 2009), a knowledge building environment (KBE) called Knowledge Forum became the underlying technology for the program. While Knowledge Forum had superficial similarities to other environments in terms of its support for such things as nested discussions, uploaded documents, inline display of a variety of multimedia formats, and links to external web-based resources, conceptually and in terms of some critical technological affordances it was very different.

The Knowledge Forum environment implemented to support the Nunavut MEd was built around three organizing principles: community, agency, and ideas (McAuley, 2004). Candidates in the program were expected to contribute to a community that worked with ideas in order to create 
new knowledge. Participation in this community required that candidates take active roles (agency) both in the processes of working with the ideas (contributing, questioning, critiquing, synthesizing, and so on) and in shaping the social processes by which the community worked (supporting each other, dividing labor, being open, and sharing resources). Agency was also critical for participants to integrate the emerging IQ principles into the online environment. Given that the principles are as much "a living technology . . . a means of organizing family and society into coherent wholes” (Arnakak, 2001) as they are a fixed set of traditional values, allowing the non-Inuit lead instructors to predefine their roles in the online environment would have been inappropriate at best. Consistent with Scardamalia and Bereiter's work on the principles underlying effective knowledge building communities and the technical and social affordances of knowledge building environments to support them (Scardamalia, 2002), and Cummins' work on effective intervention for collaborative empowerment in bilingual contexts (Cummins, 2001, 1996), the community/agency/ideas framework provided a starting point from which to begin exploring a distance learning environment consistent with both Inuit Qaujimajatuqangit and the Nunavut MEd as a decolonizing project.

Password protected and accessible via a Web browser (a more sophisticated Java-based interface exists, but might not have survived problematic Nunavut Internet connections), the Nunavut MEd Knowledge Forum environment created a single envelope for all online aspects of the program. Instructors defined the initial organizing structures for each course and students followed these structures for their initial contributions, but the fluidity of the environment allowed emergent structures as well. So, for example, if a participant wished to pursue an idea or question later in the program, she could search the entire corpus of the Knowledge Forum database for relevant contributions, create a new view, and continue to work with the material, all without leaving the environment. Regardless of when it was made, each contribution to the Knowledge Forum persisted throughout the full length of the program as a potential resource. The knowledge embodied in the Knowledge Forum was not static, but continually open to review, reassessment, and revision. In the spirit of an open community, all contributions were visible and open to comments and annotations by all participants. 


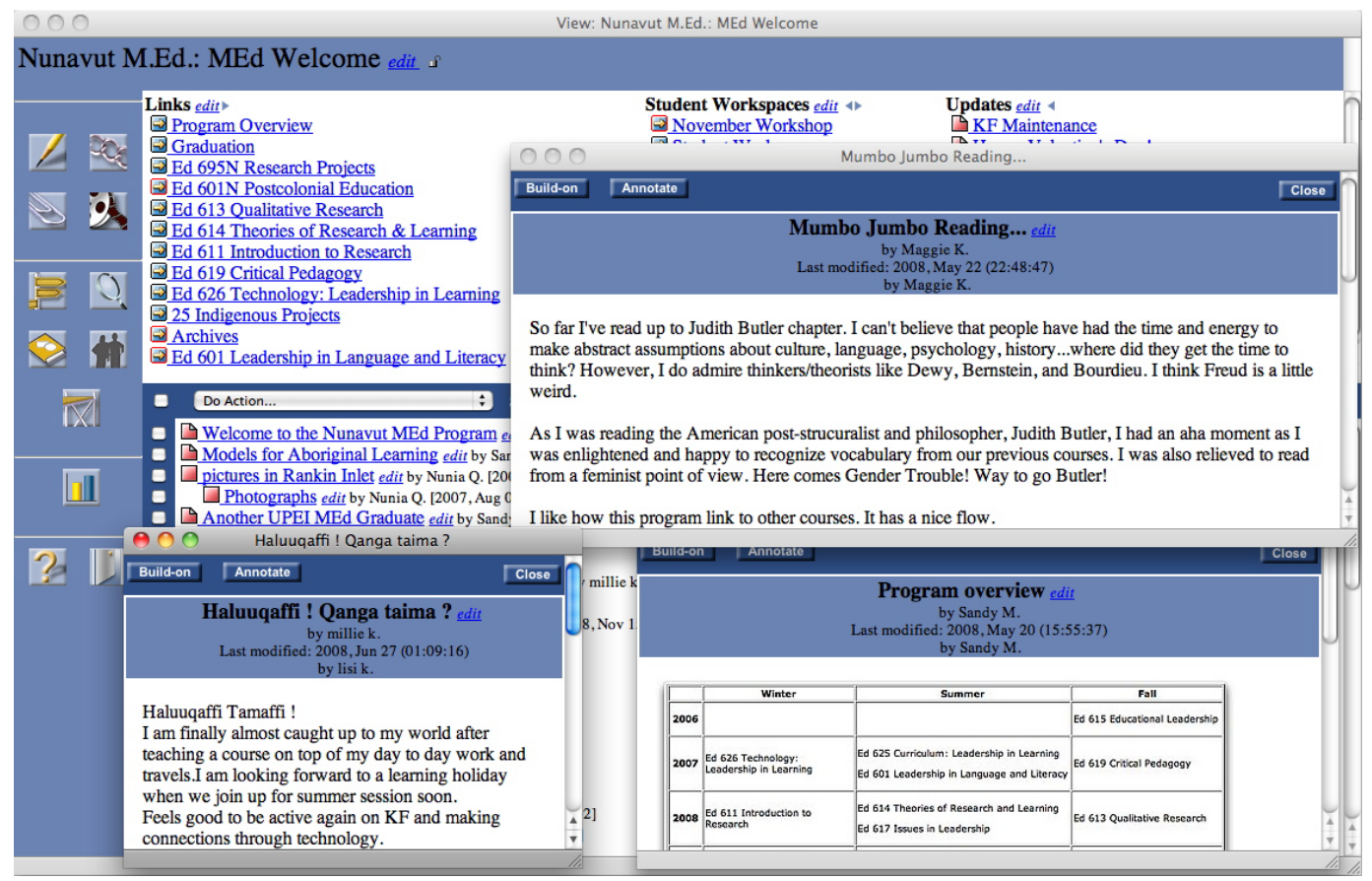

Figure 3. An illustration of some of the features of the environment.

The image in Figure 3 shows the opening view of the Nunavut MEd database and three notes, one of which is partly in Inuinnaqtun and another which contains a graphic. A view, which might be considered analogous to a topic, is an online space to which contributions in the form of notes can be posted to form threaded discussions. Notes can contain text, graphics, multimedia objects, and file attachments such as PDFs. The upper space of the view has been designed with a header that provides ready access to critical notes and commonly used hyperlinks to other views. Participants can respond to notes with "annotations" (electronic post-it notes) inserted into a note or "buildons" external to the note that are indented to form the "thread" of the discussion. The left-hand portion of the view provides access to tools that allow participants to create notes, views, and links, attach documents and multimedia objects, and search across the database using a number of criteria. Additional tools such as keywords, problem fields, discourse scaffolds, and automatic referencing facilitate participants to move beyond simply contributing to a discussion to work with the knowledge that emerges from them.

The notion of actually working with the notes contributed to the online discussions and is probably the defining feature of Knowledge Forum, distinguishing it from most other online environments. All participants, instructors, and students alike can create new views and move notes into those views from others to emphasize new or emerging understandings. They can edit and revise their notes in response to annotations or to reflect deeper understanding. This kind of "knowledge work" was probably best shown in student portfolio views, in which students drew together notes from across several views to demonstrate their learning or in pre-course assignments which asked them to reframe work from previous courses in preparation for engaging new concepts or material. 
While Knowledge Forum served as the foundation for the online support of the Nunavut MEd, Skype and low-bandwidth multimedia presentations created using Impatica for PowerPoint supplemented it in the courses offered solely at a distance. As indicated previously, Skype allowed participants and instructors to see who was online at any given time and thus encouraged communication and relationship building without incurring large costs or the time wasted playing "telephone tag." PowerPoint presentations could be created by instructors without sophisticated digital production skills and were used to support learners working in their second language and to supplement mainstream academic texts with relevant northern examples. Participants used them as user-friendly audiovisual introductions to their academic English-language texts. Figure 4 shows the first slide of one such presentation. Based on a Nunavut MEd research quilt, developed by course candidates during a fall workshop, it contextualized the first week's work in the online course beginning the following January.

\section{Introduction to Educational Research}

Week 1: More than a beginning

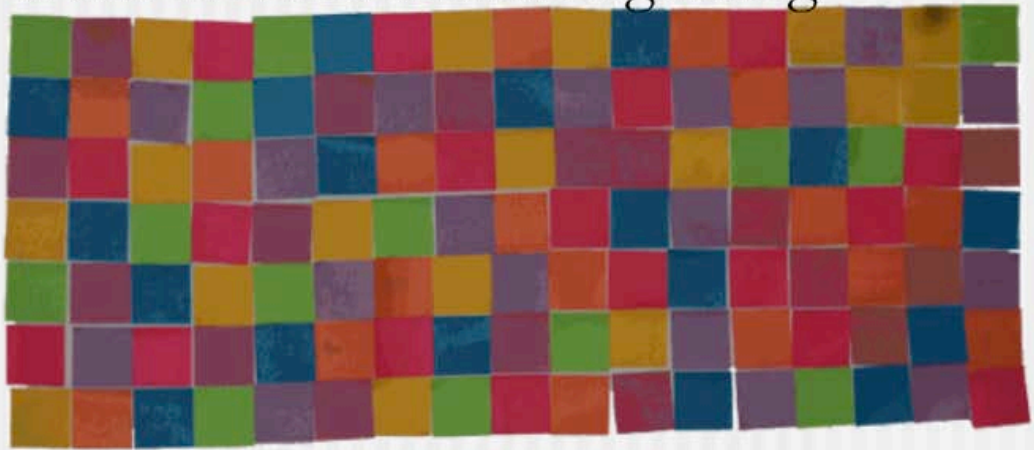

The Nunavut MEd research quilt constructed in Iqaluit, October 2007.

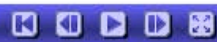

Figure 4. The Nunavut MEd research quilt.

\section{Results: The Role(s) of the Online Environment}

The following table summarizes the role of the online environment across the 10 regular courses and one makeup course of the Nunavut MEd. White rows indicate courses in which the online 
environment played little or no role, while light grey rows indicate those in which it played some role, and dark grey rows indicate courses offered completely via distance learning. A larger number in the course views column indicates greater complexity in the use of the online environment than a smaller number. The numbers of student and instructor notes provide a rough measure of the extent of online engagement. The research notes column highlights additional details about each course.

Table 1

The Role of the Online Environment

\begin{tabular}{|c|c|c|c|c|c|c|c|}
\hline Courses & Mode & $\begin{array}{c}\text { Online } \\
\text { functions }\end{array}$ & $\begin{array}{c}\text { \# of } \\
\text { instructors }\end{array}$ & $\begin{array}{c}\text { Course } \\
\text { views }\end{array}$ & $\begin{array}{c}\text { Student } \\
\text { notes }\end{array}$ & $\begin{array}{l}\text { Instructor } \\
\text { notes }\end{array}$ & $\begin{array}{l}\text { Research } \\
\text { notes }\end{array}$ \\
\hline $\begin{array}{l}\text { Ed } 615 \\
\text { Educational } \\
\text { Leadership }\end{array}$ & FTF & $\begin{array}{l}\text { Pre-course } \\
\quad \text { work } \\
\text { resources }\end{array}$ & 2 & 1 & 0 & 3 & $\begin{array}{l}\text { Students took } \\
\text { a KF training } \\
\text { session } \\
\text { during } \\
\text { course. Little } \\
\text { take-up of } \\
\text { online } \\
\text { component } \\
\text { for the course } \\
\text { itself. }\end{array}$ \\
\hline $\begin{array}{l}\text { Ed } 626 \\
\text { Technology: } \\
\text { Leadership } \\
\text { in Learning }\end{array}$ & Distance & $\begin{array}{l}\text { Primary } \\
\text { delivery } \\
\text { medium }\end{array}$ & 2 & 27 & 956 & 422 & $\begin{array}{l}\text { KF primary } \\
\text { delivery } \\
\text { mode. } \\
\text { Supported by } \\
\text { Skype \& } \\
\text { conference } \\
\text { calls. Poor } \\
\text { test results } \\
\text { with } \\
\text { iVocalize \& } \\
\text { Elluminate. }\end{array}$ \\
\hline $\begin{array}{l}\text { Ed } 601 \\
\text { Leadership } \\
\text { in Language } \\
\text { and Literacy }\end{array}$ & FTF & $\begin{array}{l}\text { Pre-course } \\
\text { work } \\
\text { resources }\end{array}$ & 2 & 3 & 167 & 30 & $\begin{array}{l}\text { Inuk } \\
\text { instructor } \\
\text { contributed } \\
\text { most of } \\
\text { instructor } \\
\text { notes. Course } \\
\text { home view } \\
\text { with } \\
\text { resources \& } 2\end{array}$ \\
\hline
\end{tabular}




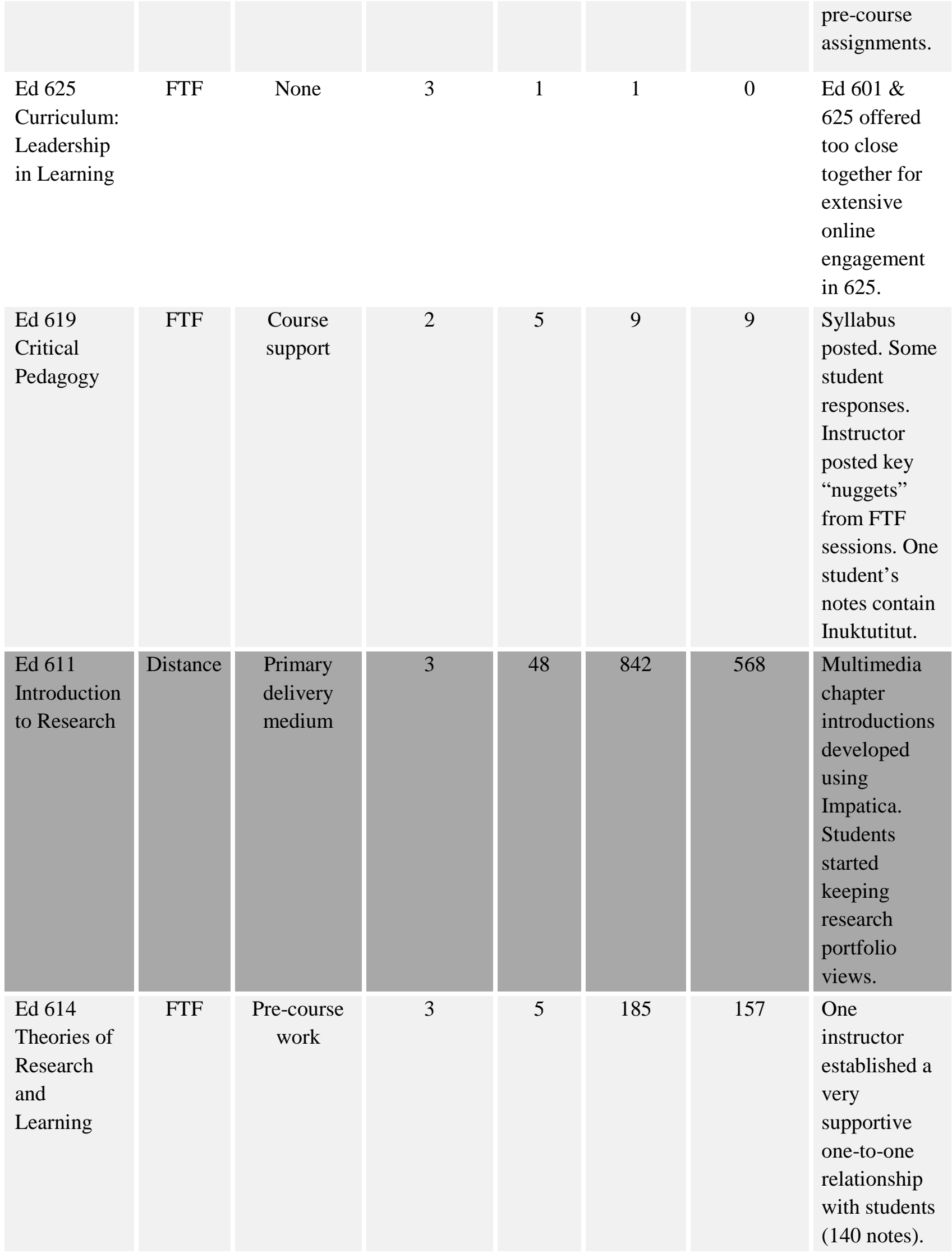




\begin{tabular}{|c|c|c|c|c|c|c|c|}
\hline $\begin{array}{l}\text { Ed } 617 \\
\text { Issues in } \\
\text { Leadership }\end{array}$ & FTF & $\begin{array}{l}\text { Introductory } \\
\text { course note }\end{array}$ & 3 & 1 & 1 & 1 & $\begin{array}{l}\text { Syllabus } \\
\text { distributed by } \\
\text { email. } \\
\text { Instructor } \\
\text { reviewed } \\
\text { student } \\
\text { contributions } \\
\text { to preceding } \\
\text { course. Ed } \\
614 \text { \& } 617 \\
\text { offered too } \\
\text { close } \\
\text { together for } \\
\text { extensive } \\
\text { student } \\
\text { engagement. }\end{array}$ \\
\hline $\begin{array}{l}\text { Ed } 613 \\
\text { Qualitative } \\
\text { Research }\end{array}$ & FTF & $\begin{array}{l}\text { Pre-course } \\
\text { work }\end{array}$ & 3 & 11 & 236 & 69 & $\begin{array}{l}\text { To begin, } \\
\text { students } \\
\text { created and } \\
\text { posted } \\
\text { PowerPoint } \\
\text { summaries of } \\
\text { their work in } \\
\text { Ed } 611.17 \\
\text { student \& } 5 \\
\text { instructor } \\
\text { notes were } \\
\text { added to } \\
\text { research } \\
\text { portfolios } \\
\text { during this } \\
\text { course. }\end{array}$ \\
\hline $\begin{array}{l}695 \mathrm{~N} \\
\text { Research } \\
\text { Projects }\end{array}$ & Distance & $\begin{array}{l}\text { Primary } \\
\text { delivery } \\
\text { medium }\end{array}$ & 7 & 29 & 43 & 40 & $\begin{array}{l}\text { Closely } \\
\text { monitored } \\
\text { (1:3 teacher- } \\
\text { to-student } \\
\text { ratio) } \\
\text { research } \\
\text { project. Each } \\
\text { student (21) } \\
\text { had a view } \\
\text { for an online } \\
\text { research }\end{array}$ \\
\hline
\end{tabular}




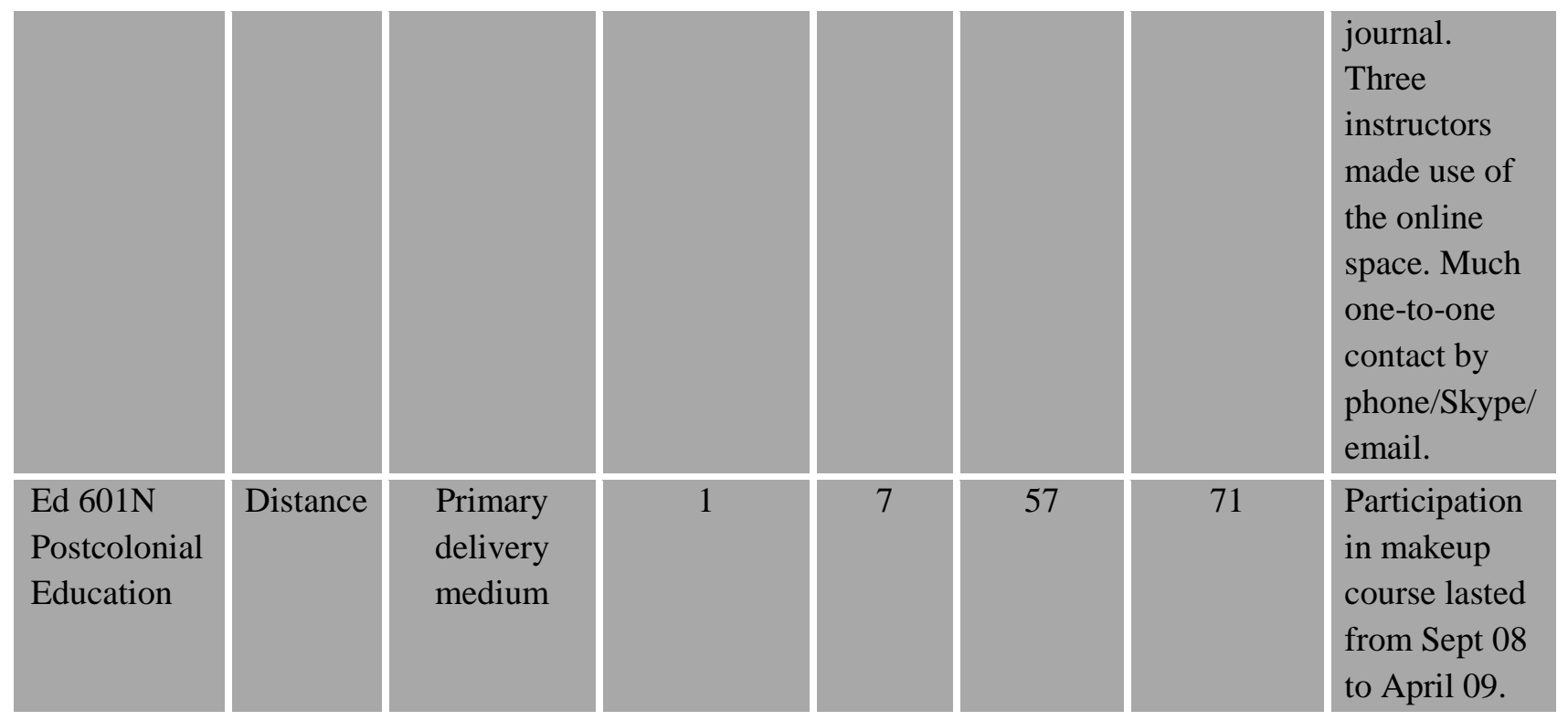

As Table 1 shows, the online environment played the main role in four of the eleven courses, a lesser role in four more, and no significant role in the remaining three. No online expectation had been set up for the first course of the program, during which a training session for using the program was held. The lack of a significant role for the online environment in the other two courses was partially the result of their being the second course in two-course, back-to-back summer offerings and partially the result of an instructor's lack of comfort with the environment.

Informal feedback, anonymous course evaluations, and feedback from structured interviews painted an almost universally positive picture of the contribution of the online component to the Nunavut MEd. Described as a "big plus" by one MEd candidate and "our lifeline" by another, its overall importance was probably best summarized in the words of a third:

Knowledge Forum allows for interaction that couldn't take place otherwise. Collaboration can take place across Nunavut. When we are forced to use technology we learn new ways to feel part of a community in such a large territory. Sometimes being forced to do something launches you into it. (Telephone interview)

Access to other students and instructors that would have otherwise been impossible was a recurring theme in much of the feedback and speaks to the creation of a community that spanned the vast distances, geographic and otherwise, that separated candidates and instructors. Another student speaks to this on a more conceptual level, noting that, "What worked was we learned to share our views online openly” (Ed 626 Student Evaluation). Given the complicated interpersonal relationships that sometimes played out in both the small communities and the face-to-face sessions, the confidence to share openly is very significant. This is not to say that the online engagement was without challenges. As another student's comment demonstrates, sometimes the complexities of life in a small community made working online difficult: "It was my first time to 
do [an] online course. It was difficult to concentrate on my work because I work at home most of the time” (Walton, McAuley, Tompkins, Fortes, \& Frenette, 2008).

Whether using the online environment as the primary delivery medium or as a supplement to face-to-face sessions and regardless of their previous experience with online or distance learning, the majority of instructors were very positive about Knowledge Forum. One instructor's comment echoes the students' opinion about the role of Knowledge Forum then goes on to extend it to one of the program goals, enhancing student writing skills: "Knowledge Forum has provided a valuable support in facilitating communication and provides a site for the development of writing skills. It needs to be maintained and used in all courses whenever possible.” The instructor elaborates, "This means that instructors not familiar with Knowledge Forum and how to use it must be told of this expectation and given support to implement it” (Walton et al., 2008, p. 30).

This comment reflects a certain initial ambivalence toward the online environment in the program as a whole. Although there were debates about the specific platform and whether a synchronous audiovisual capability was a "need" or a "want," the necessity of an online environment in the distance learning courses was never questioned. Given the skepticism about distance learning expressed by Inuit educators in the Pauqatigiit survey (Nunavut Boards of Education, 1995), the reluctance to adopt a top-down mandate that would push instructors into unfamiliar territory, and the uncertainty of whether adequate assistance could be put into place to support them fully if they ventured there, the possibility that online engagement would supplement the intensive faceto-face courses was for the most part left to chance. It took the cumulative experience of the entire three-year program to develop and demonstrate a coherent, integral role for the online component.

\section{Discussion and Conclusion}

With its juxtaposition of a graphic created by an MEd candidate using a natural media computerbased drawing program called ArtRage (which was free at that time) and a text-based reflection on the intersection of Inuit and Qallunaat ways of knowing, Figure 5 encapsulates the potential of the Knowledge Forum environment as a medium to support the processes of decolonization and Inuit Qaujimajatuqangit integral to the Nunavut MEd. 


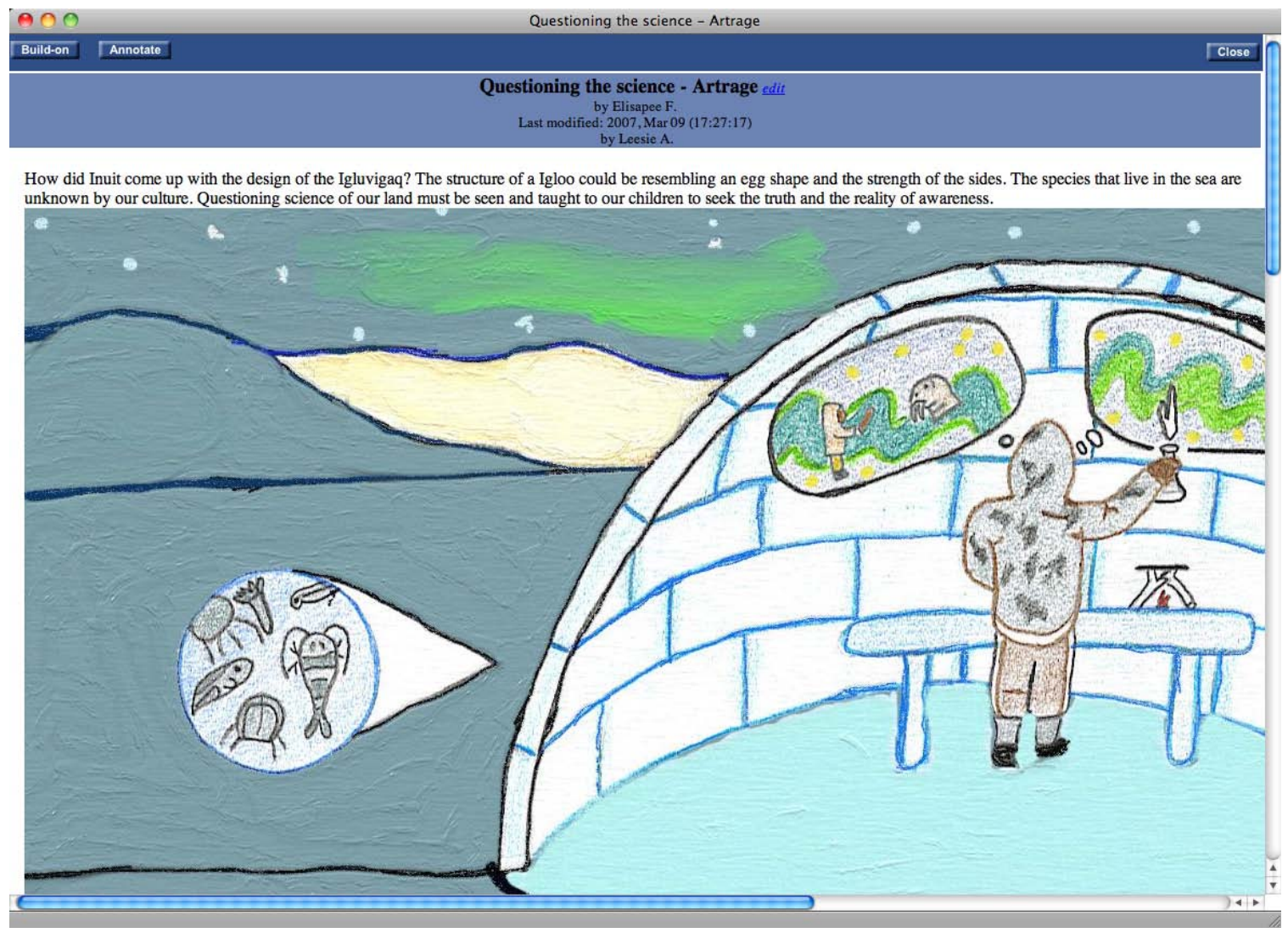

Figure 5. Questioning science.

The Knowledge Forum environment that was constructed for the program and, more importantly, that evolved over its course provided a consistent interface, a set of tools to facilitate working with knowledge contributed by both instructors and students and the flexibility to respond to emerging priorities. By supporting a single interface for all Nunavut MEd courses and providing the means to seamlessly search for, identify, and move contributions from one course to any other, the program helped to create a community with social and learning dimensions that extended across Nunavut and between the courses. As well as the course material preserved there, the online space provided a persistent, living record of many of the challenges that the candidates faced over the three years.

Although any number of other technologies might have supported similar processes to some extent, as Mott and Wiley (2009) point out, most LMSs embody a banking model of education (Freire, 1970, 2000). While straightforward and efficient, a system based on this model would have reinforced the colonial framework the Nunavut MEd was intended to problematize. The knowledge building principles and the sociotechnological affordances of Knowledge Forum based on them (Scardamalia, 2002) facilitated an approach to online support for the Nunavut MEd that explicitly acknowledged and responded to the underlying principles of the overall program, specifically the colonial history of Nunavut, its detrimental influence on Inuit education, and the effort to move beyond these through critical foci on decolonizing practices and the relational principles of Inuit Qaujimajatuqangit. Although its implementation was tentative and somewhat inconsistent over the three years of the program, this approach contributed to the 
success of an environment that encouraged one student to say in an interview, "We learned as much from each other through KF as we did from our instructors.”

While both students and instructors recommended that the second iteration of the Nunavut MEd retain the Knowledge Forum online environment when it launches in the fall of 2010, a number of changes are planned to build on the lessons learned over the last three years. Perhaps most significantly, all courses will be planned with a significant online component regardless of whether the primary delivery mode is face-to-face or at a distance. Instructors will be offered regular and consistent support to that end, both formally from the program's distance learning coordinator and informally from the experiences of past instructors returning to the program, which include a number of Inuit graduates from the previous cohort. The challenge remains, of course, to maintain and strengthen the emphasis on the underlying principles of the program while supporting an emergent online environment that responds both to instructional requirements and the sociocultural learning goals of candidates.

A final challenge remains for the longer term. Although the Nunavut MEd Knowledge Forum environment has remained open at the request of students since the program ended, no participation has taken place since shortly after the graduation ceremony in July 2009. Apparently having done its job, it has fallen silent and the knowledge created by program candidates remains inaccessible. Given the groundbreaking work completed by several candidates in their efforts to understand the colonial forces that have shaped education in Nunavut and to contribute to its decolonization, this is a major loss. To avoid similar losses in the future, an easy-to-use bridge between the walled garden of Knowledge Forum and more open and accessible web-based media must be developed. 


\section{References}

Arnakak, J. (2001). What is Inuit Qaujimajatuqangit? Retrieved from http://www.turtletrack.org/Issues01/Co01132001/CO 01132001_Inuit.htm

Cummins, J. (1996/2001). Negotiating identities: Education for empowerment in a diverse society. Los Angeles, CA: California Association for Bilingual Education.

Freire, P. (1970/2000). Pedagogy of the oppressed. New York, NY: The Seabury Press.

Government of Nunavut, Curriculum and School Services. (2005). Inuit Qaujimajatuqangit education framework. Iqaluit, NU: Author.

McAuley, A. (1998). Virtual teaching on the tundra. Technos 7(3), 11-14.

McAuley, A. (2001). Creating a community of learners: Computer support in the eastern Arctic. Education Canada, 40(4), 8-11.

McAuley, A. (2004). Illiniqatigiit: Implementing a knowledge building environment in the eastern Arctic (Unpublished doctoral dissertation). OISE/University of Toronto, Toronto ON.

McAuley, A. (2009) Knowedge building in an Aboriginal context. Canadian Journal of Learning and Technology 35(1). Retrieved from http://www.cjlt.ca/index.php/cjlt/article/view/514/244

Mott, J., \& Wiley, D. (2009). “Open for learning: The CMS and the open learning network.” In Education, 15(2). Retrieved from http://www.ineducation.ca/article/open-learning-cms-and-open-learning-network

Nunavut Boards of Education (1995). Pauqatigiit: Professional needs of Nunavut educators. Iqaluit, NU: Author.

O’Donoghue, F. (1998). The hunger for professional learning in Nunavut schools (Unpublished doctoral dissertation). OISE/University of Toronto, Toronto ON.

O’Donoghhue, F., Tompkins, J., McAuley, A., Hainnu, J., Fortes, E., Metuq, L., \& Qanatsiaq, N. (2005). Decolonizing Inuit education in the Qikitani region of Nunavut from 1980-1999. Ottawa, ON: Social Science and Humanities Research Council.

Scardamalia, M. (2002). Collective cognitive responsibility for the advancement of knowledge. In B. Smith (Ed.), Liberal education in a knowledge society (pp. 67-96). Chicago, IL: Open Court. 
Smith, L. T. (1999). Decolonizing methodologies. London, UK: Zed Books.

Tompkins, J., McAuley, A., \& Walton, F. (2009). Protecting the embers to light the qulliit of Inuit learning in Nunavut communities. Inuit Studies, 33(1-2), 95-113.

Walton, F., McAuley, A., Tompkins, J., Metuq, L., Qanatsiaq, N., \& Fortes, E. (2005). Pursuing a dream: Inuit education in the Qikiqtani region of Nunavut from 1980-1999 (Research report submitted to the Department of Education, Government of Nunavut). University of Prince Edward Island, Faculty of Education: Authors.

\section{Athabasca University $\mathbf{I}$}




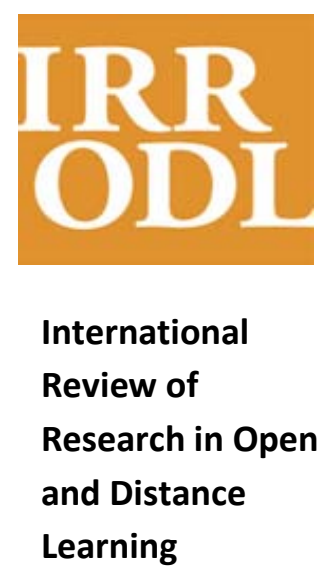

Vol. 12.4

May - 2011

\section{Attracting, Preparing, and Retaining Under-Represented Populations in Rural and Remote Alberta-North Communities}

\author{
Nancy Steel
}

Alberta-North Project, Canada

Patrick J. Fahy

Athabasca University, Canada

\begin{abstract}
For several years, the government of the western Canadian province of Alberta has drafted policies and conducted research on the problem of populations under-represented in adult education. This Alberta-North and Athabasca University study, funded by the Alberta government's Innovation Fund, uses the advice and educational experiences of northern former and present students, and of other community members, to identify ways of better attracting, preparing, and retaining under-represented populations in northern Alberta communities through provision and training in the use of distance delivery methods.
\end{abstract}

The research reported here commences with a review of the literature to investigate the following: 1) the contribution distance education makes globally to learning access in remote areas (and resulting economic growth for under-served populations); 2) how support is provided to retain isolated students; and 3) the help needed to assist remote students to complete distance programs. Community consultations with social service and education agencies in three communities were conducted in order to obtain their perspectives about what helps to attract and support students to educational programs and the barriers students typically encounter, which might be mitigated by distance methods. Finally, a survey was designed and distributed in 87 Alberta-North communities in northern Alberta and across Canada's Northwest Territories to add perspective to the consultation results.

Keywords: Distance education; e-learning; pedagogy; northern; remote areas; isolated students 


\section{Introduction}

Alberta-North is a collaboration, unique in Alberta, among seven postsecondary education institutions: Athabasca University (AU), Aurora College, Grande Prairie Regional College, Keyano College, Norquest College, Northern Lakes College, and Portage College. The AlbertaNorth partnership was established in 1994 with the goal of increasing access to postsecondary programming, particularly for under-represented populations, by providing rural and remote communities with access to online distance education courses. The Alberta-North region covers $60 \%$ of Alberta's geographic area, 9\% of the province's total population, and 51\% of Alberta's Aboriginal population.

Each institution offers online courses, from adult upgrading to career programs, and provides access through Alberta-North's 87 Community Access Point (CAP) sites located across northern Alberta and the Northwest Territories. Each CAP site contains distance education technology and an onsite coordinator to provide course information and learning support. In 2008-2009, AlbertaNorth, and its affiliates (eCampus Alberta, Canadian Virtual University, and University of Calgary), offered 4,077 courses, ranging from upgrading courses to university studies.

Alberta-North's partnership with Athabasca University was designed to address an underresearched area, namely community members' and students' views regarding the attraction, preparation, and retention of learners in remote northern communities. Some information exists already: in 2008, an Alberta-North study, funded by eCampus Alberta, examined the views of Alberta-North CAP site coordinators about "best practices." The resulting report (LetkemanMcQuilikin \& Neaves, 2009) offers suggestions for communicating course and program content to potential and current students, for conducting CAP site facility operations, and for general student retention and achievement, but leaves other questions about programming in the North unaddressed.

This project, funded by Alberta Advanced Education and Technology's (AE\&T) Innovation Fund, concerns ways of attracting, preparing, and retaining adult learners in Alberta's rural and remote northern communities, based on what potential and actual students say they want and need to achieve success. It draws on, but goes beyond, previous inquiries and, as shown in the following, is based upon a history of public and educational reports and policy on education for under-represented populations, including historical and academic sources (Maslow, 1962), in both traditional and innovative delivery models (Garrison \& Cleveland-Innes, 2005).

\section{Background}

\section{Alberta Policy and Research Statements}

In 2003, AE\&T’s First Nation, Metis, and Inuit Policy Framework: A Progress Report provided a vision and a policy statement and articulated five goals: the availability of learning opportunities for Aboriginals, proper preparation of students for postsecondary studies, 
excellence in learner achievement, effective working relationships among all stakeholders, and a highly responsive education ministry. Strategies and performance measures for each goal were described in the statement.

In 2006, A Learning Alberta set out recommendations for making Alberta a knowledge-based province. The rationale for the paper was the confluence of economics and education/training, apparent in the notable fact that

while Alberta has the highest workforce participation rate in Canada, it also has among the lowest participation rate in postsecondary studies. Participation is even lower for those living in northern and remote communities, young males, First Nations, Métis and Inuit peoples, persons with disabilities, Albertans with low income and education levels, and immigrants. (p. 1)

Several of the recommendations related to the paper's goals are significant for this project, especially those addressing the educational and social needs of under-represented learners.

More recently, the Alberta government released the Roles and Mandates Policy Framework for Alberta's Publically Funded Advanced Education System (2007) on the relation of education to economic and social prosperity. The document proposes an increase in Aboriginal enrolment, including through use of technology in remote areas. (The present project's focus on ways to attract, prepare, and retain under-represented populations is aligned with these government policies, a factor which the authors believe contributed to its funding).

Nationally, Aboriginal groups have regularly cited access and support as participation issues in postsecondary education. In November 2005, Canada produced a series of agreements (not always acted upon) for improvements to Aboriginal well-being in Canada, including changes to access and support to education (the Kelowna Accord). In 2009, the Council of Ministers of Education (CMEC) Summit on Aboriginal Education, held in Saskatoon, discussed "priorities for moving forward on eliminating the gaps between the educational achievement of Aboriginal and non-Aboriginal students in Canada” (CMEC, 2010, p. 7). Themes and priorities for future emphasis included Aboriginal language and culture, equity in funding, seamlessness in provision of services, and the problems of access, retention, and graduation/completion.

The First Nations Adult and Higher Education Consortium (FNAHEC, see http://fnahec.org/Missions.htm) has developed a First Nation vision statement containing, among others, these goals:

To promote control of First Nations standards of excellence in education through support of our own accreditation processes and mechanisms. To build and maintain partnerships in the development and monitoring of appropriate legislation, policies, and regulations for First Nations adult and post-secondary educational programs and institutions. To develop and provide a 
range of programs and services that respond to the ongoing and changing needs of FNAHEC members. To develop and pursue economic resources that will lead to long-term financial selfreliance of FNAHEC and its members.

Alberta and Statistics Canada postsecondary statistics describe the magnitude of the problems involved in achieving goals such as those above. For example, AE\&T institutional enrolment data show that Aboriginal enrolments (2008-2009) at Alberta-North partner institutions (in Alberta) collectively averaged about 20\% (AE\&T, 2010), suggesting that Aboriginal learners are under-represented in these institutions. (However, the data also show that the past-three-year trend has been toward a small but gradual increase in enrolment each year.)

Statistics Canada census data also describes a national gap between Aboriginal and nonAboriginal postsecondary participation rates. As Figure 1 reveals, while there is a gap between participation rates at the university level, Aboriginals were almost as likely as non-Aboriginals to have a trades certificate or college diploma. In 2006, one-third (33\%) of Aboriginal adults aged 25 to 54 had less than a high school education compared to about $13 \%$ of the non-Aboriginal population (Statistics Canada, 2010a, 2010b).

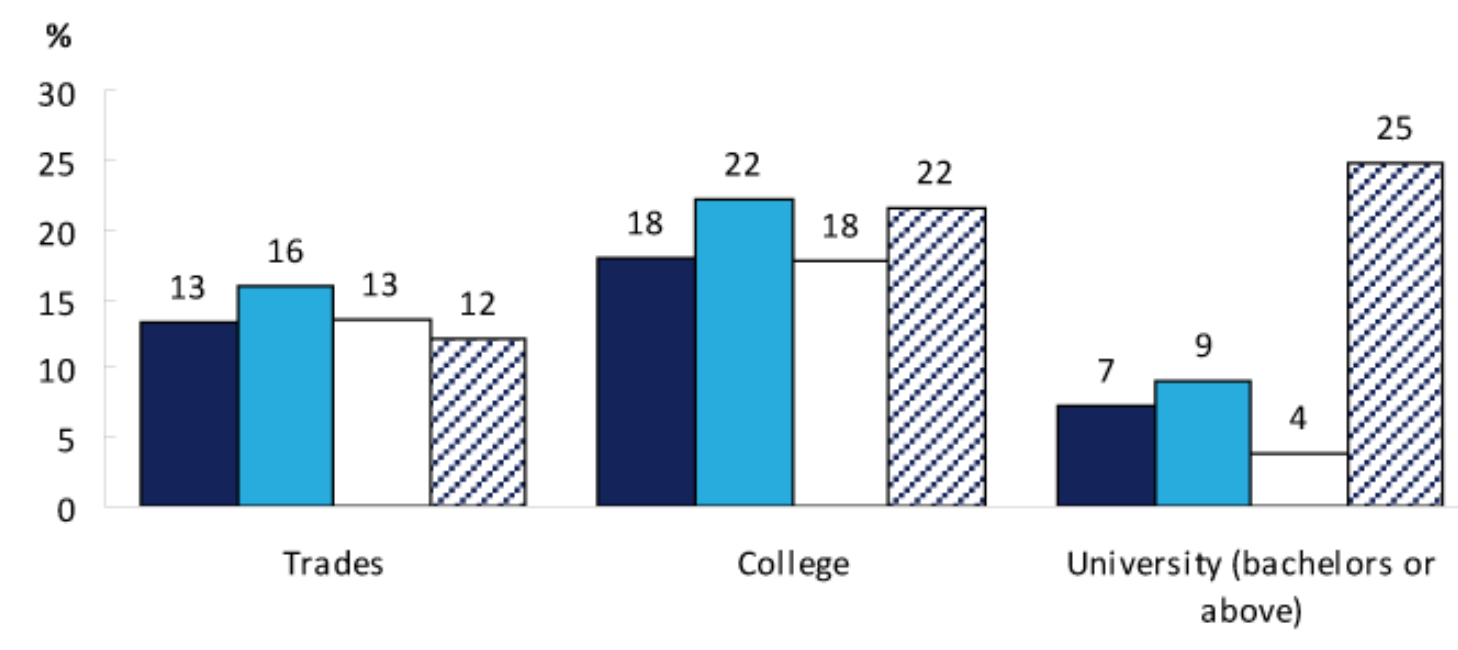

First Nations (North American Indian) $\square$ Métis $\square$ Inuit $\square$ Non-Aboriginal population

Figure 1. Postsecondary educational attainment by Aboriginal identity, population aged 25 to 54, 2006.

Provincial and federal statistics such as the above have shaped government policies and discussion papers, clarifying the present inequities in postsecondary systems. This research project attempts to find principles to bridge the gap between research awareness and practice by providing information from learners directly useful to programmers. 


\section{Literature Review}

Albertan and Canadian perspectives are the focus of this review. The results describe how other jurisdictions justified inclusion of marginal populations in education and training, often through greater use of technologies. The review included 1) the contribution distance education makes to learning access (and resulting economic growth for remote or under-served populations) in Canada; 2) how support is provided to retain students; and 3) the help needed and provided to assist remotely located students to complete distance education programs. The themes mentioned are the experience of remote learners with distance education (DE); the role of family; funding assistance systems; the return on investment (ROI) from Aboriginal education; and Aboriginal culture, values, and attitudes toward learning.

Rural and remote learners, whether in traditional or distance programs, often have special needs. Bennett (2003) says of rural learners, with direct implications for distance education, "Rural communities lack a strong learning culture and rural residents may lack the literacy skills required to function in such a self-directed educational environment” (p. 5). She argues that rural residents face "a learning environment with higher attrition rates than occurs in more classroom-based offerings" (p. 6). In her opinion, and tellingly, DE approaches have in the past often been derived from the "perspective of the institution and its traditional, residential student paradigm" (p. 6) and not from "the unique community situations" of rural learners. Boud and Tennant (2006) raise a similar criticism in relation to graduate programming in Australia.

McMullen and Rohrbach (2003) see special, but unfulfilled, capabilities in distance delivery: "Distance education has the ability to provide education opportunities to students in remote Aboriginal communities. To date, distance education has failed to meet this ability. Why?” (p. 6). They assert that "We have been continually told that our students have failed distance education courses. We contend that in many cases distance education courses have consistently failed the student” (p. 6). Through a series of case studies, they identified common barriers to DE for experienced learners in rural and remote communities and suggested better practices for resolving them. These and similar studies provide important perspective to our project as most northern students reside in remote communities, far from resources and assistance.

The central role of family as a support mechanism for all postsecondary students, prominent in the literature, emerged as a theme from our project survey findings. Bryan and Simmons (2009) investigated the impact of the family role on postsecondary educational success for firstgeneration Appalachian students. The Appalachian region resembles Alberta-North's northern communities in that both are rural and remote, there is a level of poverty that exceeds the national average and affects postsecondary participation, and there is a strong association to community that makes leaving the community a challenge.

Taking a case study approach to conducting research with first generation postsecondary students, the authors reached several conclusions: students, often the first in the family to attempt higher education, frequently feel daunting pressure to succeed, potentially affecting their academic performance; poverty can be another form of pressure because "You know if you fail, your family 
is not going to be able to bail you out of it or help you . . . and you know that you're different than middle class sort of families” (Bryan \& Simmons, p. 401); and students may become isolated from family members, who lack direct familiarity with the student's postsecondary experience.

The Environics Institute (2010), in its study of urban Aboriginal people in Canada, also notes the central role that family plays in helping learners engage and succeed in postsecondary education. The study included students who have previously attended, those currently engaged, and those planning to attend postsecondary education. When asked about key influences on the decision to enrol in postsecondary education, a resounding response was "family," although others were also mentioned, as shown below.

Table 1

Key Influences on Decision to Pursue Postsecondary Education

\begin{tabular}{|l|c|c|c|}
\hline & $\begin{array}{c}\text { Previously } \\
\text { attended } \\
\text { PSE \% }\end{array}$ & $\begin{array}{c}\text { Currently } \\
\text { attending } \\
\text { PSE \% }\end{array}$ & $\begin{array}{c}\text { Planning } \\
\text { to attend } \\
\text { PSE \% }\end{array}$ \\
\hline Parents/guardians & 53 & 60 & 70 \\
\hline Other family & 41 & 43 & 62 \\
\hline Role model & 39 & 50 & 62 \\
\hline Teachers & 33 & 35 & 65 \\
\hline Friends & 30 & 34 & 52 \\
\hline $\begin{array}{l}\text { Guidance } \\
\text { counsellors }\end{array}$ & 24 & 25 & 50 \\
\hline PSE representative & 21 & 25 & 33 \\
\hline
\end{tabular}

Source: Environics Institute (2010, p. 123).

In the above study, "family," "teachers/counsellors," and "friends" were cited most often as significant supporting factors.

Another important theme that was found in the review of the literature, confirmed in our survey, is the difficulties associated with funding for Aboriginal education. Stonechild (2006) recorded the history of the Indian struggle for access to funding for postsecondary education in Canada, and the difference between the Aboriginal and the federal government interpretation of treaty rights regarding postsecondary education funding. In 1977, the federal government created the Post Secondary Student Support Program (PSSSP), which provides funds for postsecondary education (upgrading education is exempt) administered and distributed by band councils. Helin and Snow (2010), among others, criticize this system as ineffective.

Whatever the difficulties and criticisms of the current funding system, the literature indicates that investment in Aboriginal postsecondary education in developed countries is economically 
justified. The relationship between earnings and education level in Canada can be seen in Table 2.

Table 2

Median 2005 Earnings for Full-Year, Full-Time Earners by Education, Both Sexes, Total-Age group 25 to 64, for Canada, Provinces and Territories-Alberta

\begin{tabular}{|l|l|l|l|l|l|l|}
\hline $\begin{array}{l}\text { Less than } \\
\text { high } \\
\text { school }\end{array}$ & $\begin{array}{l}\text { High } \\
\text { school }\end{array}$ & $\begin{array}{l}\text { Trades or } \\
\text { apprenticeship }\end{array}$ & College & $\begin{array}{l}\text { University } \\
- \text { below } \\
\text { bachelor }\end{array}$ & Bachelor & $\begin{array}{l}\text { Post- } \\
\text { bachelor }\end{array}$ \\
\hline \$35, 442 & $\$ 39,196$ & $\$ 50,509$ & $\$ 46,064$ & 52,253 & 61,495 & 73,607 \\
\hline
\end{tabular}

Source: Statistics Canada (2010b, 2010c).

Canadian and Alberta demographic trends are similar to each other, and to international patterns: the Aboriginal population is growing nearly six times faster than the non-Aboriginal population, and the Aboriginal population is significantly younger than the non-Aboriginal population (median age for Aboriginals is 27, 25 in Alberta, compared to 36 for non-Aboriginals) (Alberta Finance and Enterprise, 2008). Given Alberta’s aging population and predicted skills shortages, Alberta Employment and Immigration (2009) concludes that the Aboriginal population represents an untapped labour force, and increasing Aboriginal access to higher education may be seen as an investment in the province's future and economy. Sharpe and Arsenault's (2009) study draws this blunt conclusion:

Given that educational attainment is one of the key drivers of participation and employment rates, there are clear incentives for the Canadian government to make Aboriginal education a priority. If in fact Aboriginal education is not made a priority, the drag on Canadian productivity caused by below-average Aboriginal education will grow as the Aboriginal population's share of Canada's labour force increases over time. (p. 17)

Citing a Canadian Council on Learning report from 2007, Malatest (2008) points out that there are other benefits besides economic ones to higher education. Postsecondary education is also associated with better health and well being, and higher levels of civic and community engagement (Brown, 2009). While not a new insight, this point broadens the discussion beyond the purely economic.

A final theme that emerged from the literature review was the issue of Aboriginal culture, values, and attitudes toward learning. McMullen and Rohrbach (2003) point out that the oral tradition has historically been the main learning teaching/learning method, along with the modeling tradition, the "watch then do" approach to skill development. The authors suggest that learning tasks best suited to Aboriginal traditions involve those that are global versus analytic; those that involve images, symbols, and diagrams, rather than standalone verbal; those that are more 
concrete than abstract; and those that involve reflection. These traditional Aboriginal learning values have clear implications for learning designers.

\section{Methods}

The focus of the study was the question, given the lack of opportunities for non-urban people in the present postsecondary education system, and the importance of training opportunities for this group, of what actions or resources might better attract, prepare, and retain northern residents in postsecondary education programs, specifically those delivered by distance education.

Community consultations, interviews, and a written survey questionnaire were used in a variety of venues to gather input from students and others in northern communities. In the spring of 2009, the project manager visited three Alberta communities, Fort McKay, Frog Lake, and Grande Cache, to consult with community agency representatives about their services and experiences with potential or current postsecondary students. Taking an appreciative inquiry approach, which "involves the art and practice of asking questions that strengthen a system's capacity to apprehend, anticipate and heighten positive potential” (Cooperider \& Whitney, 2005, p. 3), the project manager asked questions about which approaches or strategies, in the opinion of the participants, would attract students to adult education, prepare them for program success (especially using distance technologies), and help them persist in their programs.

Also in the spring of 2009, the project team developed a survey for past, current, and potential students in Alberta-North communities. The survey was first field-tested with residents of the Peavine Métis Settlement, Alberta, and then, after revisions, was sent to all CAP coordinators, who were asked to copy, distribute, and collect completed surveys. Having CAP coordinators involved was advantageous because they are recognized education representatives in their region and have regular contact with their communities. Data analysis (by the authors) incorporated SPSS and ATLAS.ti software. In all, 482 surveys were returned from 45 communities, providing good regional scope in the data.

\section{Findings: Community Consultations}

Because the focus was on how programming might be made more appealing and effective for northern residents, the consultation was based on a discussion of needs, not necessarily delivery models (distance education was not mentioned as a specific delivery strategy, though questions about it were answered wherever they arose since community members knew the study included alternative delivery models). Findings are presented below using Cross's (1981) description of the dispositional, situational, and institutional influences that affect student participation in postsecondary (adult) education. For the purpose of the research, a fourth factor was added, the systemic factors that affect participation. Table 3 shows the main results of the interviews; implications for distance delivery are discussed in the next section. 
Table 3

Critical Influences on Attraction, Preparation, and Retention

\begin{tabular}{|c|c|c|c|}
\hline & Attract & Prepare & Retain \\
\hline Dispositional & $\begin{array}{ll}\text { - } & \text { mentoring } \\
\text { - } & \text { orientation }\end{array}$ & $\begin{array}{ll}- & \text { fear, lack of } \\
& \text { confidence } \\
\text { - } & \text { orientation, } \\
\text { engagement, } & \\
\text { relationships }\end{array}$ & $\begin{array}{ll}\text { - } & \text { coping skills } \\
\text { - } & \text { exit and re-entry } \\
& \text { with dignity } \\
\text { - } & \text { more flexible } \\
\text { program design } \\
\text { - } \\
\text { more interagency } \\
\text { cooperation }\end{array}$ \\
\hline Situational & $\begin{array}{ll}\text { - } & \text { transportation } \\
\text { - } & \text { daycare } \\
\text { - } & \text { convenient location, } \\
\text { scheduling } \\
\text { - } \\
\text { - } \\
\text { pear } \\
\text { remediation, prerequisites, }\end{array}$ & $\begin{array}{ll}\text { - } & \text { daycare } \\
\text { - } & \text { transportation }\end{array}$ & $\begin{array}{ll}- & \text { suitable, } \\
& \text { comfortable } \\
& \text { environment } \\
\text { - } & \text { childcare } \\
\text { - } & \text { transportation }\end{array}$ \\
\hline Institutional & $\begin{array}{ll}\text { - } & \text { reliable programming (no } \\
\text { late course or program } \\
\text { cancellations) } \\
\text { - } \text { conducive locations, } \\
\text { environment } \\
\text { - preparation, prerequisites } \\
\text { - advising, support, } \\
\text { mentoring } \\
\text { - PLAR }\end{array}$ & $\begin{array}{ll}\text { - } & \text { orientation } \\
\text { - } & \text { mentoring, role } \\
\text { models } \\
\text { - } & \text { PLAR }\end{array}$ & $\begin{array}{ll}\text { - } & \text { regular instructor } \\
\text { feedback } \\
\text { - } & \text { tutorial and } \\
\text { technology } \\
\text { support } \\
\text { - } \text { motivational } \\
\text { seminars }\end{array}$ \\
\hline System & $\begin{array}{ll}\text { - } & \text { funding } \\
\text { - } & \text { awareness }\end{array}$ & $\begin{array}{ll}\text { - } & \text { preparation } \\
\text { - } & \text { reduced funding } \\
& \text { complexity }\end{array}$ & $\begin{array}{ll}\text { - } & \text { reducing funding } \\
\text { complexity } \\
\text { - } & \text { family support }\end{array}$ \\
\hline
\end{tabular}

The findings in Table 3 lead to the following general conclusions about attracting students to education and training programs:

1. Programs must be offered conveniently, and housed in locations that reflect the adult nature of the target clientele.

2. Logistic concerns of young adults, such as daycare and transportation, must be addressed.

3. Students must be assured that they will have personal and institutional support, including technical assistance, to feel confident enrolling in a course or program.

4. Students should be made aware of the availability of and their potential eligibility for funding. 
These are the conclusions about preparation contained in Table 3:

1. Preparation, prerequisites, and remediation will likely be needed by many adults returning to learning.

2. Reluctance, lack of confidence, and fear issues must be anticipated and addressed.

3. Orientation and relationship building may help prepare students for their PSE experience.

Table 3 suggests these conclusions about retention of adult learners in northern locations:

1. Flexibility in program design would include options for entry and reentry into programs, as stop-outs become necessary.

2. Logistical supports, such as transportation, childcare, and funding, need to be stable and predictable, and complexities in acquiring and retaining these supports should be reduced.

3. Tutorial and technical support are required throughout the program.

Regarding systemic needs, Table 3 suggests the following:

1. Potential learners must be aware of programming options, including funding opportunities.

2. Needs include increased preparation and reduced complexity.

3. Funding and support (initial and ongoing) contribute to completion.

\section{Survey Results}

The survey distributed by the CAP coordinators gathered respondent demographic data and then posed these questions, designed to supplement the community consultation results discussed above:

1. What training or education have you completed a) in this location, b) elsewhere?

2. Why did you leave?

3. What helped you prepare for your education in the community?

4. What hindered you, or what barriers did you have to overcome?

5. What suggestions do you have to make local training and education easier or more successful for those who take it?

6. Have you heard of Alberta-North? If so, what do you know about it?

The survey also invited respondents to provide contact information voluntarily for possible interview follow-up. 


\section{Respondent Information}

Some of those who completed surveys did not provide information for every question. Survey participants were primarily female (58\%), with a high percentage (45\%) 35+ years of age. That nearly half of the respondents were 35 years of age and older is not surprising. A Canadian Council on Learning report (2009) notes that

a larger proportion of Aboriginal people return to complete their high-school education at a later age than is found in the nonAboriginal population. This means that for a large share of Aboriginal young adults, high-school participation occurs in early adulthood rather than through the teen years, and PSE readiness can occur at a later age. (p. 44)

Of the survey participants who provided information, the majority (69\%) self-identified as Aboriginal, and 29\% indicated that they were First Nations, living on reserve. When asked about the highest level of education attained, nearly half (40\%) indicated that they had completed some high school education, and 35\% said they had some form of postsecondary education. The sample may not be representative of northern residents; it is, however, representative of the views of those northerners who have had PSE experience and who agreed to share their opinions and experiences.

\section{Free Responses to Survey Questions}

Table 4 shows the results of two questions designed to determine the education backgrounds of respondents.

Table 4

Educational and Training Experience

\begin{tabular}{|c|l|}
\hline What training have you taken locally? & $\%$ \\
\hline Response rate & $85 \%$ \\
\hline Responses: & \\
$\circ \quad$ Upgrading & $46 \%$ \\
$\circ \quad$ Certificate & 34 \\
$\circ \quad$ Diploma & 17 \\
$\circ \quad$ Degree & 2 \\
\hline What training have you taken elsewhere? & \\
\hline Response rate & $67 \%$ \\
\hline$\circ \quad$ Certificate & 28 \\
\hline$\circ$ Upgrading & 16 \\
\hline$\circ$ None & 16 \\
\hline
\end{tabular}




\begin{tabular}{|c|c|}
\hline$\circ$ Diploma & 10 \\
\hline$\circ$ Degree & 6 \\
\hline
\end{tabular}

Why did you leave the program?

Top responses:

1. personal reasons

2. family reasons

3. no funding; no childcare

Other reasons included:

- medical

- expelled

- dropped out because lost interest

- no housing

The above question squarely addresses reasons why students do not persist, and helps to define what “personal reasons” might actually mean. Malatest \& Associates (2002, p. 20) cite Donald Unruh, speaking of students at the University of Manitoba:

By far the most difficult area, and the area in which, despite our best efforts, we continue to face the greatest problems, is the area of personal and family supports. More students drop out of the programs for 'personal reasons' than all other reasons combined. (In fact, academic failure comes last as a reason for leaving.) . . . Family stress, discrimination, loneliness, and an alien environment combine to overwhelm students.

Our survey findings agree, and, in the above and in the following, further define what "personal" means in the context of persistence. (More is said about this point in the next section of the paper.)

What helped prepare you for your education in the community?

Sixty-seven percent of survey participants responded to this question. Top responses:

1. support from family/friends

2. personal self-confidence and motivation

3. upgrading courses, evening and part-time courses, community courses

4. work influences such as on the job experience, volunteering, employer encouragement, and work experience 
The influence of family on an individual's decision to enrol is made clear in the literature and here in our survey's finding. The nuances of that role merit exploration to discover ways that it can be supported and strengthened.

What hindered you, or what barriers did you have to overcome?

Eighty-nine percent of survey participants responded to this question. Top responses:

1. lack of funding

2. lack of transportation

3. lack of childcare

4. location of program

5. fear

Of those who responded, a small percentage $(n=10)$ indicated that the question did not apply or that nothing hindered them- that they did not face any barriers.

The "fear factor" is reported regularly in the literature. Fear usually includes lack of selfconfidence, trepidation at the prospect of failure, reluctance to embark on a new path (particularly if the student is a first-generation postsecondary or adult student), and reluctance to change. More research about fear is warranted in order to define it better and to explore solutions for those who experience it as a barrier to participation.

What suggestions do you have to make local training and education easier or more successful for those who take it?

Sixty-six percent of survey participants responded to this question. Top responses:

1. more courses, more evening options, more programs, more online, more upgrading, more science and academic courses

2. more access to funding, more funding availability, more help with application process

3. more self-confidence, more motivation

4. more tutors, more on-to-one, more face-to-face

As noted in the literature review, the paucity of funding, coupled with the difficult application process and requirements, makes this an ongoing barrier to participation in postsecondary education. Our survey respondents ranked funding as the top barrier and placed it second in suggestions for improvements. 
Have you heard of Alberta-North? If so, what do you know about it?

Thirty-three percent of survey participants responded to this question. It can be assumed, in this case, that a non-response might mean a "no" answer, that respondents did not know about Alberta-North. Of those who responded, 48\% answered "yes."

To the question about what they know about Alberta-North, respondents provided a variety of related responses: Distance, online, education, Web, technology or computer. Some described how they heard about Alberta-North: through affiliation with a postsecondary institution, through word-of-mouth, and through print advertising (posters, pamphlets, newsletters).

The survey activity itself served a number of purposes. Apart from its main purpose, to solicit past, current, and potential students' ideas about their postsecondary education experience and suggestions for improvements, it also served to engage CAP coordinators in the research project and to raise the Alberta-North profile in regional communities.

The survey findings echo some of the themes found in the literature and the community consultation results, particularly the significant role that family plays as a support to students, and funding availability and access challenges.

\section{Research and Programming Implications for the Project}

The study established the following facts about the present provision of adult and postsecondary programs in remote northern Alberta. This analysis also reveals the potential of distance delivery to address many of the barriers students face, as shown in the comments in italics below each point:

1. Most programs are delivered face-to-face.

Distance education, as it is not face-to-face (or not wholly), either does not precipitate, and may ameliorate, the impact of many of the logistical problems identified by the respondents: daycare, family and employment commitments, transportation, costs of participation, conflicts with location and scheduling, etc.

2. Location and timing of programs are barriers for some.

Less of an issue with distance education as more choice is in the hands of the student.

3. Predictable barriers are transportation, costs, and daycare. 
Less of an issue with distance education as either not needed at all, or other resources may become available when fixed schedules and locations for study are not imposed.

4. Families are very often the primary support for learners, both in enrolling and in persistence. (Yet, very little is known about how families contrive to provide the required support, and whether assistance might increase their positive impacts on students.)

Families become more important in a distance model: families can assist with childcare, transportation, and other family management issues. Families can also use the technologies of distance to communicate with one another.

5. Alberta-North is not well known as a source of information or assistance by potential students.

A role for Alberta-North might become the link to available distance programs and to resources that support success of learners in their use. Further study is needed to determine the extent of this problem and potential solutions.

6. The constraint of minimal numbers for face-to-face programs sometimes frustrates and discourages students, potential students, and support people.

More programs may potentially be available at a distance than can reasonably be expected in face-to-face or synchronous delivery modes.

7. The impact of mentoring, role-modeling, job-shadowing, and other forms of local motivation has not been carefully studied in Alberta.

Distance mentoring and role-modeling are potential future studies, as discussed below.

The above indicates how distance delivery might complement existing face-to-face models to address the major barriers to participation in formal learning in northern Alberta. The distinction between remote and isolated become critical (On the Frontier, 2007): Students may be the former, but, with intelligent use of technology, they need not experience the latter. Simonson, Smaldino, Albright, and Zvacek (2009) nicely summarize the distance delivery model of the future with obvious application to remote communities:

Interactive instruction is possible because telecommunications technologies permit the learner to contact databases, information sources, instructional experts, and other students in real-time and 
interactive ways. . . . Instruction is authentic because it is not teacher centred; rather it is content and learner centred. (pp. 22-

23)

On the basis of the above analysis of distance education's potentials, the project Advisory Committee is investigating, through two projects, how new supports might reduce barriers to learning participation for adults in remote communities. One project will see the development of a handbook of suggestions for CAP coordinators, for instructors, and for college administrations to better attract, prepare, and retain Aboriginal students. The second project will investigate the interest of a select number of CAP coordinators in expanding their role as service providers to that of mentors. If there is an interest, mentor training will be developed and delivered, a mentorship program awareness strategy developed, and mentor-mentee activities documented. The goal of such a program is to provide students with additional support, and it is to be piloted between January 2011 and June 2011. Further reports will follow as these projects produce results. 


\section{References}

Alberta Advanced Education \& Technology (2002). Campus Alberta: A policy framework. Retrieved from http://aet.alberta.ca/media/134142/campusalbertframework.pdf

Alberta Advanced Education \& Technology (2003). First Nations, Metis, and Inuit education policy framework: A progress report. Retrieved from http://www.education.gov.ab.ca/FNMI/fnmiPolicy//pdfs/FNMIProgRep.pdf

Alberta Advanced Education \& Technology (2006). A learning Alberta. Retrieved from http://aet.alberta.ca/media/133863/steering_committee_final_report.pdf

Alberta Advanced Education \& Technology. (2007). Roles and mandates policy framework for Alberta's publically funded advanced education system. Retrieved from http://aet.alberta.ca/media/133783/roles\%20and\%20mandates\%20policy\%20framework \%20final.pdf

Alberta Advanced Education \& Technology. (2010). Campus Alberta planning framework: Profiling Alberta's advanced education system. Retrieved from http://aet.alberta.ca/capf

Alberta Employment and Immigration (2009). Alberta's aging labour force and skills shortages. Retrieved from http://employment.alberta.ca/documents/LMI/LMI-SSA aging-andshortages.pdf

Alberta Finance and Enterprise (2008). 2006 Census of Canada, Aboriginal release. Retrieved from http://www.finance.alberta.ca/search/query.aspx?sitesearch=www.finance.alberta.ca\&req uiredfields $=\&$ partialfields $=\& q=$ aboriginal $\& b t n G$

Bennett, G. (2003). Strangers in a strange land: Rural learners in distance education (Unpublished master's thesis). St. Francis Xavier University, Antigonish, NS.

Boud, D., \& Tennant, M. (2006). Putting doctoral education to work: Challenges to academic practice. Higher Education Research and Development, 25(3), 293-306.

Brown, T. (2009). Supporting the engagement, learning, and success of at-risk students, Part I. Innovative Educators Webinar Series. Retrieved from http://www.innovativeeducators.org/v/vspfiles/V4_Backup/atrisk1.ppt

Bryan, E., \& Simmons, L.-A. (2009). Family involvement: Impact on post-secondary educational success for first-generation Appalachian college students. Retrieved from http://0-

proquest.umi.com.aupac.lib.athabascau.ca/pqdweb?RQT=572\&TS=1265063697\& 
$\mathrm{d}=12302 \&$ VType $=$ PQD \&VName=PQD\&VInst $=$ PROD \&PMID=22023\&PCID=4767905 $1 \&$ SrtM $=0 \&$ SrchMode $=3 \&$ aid $=2$

Canadian Council on Learning. (2009). Post-secondary education in Canada: Meeting our needs? Retrieved from http://www.ccl-cca.ca/pdfs/PSE/2009/PSE2008_English.pdf

Cooperider, D., \& Whitney, D. (2005). A positive revolution in change: Appreciative inquiry. Retrieved from http://appreciativeinquiry.case.edu/uploads/whatisai.pdf

Council of Ministers of Education Canada. (2010). Strengthening Aboriginal Success: CMEC summit on Aboriginal Education. Retrieved from http://www.cmec.ca/Pages/Default.aspx

Cross, P. (1981). Adults as learners. San Francisco: Jossey-Bass.

Environics Institute. (2010). Urban Aboriginal peoples study. Chapter 10, Educational values, aspirations and experiences (pp. 117-128). Retrieved from http://www.uaps.ca/

Garrison, D. R., \& Cleveland-Innes, M. (2005). Facilitating cognitive presence in online learning: Interaction is not enough. American Journal of Distance Education, 19(3), 133-148.

Helin, C., \& Snow, D. (2010). Free to learn: Giving Aboriginal youth control over their postsecondary education. Retrieved from http://www.macdonaldlaurier.ca/home/

Letkeman-McQuilikin, J., \& Neaves, V. (2009). Successful practices for distance learners. Available by request from Alberta-North email alberta-north@northernlakescollege.ca

Malatest \& Associates. (2002). Best practices in increasing Aboriginal postsecondary rates. Retrieved from http://www.cmec.ca/Publications/Lists/Publications/Attachments/49/malatest.en.pdf

Malatest, R. A. (2008). Factors affecting the use of student financial assistance programs by Aboriginal youth: Literature review. Retrieved from http://www.cmec.ca/Publications/Lists/Publications/Attachments/197/factors-affectingaboriginal-youth.pdf

Maslow, A. (1962). Toward a psychology of being. Princeton, NJ: Van Nostrand Reinhold Co.

McMullen, B., \& Rohrbach, A. (2003). Distance education in remote aboriginal communities. Retrieved from http://www.cnc.bc.ca/_shared/assets/Distance_Education_in_Remote_Aboriginal_Com $\underline{\text { munities7675.pdf }}$ 
On the frontier. (2007, November 17). The Economist, 385(8555), 40.

Sharpe, A., \& Arsenault, J.-F. (2009). Investing in Aboriginal education in Canada: An economic perspective. Retrieved from http://www.cprn.org/theme.cfm?theme=62\&l=en

Simonson, M., Smaldino, S., Albright, M., \& Zvacek, S. (2009). Teaching and learning at a distance: Foundations of distance education (4th ed.). Upper Saddle River, NJ: Pearson Education, Inc.

Statistics Canada. (2010a). Aboriginal statistics at a glance. Statistics Canada Catalogue no. 89-645-X. Retrieved from http://www.statcan.gc.ca/pub/89-645-X/2010001/educationeng.htm

Statistics Canada. (2010b). Postsecondary educational attainment by Aboriginal identity, population aged 25 to 54, 2006. Statistics Canada catalogue no. 89-645-X. Retrieved from http://www.statcan.gc.ca/pub/89-645-x/2010001/c-g/c-g009-eng.htm

Statistics Canada. (2010c). Median 2005 earnings for full-year, full-time earners by education, both sexes, total - age group 25 to 64, for Canada, provinces and territories. Retrieved from

http://www12.statcan.ca/english/census06/data/highlights/earnings/Table803.cfm?GH=4

\&Lang $=\mathrm{E} \& \mathrm{O}=\mathrm{A} \& \mathrm{SC}=1 \& \mathrm{SO}=99 \& \mathrm{~T}=803$

Stonechild, B. (2006). The new buffalo: The struggle for Aboriginal post-secondary education in Canada. Winnipeg: University of Manitoba Press.

\section{Athabasca University $\mathbf{A}$}




\section{ORR \\ International \\ Review of \\ Research in Open \\ and Distance \\ Learning}

Vol. 12.4

May - 2011

\section{Helping Autism-Diagnosed} Teenagers Navigate and Develop Socially Using E-Learning Based on Mobile Persuasion

\author{
Peter Øhrstrøm \\ Aalborg University, Denmark
}

\begin{abstract}
The HANDS (Helping Autism-diagnosed teenagers Navigate and Develop Socially) research project involves the creation of an e-learning toolset that can be used to develop individualized tools to support the social development of teenagers with an autism diagnosis. The e-learning toolset is based on ideas from persuasive technology. This paper addresses the system design of the HANDS toolset as seen from the user's perspective. The results of the evaluation of prototype 1 of the toolset and the needs for further development are discussed. In addition, questions regarding credibility and reflections on ethical issues related to the project are considered.
\end{abstract}

Keywords: E-learning; autism; mobile learning; persuasive technology

\title{
Introduction
}

Autism spectrum disorders (ASD), including, among others, Asperger's Syndrome, are developmental disorders of the human nervous system. They result in a lifelong condition (see Volkmar et al., 2004). Many individuals with ASD find it difficult to handle daily tasks and to interact with others, often resulting in social marginalisation. Most individuals with autism require social, psychological, and/or pedagogical support services. Early intervention is crucial. In childhood and in the teenage years, support is often provided through the school, and teachers play an important role. The Helping Autism-diagnosed teenagers (of an age range between 13 and 18 years) Navigate and Develop Socially (HANDS) project aims to develop computer-based tools that teachers can individualize to support teenage students with an autism diagnosis. The HANDS toolset is supposed to facilitate the design of individual e-learning programs for teenagers with an autism diagnosis. Using the HANDS toolset, the teacher and teenager work together to tailor an individualized toolbox. The HANDS toolbox is implemented on a smart phone in order to provide support when required. The tools in the individual toolbox may be called e-learning tools because they have been designed by the teacher (in cooperation with the teenager) to support the teenager in learning how to obtain and better support social integration and inclusion and 
independence in daily life. Implemented on smart phones, these individual HANDS tools provide portable, accessible support to assist with social and self-management skills.

HANDS is an EU-financed research project, which started in June 2008 (see http://handsproject.eu/). Ten partners from six different countries are involved in HANDS, and the project is coordinated from Aalborg University, Denmark. The purpose of the project is to improve the quality of life for teenage students with an autism diagnosis by providing an ICT toolset for designing assistive technology to support the teenager's social development.

The project is based on the idea that teenagers with autism should have an individually designed toolbox implemented on their personal smart phones in order to assist with and improve their social and self-management skills and thus promote their social integration and independence. The toolbox is designed in a cooperative process with the teenager's teacher.

Prototype 1 of the toolset was ready for use in November 2009. During the following months the system was evaluated based on observations, interviews, and various tests carried out at the four partner schools in the HANDS project (see Aagaard et al., 2010; Mintz et al., 2010; Gyori et al., 2010.)

During the evaluation of prototype 1, various questions were studied; for example, in which situations and under which conditions can the HANDS toolset be expected to be useful for the teenagers, and how can the use of the HANDS tools support the work of the teachers and the schools in their everyday practice? Although such questions cannot be fully answered at the present stage, some partial answers can be given based on the studies so far.

In this paper, some general aspects of the development and use of software as assistive technology for individuals with autism spectrum disorders will be considered. Also, the choice of persuasive technology as a theoretical framework for the HANDS project is described, the general design of the HANDS toolset and its potential uses for e-learning are discussed, and the results of the evaluation of prototype 1 are outlined. The need for further development of the toolset is discussed as well, and, finally, there is a discussion of fundamental ethical issues related to the HANDS project.

\section{The Use of Assistive Technology for Individuals with Autism}

The theoretical framework and the design of the HANDS project are based on an analysis of the literature on the use of assistive technology for individuals with autism spectrum disorders. Indeed, prior to the start of the HANDS project in 2008, ICT solutions were developed to assist individuals with an autism diagnosis. In some cases these products have specific educational purposes. ICT-based tools have many properties that teenagers with ASD and their teachers may find attractive and useful. As pointed out in Bell et al. (2006), the computer applications potentially offer some important features in the communicative situation of young people with autism. In particular, the teenagers normally see computer applications as high status devices, and such devices can be flexible as learning tools. In addition, individuals with ASD typically 
appreciate that the dialogue with the device is a safe experience in the sense that it is predictable within a very narrow scope, which matches the focused attention that in many cases characterize individuals with ASD.

Unfortunately, only few of the software products designed for young people with autism have been created explicitly to support the development of social skills. However, the project "Systemizing Empathy" (Golan \& Baron-Cohen, 2006) should be mentioned. With this educational software it is possible to focus on empathy. This application makes use of a sort of a social simulator. Others have used a similar approach, but according to Bölte (2004), the long lasting effects of the use of these products are somewhat discouraging. Bölte argues that in order to be efficient, such educational applications should be customised to the needs of the individual user and designed to be used not only in a classroom setting but also at home and in other relevant environments. It should be pointed out that many software projects, which performed well in the laboratory, failed in the field test (Dawe, 2006). This means that the assistive software in question should be tested not only in a classroom setting but also in relevant environments outside the school.

It is important to be able to customize the assistive software to the individual user and also to be able to offer suggestions at the right time. In this way the user may be taught to use the application when and where there is a need for the assistance that the systems offer. The possibility of customizing the applications makes it realistic to take the user's intuition and knowledge into account in the actual design and development of the assistive software system in question.

If software products designed for young people with autism should focus explicitly on the development of social skills, it would be an attractive idea to implement the tools using mobile technology. Significant success has been reported from small studies of the use of various applications managing everyday life activities (Myles et al., 2007; Sørensen 2005). Given that the HANDS tools are meant to support and guide teenagers with ASD in their social development in everyday settings, a theoretical framework with a clear focus on individual e-learning involving mobile technology is an obvious choice.

In the following section we shall present some of the key ideas within persuasive technology. The assumption is that this theory can provide a theoretical framework corresponding to the ambition on which the HANDS project is based.

\section{Mobile Persuasion as a Useful Theoretical Framework}

Persuasive technology or persuasive design is a new field introduced by Professor B.J. Fogg at Stanford University. It is sometimes called captology, which is a term derived from the acronym CAPT (computers as persuasive technology), first suggested by Fogg in 1996. In short, captology is the study of the possibilities and problems related to the use of computers for persuasive purposes. 
The study of persuasive technology is a rapidly growing research field. A large number of scientific papers have been published within the field during the last decade. Since 2006 yearly conferences have been organized (see http://www.persuasive2010.org/). There is also a growing interest in the use of mobile technology for persuasive purposes (see http://www.mobilepersuasion.org/).

Fogg’s book Persuasive Technology: Using Computers to Change What We Think and Do (2003) is the most important attempt to define the scope of the field. According to Fogg, interactive technology can be persuasive in three different ways:

1. as tools,

2. as media, and

3. as social actors.

If the interactive system is a tool, the crucial point is that the system can give the persuader an increased capability. Such a tool-like system can be persuasive by making the target behavior easier to do, by leading the user through a process, or by performing calculations or measurements that can motivate the user.

If the system in question is seen as a medium, it can offer users an important experience. Fogg has pointed out that in this case the persuasiveness of the system will typically allow users to explore some important cause-and-effect relationships and thereby provide them with an understanding of some important relations or with some vicarious experiences that can motivate or help to rehearse a behavior.

When the computer serves as a social actor, it can be persuasive by rewarding users with positive feedback, by modeling a target behavior or attitude, or by providing social support.

In his discussion of computers as persuasive tools, Fogg has identified and discussed the following seven types of persuasive technology functioning as tools:

1. reduction: persuading through simplifying;

2. tunneling: guided persuasion;

3. tailoring: persuasion through customization;

4. suggestion: intervening at the right time;

5. self-monitoring: taking the tedium out of tracking;

6. surveillance: persuasion through observation; and

7. conditioning: reinforcing target behavior.

In his discussion of computers as persuasive media, Fogg has mainly considered persuasion through simulation. He has proposed that the following three categories are particularly relevant to the design of persuasive technology:

1. cause-and-effect simulations (offering exploration and insight);

2. environment simulations (creating spaces for persuasive experiences); and 
3. object simulations (providing experiences in everyday contexts).

Regarding the use of computers as persuasive social actors, Fogg has discussed five social cues through which the user may be persuaded:

1. physical cues,

2. psychological cues,

3. language,

4. praise, and

5. social dynamics.

Two chapters in Fogg's book are devoted to the discussion of issues related to credibility. This clearly has to do with the simple fact that a technological device is unlikely to be persuasive to the user unless it is considered to be credible. If we consider a computer system, which offers, for instance, advice to the user in a specific situation, it will, of course, be interesting to ask how the user will evaluate the advice given by the system. To what extent will the user conceive the advice as credible?

Although there are several rather complicated aspects of credibility, and although any numerical measure of credibility will represent some kind of reduction, it may be useful to introduce a measure expressing the degree to which the user believes that the technology in question will be helpful. Fogg suggests that the perceived credibility of the computer system may be understood as a sum of two components, namely perceived trustworthiness and perceived expertise. In other words, Fogg says that the following equation can be used:

$$
\text { perceived trustworthiness }+ \text { perceived expertise }=\text { perceived credibility }
$$

Here the perceived trustworthiness will depend on how the user evaluates the personal qualities of the advisor behind the advice given by the computer system. Is the originator of the advice somebody who is truthful, fair, and unbiased? Has the advisor actually done her or his best to provide good advice?

The other component in Fogg's equation, perceived expertise, has to do with the intellectual qualities of the advisor behind the advice given by the computer system. Is the originator of the advice somebody who is actually skilled and able to give good advice in this case? Is the advice actually based on a sufficiently high level of expertise, knowledge, competence, and experience?

Fogg is correct in claiming that these two components both contribute to the perceived credibility of the application in question. However, Fogg's equation may still be criticized. Let us assume that the expertise of the advisor behind the system is maximal (i.e., perceived expertise $=1$ ) but that the advisor is without any trustworthiness at all (i.e., perceived trustworthiness $=0$ ). Following Fogg's equation the perceived credibility then becomes $50 \%$ of the maximal value. It can certainly be argued that this is unacceptable. At least, it appears just as reasonable to say that the perceived credibility of the advice in this case should be $0 \%$ because the advisor is totally 
unreliable. On such grounds, it may seem more correct to see perceived credibility as a product of perceived trustworthiness and perceived expertise.

Clearly, both components of the perceived credibility are dynamic because they may change from time to time. In the HANDS project it is seen as rather important to find a practical way to follow this change. In order to do so, we need a way to quantify the degree to which the teenager believes that he or she can find help in relevant situations by using a particular component in his or her HANDS toolbox (we shall come back to this challenge).

It is easy to read Fogg's 2003 book as a contribution to e-learning, although there are certainly other perspectives of the theory. But persuasive technology can clearly be applied to the teaching and learning situation studied in the HANDS project. When conceived in this way the theory suggests a number of strategies and techniques for making tools that can support the teenager with autism in his or her social development. In persuasive technology there is a strong emphasis on customization. This means that the teacher in close cooperation with the teenager has to tailor the relevant tools individually. In order to make this possible, it is essential that the appropriate components are available in the HANDS toolset.

Fogg is very much aware of the fact that the use of persuasive technology may give rise to a number of ethical considerations. He has devoted one chapter in his book to the study of ethical issues. However, there remains much to be done in the study of the ethical perspective of the development and the use of persuasive technology.

Fogg has suggested that persuasion can be broadly defined as "an attempt to change attitudes or behaviors or both (without coercion or deception)” (2003, p. 15). This definition may however be slightly problematic because it is not always clear when something is coercive or deceptive. A more useful way of talking about this would be to distinguish between ethically acceptable types of persuasion and ethically unacceptable or problematic types of persuasion, such as coercion, deception, manipulation, and so on. This strategy leaves us with a definition of persuasion as "an attempt to change attitudes or behaviors or both" with a challenge to formulate principles according to which certain types of persuasion should be regarded as ethically acceptable whereas other types should be regarded as unethical. Within the HANDS project it is seen as essential to deal systematically with the ethical questions that occur.

\section{The General Design of the HANDS Toolset and its Use for E-learning Purposes}

The HANDS toolset has been developed using the ideas from persuasive technology. There is an emphasis on designing individual tools for the users. It has been the ambition in HANDS to make the specific techniques and options available for the teachers as they are designing individual tools for their students. The assumption is that the use of mobile persuasion will turn out to be effective for this purpose. 
The HANDS toolset consists of software developed at two levels:

1. systems running on a server accessible on the Internet, and

2. software that can be used by the teachers in order to develop applications that can be downloaded to run on smart phones belonging to the teenagers participating in the project.

The following diagram outlines the general system design in HANDS.

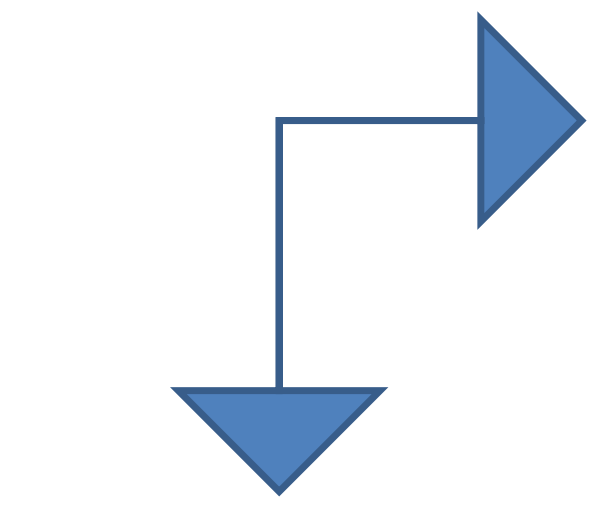

Teacher working at a school for young people with autism
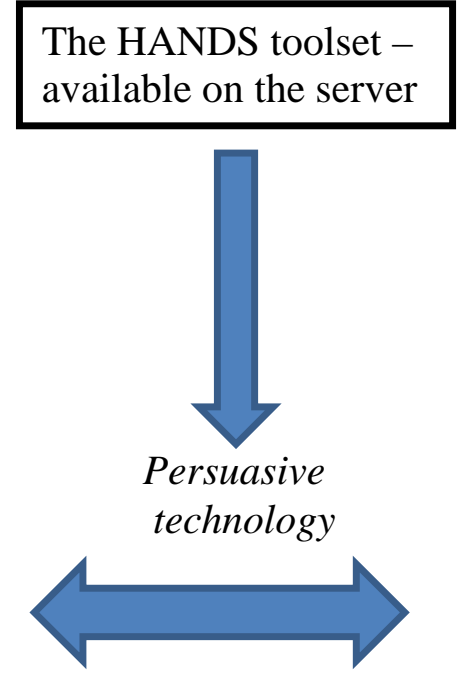

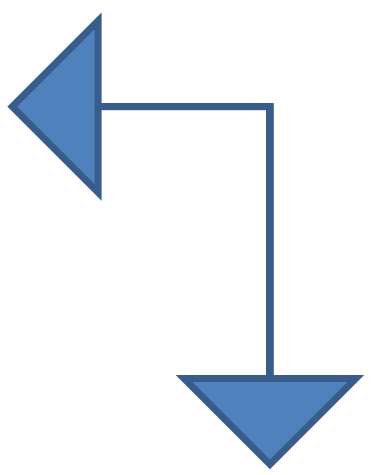

Teenager with an autism diagnosis and with average or higher IQ

Figure 1. The general HANDS system design.

Each of the teenagers in the project is supposed to use the applications in an individually tailored format. The teachers develop the individual applications using the HANDS toolset available on the server. Then the individual applications are downloaded from the HANDS server onto the smart phone. The result, an individual collection of HANDS tools implemented on a specific smart phone, is called a toolbox. It is important that the toolbox is tailored in close cooperation with the teenager, who is supposed to use it as a practical help in everyday life. The teacher can update the HANDS toolbox on the server, from where the updated applications may be downloaded to the smart phone belonging to the individual teenager. The teenager may choose to synchronize her or his toolbox with the server at any time. In doing so the teenager accepts to have her or his toolbox updated.

It is assumed that the smart phone can be an attractive platform for the use of the personal toolbox and for individually organized training and e-learning. In this way the teenagers may learn to handle what they see as difficult situations occurring in various everyday situations.

The HANDS software implemented on the server include a number of tools, developed from ideas originally formulated by the teachers and the teenagers at the partner schools in close cooperation with the researchers at the partner universities. The development of the HANDS tools 
has been strongly influenced by the ideas of persuasive technology. The HANDS toolset includes the following main functionalities:

1. The Handy Interactive Persuasive Diary (HIPD),

2. The Simple-Safe-Success Instructor (SSSI),

3. The Personal Trainer (TT),

4. The Individualizer (TIn),

5. The Sharing Point (SPo),

6. The Credibility-o-Meter (CoMe).

Functionalities 1-4 have been implemented in prototype 1 of the HANDS toolset, whereas 5-6 have not. All the functionalities will be included in prototypes 2 and 3.

The HIPD is an interactive calendar with a number of additional possibilities. The purpose of the HIPD is to support the teenager in the temporal organization of her or his everyday life and also to give the teachers a tool which can make it easier to be prepared for situations where the user is likely to be persuaded to adopt a new behavior or attitude (Ranfelt et al., 2009).

Each of the tools must offer advice at the right time. In the theories of persuasive design, the idea of Kairos, which includes the notion of the right or the appropriate time, is considered essential with respect to the persuasive effect (Aagaard et al., 2008).

The SSSI and TT are both believed to support the teenager when he or she wants to learn how to navigate certain situations better. The following is an example illustrating the kind of problems in question (Schärfe et al., 2009):

Morning time is very hectic in AA's home. His mum has to get three children ready for school, and it would be good if AA takes responsibility for preparing his school bag. Besides managing time effectively, AA also should remember what he should pack for the school day. Doing so will make both AA and his mum less anxious and angry in the morning. Understanding that there is a need to change AA's behavior, AA's teacher and AA have designed an application for AA's toolbox on his smart phone. This application can stepwise tell AA what to pack in his school bag. In this way it can support that AA's behavior in the morning situation is changed.

This approach is inspired by the so-called social stories (Gray 2000), that is short stories describing a specific type of situation considered to be problematic, challenging, or difficult for the individual teenager with autism. The idea is to use the story to focus on the social aspects of the situation. In this context, the teenager and the teacher may agree on some behavioral changes that they both want to see. Using such social stories, relevant pictures, and written advice, it may 
be possible to develop an application on the smart phone that can direct the teenager to an appropriate behavior in the situation in question (Gyori et. al, 2010).

It is generally believed that the HANDS software will only be accepted by the teenager with autism if it has been individually designed and personalized. The user should be able to choose the colors and other features of the user interface. This is the purpose of the TIn tool. Using this tool from the HANDS toolset, the teenager will be able to individually tailor the HANDS toolbox. The toolbox can be adapted so it has a unique appearance and functionality for each person. In this way the HANDS value, one for each, can be carried out in pedagogical practice.

The purpose of the SPo tool is to allow the teachers in the HANDS project to share their experiences. In addition, the tool should provide a communication platform for the teenagers in the project. The SPo is still under development and was not included in prototype 1 of the HANDS toolset.

The teacher would clearly like to know the extent to which the use of the toolbox can actually influence the behavior of the teenager. However, this is not sufficient. It will also be important for the teacher to know to what extent the teenager believes that the toolbox can be of any help. When using the HANDS toolbox in a practical learning situation in cooperation with a particular teenager with autism, the teacher needs to know, at least approximately, to what extent the HANDS toolbox is experienced as being credible by the teenager. It is the purpose of the Credibility-o-Meter (CoMe) to establish this information. The Credibility-o-meter is partly based on the electronic footprints left by the user on the mobile device during normal use. CoMe is still under development and it has not been included in prototype 1. Some of the basic questions involved in this development will be discussed.

From the teenager's perspective, the HANDS toolbox offers help whenever certain situations arise. These situations were previously identified when the teacher and teenager cooperatively constructed the toolbox. Typically the smart phone will prompt the teenager when a situation is becoming nearer in proximity, either in time or place. A built-in GPS in the smart phone allows the prompt or alert to be location-related, that is the situation may be related to a certain location. Whenever the user comes close to this location, a warning is issued.

All actions performed by the teenager and the GPS data will be logged on the HANDS server. This means that the teenager is under the surveillance of the teacher, as well as the researchers and the parents (given that the teenager has consented).

The general system architecture as seen from the user's perspective may be presented in the following manner. 


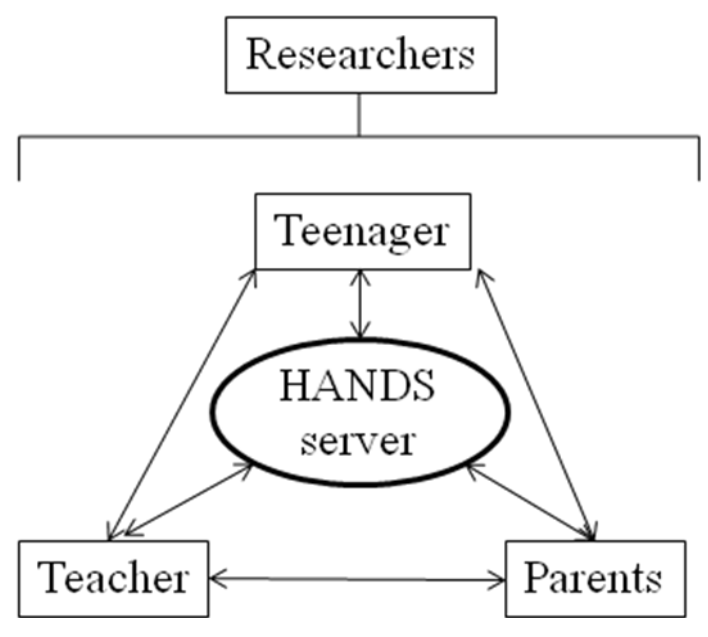

Figure 2. The general system architecture as seen from the user's perspective.

This high level of surveillance gives rise to ethical considerations.

\section{Prototype 1 Evaluation}

Prototype 1 of the HANDS toolset has been evaluated at the four schools in the HANDS project from November 2009, and a part of it from September 2009. However, because of various delays and practical problems not much testing was carried out before December 2009. In fact most of the testing was done in the late spring of 2010. The test period ended in June 2010.

Twenty-nine teenagers and their teachers at the four schools have participated in the test of prototype 1 . The teachers have been asked to use the HANDS toolset in cooperation with the teenagers in order to create individual toolboxes, which the teenagers should download on their smart phones. The teachers have also been asked to continue their pedagogical practice as usual involving the HANDS software as much as possible. In particular, the teachers have been asked to look for cases in which the teenager could benefit from the use of the HANDS software in order to learn to navigate better socially. All teachers and all teenagers were interviewed after the test period. In addition, all activities on the smart phones have been recorded on the HANDS server.

A total of 5,990 instances of use were recorded on the server during the test period. This is less than expected which probably is due to the fact some of the teenagers started using the software very late in the test period.

The two most frequently used applications were the calendar functions with HIPD (2,171 instances) and the Personal Trainer (TT) and Simple-Safe-Success Instructor (SSSI) (2,122 instances). This is in full accordance with what was expected. Both of these major HANDS facilities have been assumed to be attractive for the teenagers in the HANDS project. 
Some of the teenagers used the HANDS software frequently, whereas others almost never used it. It is tempting to link this to the teacher's degree of motivation to use ICT. However, it is simplistic to assume that the teacher must be highly motivated to use ICT in order for the teenager to use the HANDS software actively. In fact, there are cases from the test period of teachers with a very low interest and motivation to use ICT in their teaching, who nevertheless developed HANDS toolboxes with their students, and the students then became very active HANDS users.

The most interesting result from the test period is probably that it has been clearly documented that there are cases in which the teenagers and their teachers found the HANDS software very useful in supporting the teenagers in their social development. In a report of prototype 1 findings (Mintz et al. 2010, p.24), teachers and students identified the following cases as examples of how the use of the HANDS toolset helped in their development of social and life skills.

- Communication: One of the teenagers "says goodbye to his/her grandmother with the help of the machine's instructions - this never happened before."

- Socializing and making friends: Some teenagers formed new friendships with other teenagers using the smart phone.

- Managing emotions: Some teachers reported that the use of the HANDS toolbox in practical situations was a useful way for the teenagers to learn "how to handle stressful thoughts.”

- Organization: A teacher reported that "Tidying up and homework, just with SSSI, helped the child's independence.”

- Independence: A teacher pointed out that the HANDS software seems to provide a more effective way of doing things than the earlier methods: “On account of the interest in using the machine, [the teacher] was capable of independently carrying out any activity, which in the previous paper format was not at all typical."

- Life skills: A teacher reported the following: “Arts and crafts - capable of sewing with the help of a series of diagrams, willing to use scissors - he/she likes the machine giving him/her 'instructions'."

- Personal hygiene and health: One of the teenagers benefitted from the use of the toolset because "He is being reminded of some rules in, e.g., sex and health."

- Taking medication: A teacher reported that "With the help of the machine he/she was capable of independently preparing, packing together necessary equipment (every time he/she leaves the school building, it is necessary for them to take their essential diabetic medical equipment with them)."

- Shopping: A teenager learned how "to get to the store and shop for groceries."

- Daily routine: A teenager reported that the software has helped him "with his daily routine at home and stuff like that.”

Based on the finding of the evaluation of prototype 1, the HANDS software can be helpful for teenagers with autism. In particular, it has been emphasized by several of the teachers that in this way, teenagers may learn how to act more independently in society. On the other hand, the 
findings do not give a clear indication of why some teenagers in the test group benefitted from the use of the toolbox and others did not.

\section{The Need for Further Development of the HANDS Toolset}

Two of the planned functionalities, The Sharing Point (SPo) and the Credibility-o-Meter (CoMe), were not implemented in prototype 1 of the HANDS toolset. However, some design considerations have already been carried out in order to make a qualified decision on how these two functionalities should be implemented.

Some of the findings from the evaluation of prototype 1 attest to the importance of the idea on which the planned SPo functionality is based. It has been noted that there is a potential in the use of HANDS for socializing and making friends simply by sharing the experiences from the use of the toolset. Similarities between HANDS and social media such as Facebook have also been noted.

In order to develop the Credibility-o-Meter, it will be necessary to establish a way to quantify the degree to which teenagers believe that they can find help in certain kinds of situations by using a particular component in the HANDS toolbox. Such quantification may be based on

- input from the electronic footprints logged on the HANDS server system, and

- information provided by the teenager to the teacher.

On the basis of this input, the teacher could estimate the degree of credibility on a scale (e.g., from 1 to 10). It is important to distinguish between the credibility as evaluated by the teenager and the credibility as evaluated by the teacher. The two values may be very different and both are useful in pedagogical practice.

Let us assume that a particular teenager with an autism diagnosis has to face a certain type of difficult situation every morning on the school bus. Let us assume that the kind of problem he has to deal with involves communicating or relating to other people on the bus. The teenager recognizes the problem and has discussed it with his teacher. Together they have developed a strategy, which may help the teenager to cope with the problem. The strategy is in fact a stepwise procedure, which the teenager will be advised to follow whenever he finds himself in the difficult situation in question. This strategy has been implemented on the smart phone, which the teenager brings with him wherever he goes. The question is how we may estimate the credibility of the individual HANDS toolbox components designed to help the teenager in the difficult situation he is facing on the bus every morning. The idea is that the estimate of this credibility should be a result of a discussion between the teacher and the teenager, partly based on the data from the HANDS server. The general procedure in this regard is illustrated in Figure 3. 


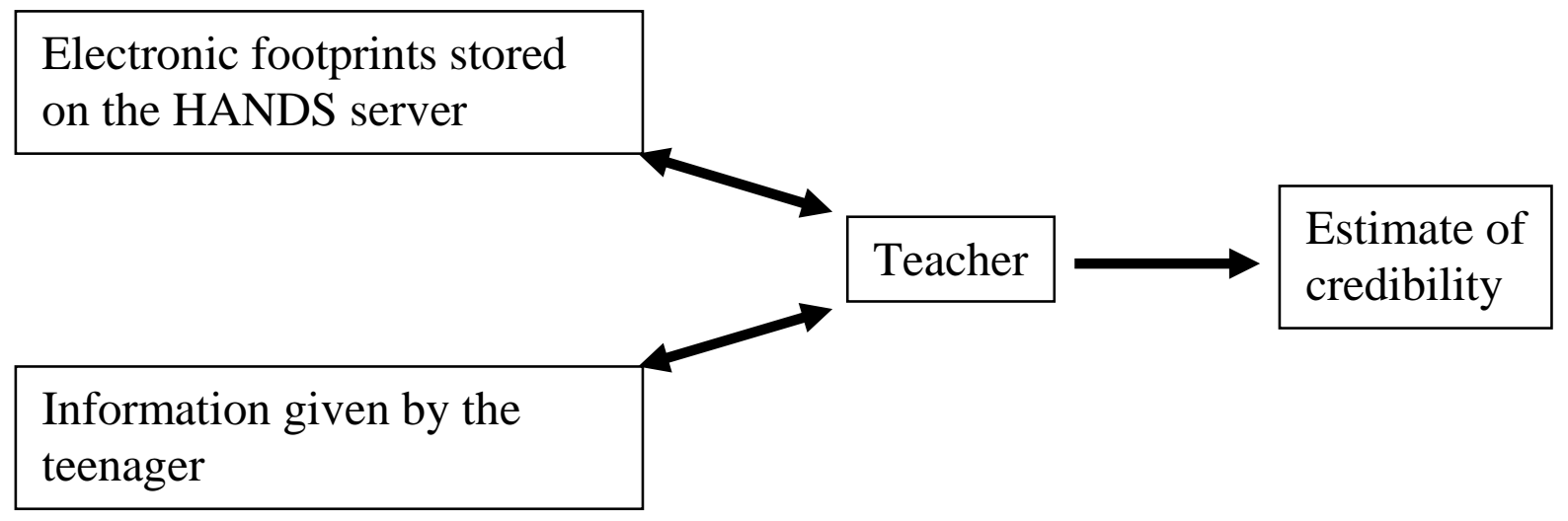

Figure 3. The teacher has to estimate how credible the teenager finds the particular component in his individual HANDS toolbox. The degree of credibility is an estimate of how helpful the component is according to the evaluation of the teenager. In addition to this, it is useful to have an estimate of how helpful the component could be according to the evaluation of the teacher.

The estimates of credibility established in this way will to some extent be subjective. It is, however, one of the interesting challenges of the HANDS project to develop standards for this evaluation procedure in order to make it as reliable and useful in practice as possible. Such standards may be incorporated in an interview guide to be used by teachers when communicating with the teenager in order to estimate the degree of credibility of a component in an individual HANDS toolbox. One problem in this regard will be how the teacher should make use of the electronic footprints logged on the HANDS server system. How should the teacher react if the data from the server indicate that the teenager has been in a difficult situation several times, without activating the relevant component on his smart phone in order to get help? One possible interpretation of this finding could be that the teenager does not find the component credible. Alternatively, it could be that he tends to forget everything about the system on his smart phone when he gets into the difficult situation in question. During the interview the teacher should try to find the most probable interpretation of the data from the server as seen in relation to what is known about the practical experiences of the teenager.

In some cases the credibility as evaluated by the teenager and the credibility as evaluated by the teacher may be very different. If the teacher's evaluation is significantly higher than the teenager's evaluation, the teacher needs to find a way to persuade the teenager to use the component. In dealing with this challenge, the teacher may make use of various persuasive technology tools involving praise and rewards.

The numerical level of the credibility of a given system in a certain context is not the only aspect of credibility. It will also be relevant to consider to what extent the user has obtained direct experience and interaction with the system. Fogg (2003, p. 131) has suggested a distinction between "presumed credibility" (based on general assumptions in the mind of the perceiver), "surface credibility" (based on simple inspection or initial firsthand experience), "reputed credibility" (based on third party endorsements, reports, referrals), and finally "earned credibility" (based on firsthand experiences that extend over time). Here the first two and the last have to do 
with the user's direct experiences with the system, whereas reputed credibility is based on reports from others. Alternatively, Gerdes et al. (2010) suggest that the assessment of system credibility may evolve through the following four identifiable stages:

1. initiation,

2. interaction,

3. personalization, and

4. integration.

Such considerations indicate that credibility as a receiver-based construct is a complicated idea. Maybe we should operate with different kinds of credibility or see credibility as a notion with several dimensions. Actually, we may see the degree of credibility and the four stages just mentioned as two different dimensions, which are both relevant in the discussion of credibility and e-learning. In fact, the four stages may be understood as an indication of the extent to which the system has been brought into practical use. One may speak about the degree of technological involvement or perhaps about the degree of embodied credibility.

\section{Ethical Issues}

The founder of the field of persuasive technology, B.J. Fogg, has put emphasis on the importance of ethical issues (2003, p. 211). One may ask the fundamental question concerning the use of persuasion: In principle, is it unethical to use persuasion? There is no quick and obvious answer, but it is clear that ethical problems arise if coercion or manipulation is used to make people change their attitudes or behavior as such techniques or strategies might not respect human freedom and dignity

As indicated in Figure 2, the general system architecture as seen from the user's perspective, a high degree of surveillance is involved in the HANDS project. Every time a teenager in the project updates his or her toolbox and every time one of the tools in the toolbox is used, it will in principle be reported to the HANDS server from where the teacher, the parents, and the researchers may download the information. The stored data also include all the responses given by the teenagers as they have been using the software. In addition, when prototype 2 of the HANDS toolset has been implemented, the server may also contain GPS data corresponding to the geographical movements of the teenagers. The collection of data based on the various kinds of surveillance in this context should be explicitly justified. The researchers must present valid arguments that this level of surveillance is in the best interest of the teenagers, is not harmful, and does not violate the basic rights of the individuals in question. Such arguments should be established before the surveillance software is implemented (Jespersen et al., 2007).

The data stored on the HANDS server is a potential threat to the privacy of the teenagers in the project. Therefore it must be carefully discussed with the teenagers and their parents to determine which data should be available to the parents, to the teachers, and to the researchers. It is essential to look carefully into the ethical principles for giving access to the study of personally sensitive data (Øhrstrøm et al., 2007). 
If a user finds a tool very credible, he might get highly involved with it. In fact, we can imagine that the tool is fully integrated in the everyday practice of the user. In some cases, this means that the tool should almost be conceived as a part of the user's body (Gerdes et al., 2010). In consequence, we may ask whether the user will become addicted to this tool. Will the teenager actually depend too much on it? This question should be carefully considered in relation to each of the tools in the toolbox. Whenever there is a risk for a teenager to develop a high degree of dependence on a certain tool, the teacher or researcher must provide a convincing argument justifying the introduction of the tool before the tool can be a part of the user's toolbox.

In some cases the teenager may not want to use the toolbox because he or she does not find it credible. In such cases the teacher might try to convince the teenager to change his or her view on the credibility of a certain tool in the toolbox. However, it is important that such attempts are only carried out if there are good reasons for trying to make the teenager change his or her view. For instance, a teacher should not try to convince a teenager that a certain tool is more credible than the teenager perceives it to be.

In order to establish a careful investigation of the ethical problems related to the development and the use of the HANDS toolset, an ethical board has been formed that includes members who are independent specialists in research ethics and in the treatment of young people with ASD and members who represent the parents of children at the test schools (Holm et al., 2010).

One possible position regarding the ethics of the use of persuasive technology is that it is acceptable if it is carried out according to informed consent. Whenever possible, the teenagers with an autism diagnosis should be asked to give informed consent prior to participating in the tests. However, the HANDS project is dealing with a vulnerable population who may not be able to give fully informed consent, even when given all appropriate information. In such cases, the acceptability of consent given by a parent or legal guardian alone will have to be considered by the ethical board. Another important aspect in this consideration should be the age of the teenagers. The older the subjects, the more problematic it will be to accept their participation in a test based on informed consent from their parents but without their own informed consent. Clearly, the teenagers should not be forced to take part in any test. It is important for the ethical board to consider the possible stress and irresolvable ambivalences caused by pressure being put on those autistic subjects who are not initially willing to participate.

Even if such consents are given by the teenagers and their parents, an independent ethical evaluation should be carried out by the ethical board prior to the tests. In fact, the ethical considerations should be carried out before the actual test phase, during the design and implementation phase. The HANDS project attempts to employ the ethical standards during the development process in close cooperation between researchers working with ICT ethics and system developers. This is an attempt inspired by value sensitive design, which according to Friedman et al. (2002) can be presented as "a theoretically grounded approach to the design of technology that accounts for human values in a principled and comprehensive manner throughout the design process.' From a practical point of view, this means that all stakeholders have been 
involved from the early stage of the design and implementation of the HANDS software. In particular, the ethical board has been involved during the requirement elicitation, prototyping, and testing phases of the software.

\section{Conclusion}

It can be concluded that it is possible to create e-learning tools designed for teenagers with autism using server and mobile technology and based on ideas from the theory of persuasive technology. Studies in the use of assistive technology for individuals with autism suggest that the choice of this theory may provide a useful framework for the further development of software to be used by teenagers with ASD and a normal or high IQ.

The test of prototype 1 of the HANDS toolset shows that we may create tools which can at least in some cases be very helpful for teenagers with autism in their social development. In order to be helpful, the tools have to be tailored individually.

However, some teenagers with autism do not find such tools helpful. It is still an open question why some teenagers with ASD find the HANDS tools very helpful in order to gain independence in their social life, whereas others do not find this kind of technological solution helpful. One possibility is that the members of the latter group for some reason do not find the tools credible. This possibility should be further investigated based on an elaborated and quantifiable notion of credibility.

The use of mobile persuasion, as in the HANDS project, gives rise to a number of important ethical problems. In particular, the use of the server solution and the high level of detailed surveillance may cause concerns regarding the privacy of the teenagers involved in the project. It has been argued, however, that it is possible to deal with such ethical problems in a satisfactory manner by involving an independent ethical board with some members representing the parents and some members with specialist qualifications in research ethics and the treatment of young people with autism. 


\section{References}

Aagaard, M., Øhrstrøm, P., \& Moltsen, L. (2008). It might be Kairos. Persuasive, 08. Oulo, Finland.

Aagaard, M., Schärfe, H., \& Øhrstrøm, P. (2010). Evaluation of prototype 1 and requirements for prototype 2 - as seen from the perspective of persuasive technology (HANDS Deliverable D4.3.1). Retrieved from http://hands-project.eu/.

Bell, E., Potter, D., \& Walsch, B. (2006). Computer applications for people with autism. London, England: National Autistic Society.

Bölte, S. (2004). Computed-based intervention in autism spectrum disorders. In O.T. Ryaskin (Ed.), Focus on autism research (pp. 247-260). New York: Nova Science Publishers.

Dawe, M. (2006). Desperately seeking simplicity: How young adults with cognitive disabilities and their families adopt assistive technologies. In Proceedings of the SIGCHI Conference on Human Factors in Computing Systems (pp. 1143-1152). New York: ACM Press.

Ferguson, H., Myles, B.S., \& Hagiwara, T. (2005). Using a personal digital assistant to enhance the independence of an adolescent with Asperger Syndrome. Education \& Training in Developmental Disabilities, 40(1), 60-67.

Fogg, B.J. (2003). Persuasive technology: Using computers to change what we think and do. San Francisco: Morgan Kaufmann Publishers.

Friedman, B., Kahn, P.H., \& Borning, A. (2002). Value sensitive design: Theory and methods. UW CSE Technical Report, 02-12-01.

Gerdes, A., \& Øhrstrøm, P. (2010). Issues of credibility in developing mobile solutions for autism-diagnosed teenagers. Persuasive. Copenhagen.

Golan, O., \& Baron-Cohen, S. (2006). Systemizing empathy: Teaching adults with Asperger syndrome or high-functioning autism to recognize complex emotions using interactive multimedia. Development and Psychopathology, 18(2), 591-617.

Gray, C. (2000). The new social story book. Arlington, TX: Future Horizons.

Gyori, M., Stefanik, K., Kanizsai-Nagy, I., \& Öszi, T. (2010). Evaluation of prototype 1 and Requirements for prototype 2 - in the perspective of cognitive psychology (HANDS Deliverable D2.4.2). Retrieved from http://hands-project.eu 
Holm, S., \& Ploug, T. (2010). Ethics board - annual report year. HANDS/D1.5.2/AAU/R/PU/2010-7-15.

Jespersen, J.L., Albrechtslund, A., Øhrstrøm, P., Hasle, P.F.V., \& Albretsen, J., (2007). Surveillance, persuasion, and panopticon. In Lecture Notes in Computer Science: Persuasive Technology: Second International Conference on Persuasive Technology, PERSUASIVE 2007: Revised Selected Papers (pp. 109-120). Berlin/Heidelberg : Springer.

Mintz, J., Branch, C., Lerman, S., \& March, C. (2010). Evaluations of prototype 1 and requirements for prototype 2 (HANDS Deliverable D3.4.1). Retrieved from http://handsproject.eu.

Myles, B.S., Ferguson, H., \& Hagiwara, T. (2007). Using a personal digital assistant to improve the recording of homework assignments by an adolescent with Asperger Syndrome. Focus on Autism and Other Developmental Disabilities, 22(2), 96-99.

Øhrstrøm, P., \& Dyhrberg, J. (2007). Ethical problems inherent in psychological research based on internet communication as stored information. Theoretical Medicine and Bioethics. 28(3), 221-241

Ranfelt, A.M., Wigram, T., \& Øhrstrøm, P. (2007). Towards a handy interactive persuasive diary for teenagers with a diagnosis of autism. Proceedings of the 4th International Conference on Persuasive Technology. Association for Computing Machinery. ACM International $\begin{array}{lll}\text { Conference } \quad \text { Proceeding Series, } & 350 .\end{array}$ http://portal.acm.org/citation.cfm?doid=1541948.1541953

Schärfe, H., Øhrstrøm, P., \& Gyori, M. A conceptual analysis of difficult situations - developing systems for teenagers with ASD. International Conference on Conceptual Structures (ICCS-2009), CEUR Workshop Proceedings. 483. http://ftp1.de.freebsd.org/pub/publications/CEUR-WS/

Sørensen, M. (2005). En PDA - hva’ for noget? Autismebladet, 3, 32-33.

Volkmar, F.R., Lord, C., Bailey, A, Schultz, R.T., \& Klin, A. (2004). Autism and pervasive developmental disorders. Journal of Child Psychology and Psychiatry, 45(1), 135-170.

\section{Athabasca University $\mathbf{A}$}




\section{ODR \\ International \\ Review of \\ Research in Open \\ and Distance \\ Learning}

Vol. 12.4

May-2011

\section{Internet Technology-Based Projects in Learning and} Teaching English as a Foreign Language at Yakutsk State University

\author{
Lena Zamorshchikova, Olga Egorova, and Marina Popova \\ Yakutsk State University, Russia
}

\begin{abstract}
This paper discusses recent uses of information and communication technologies (ICTs) in fostering Internet-based projects for learning English as a Foreign Language (EFL) at the Faculty of Foreign Languages in Yakutsk State University, Russia. It covers the authors' experiences integrating distance education and creating educational resources within the Moodle LMS and wiki projects based on Web 2.0 social networking technologies. Also it discusses our international project, Net-based Course Development: English through Digital Storyline, in cooperation with the University of Tromsø, Norway.
\end{abstract}

Keywords: E-learning; IT technologies; English as a Foreign Language; wiki; social networks

Possibilities provided by the Internet for educational purposes have been attracting more attention in recent studies devoted to the problems of using information and communication technologies (ICTs) in education. This tendency is fed by the development of Internet infrastructure and technologies, by their increasing availability and use, and by the ongoing search for new ways to improve educational quality through the use of technology.

E-learning in the Sakha Republic (Yakutia) is developing at the same pace as in the rest of Russia. The Republic is considered to be well equipped with computer aids, but in order to manage a distant educational process and Internet interaction of all the participants of the educational process, it is crucial to provide an advanced and modernized ICT infrastructure on a qualitatively new level. The IT infrastructure is believed to play a leading role in managing distance learning and in increasing the effectiveness of the educational process and the overall educational system. 
Many digital training materials have been created, but the developed materials are not widely and effectively used by teachers in the learning process. There are many reasons for this: no access to the Internet, slow Internet, and lack of compensation for creating media, and so on. However one of the main reasons is that ordinary teachers are not prepared to actively include e-learning in the curriculum. Some teachers do not have the necessary skills or an understanding of the advantages of e-learning, despite the fact that ICT training workshops for teachers on how to use and work on computers have been held for many years.

Teachers should remember the different modes of using computers in class. The first is administration: Computers can be used for creating timetables, planning courses, and so on. The second is testing: Computers can be used to ascertain the student's knowledge of the language, including everything the teacher has in mind. The third mode is as a classroom teaching aid, for example using a CD recording to start a lesson. In this mode, computer-introduced material leads to class discussion and activity to which the computer itself is not central. Thus the computer presents a piece of grammatical information, or a text that can be discussed by the students and the teacher, or a set of information for a logical problem or a role play. The fourth mode is direct teaching - using the computer for teaching some aspect of language (Brumfit, 1985).

One of our earliest experiences in distant education at the Faculty of Foreign Languages was a project on Expository Writing between Pembroke College, Oxford University and Yakutsk State University in 2002. The interactive course involved students in Yakutsk State University (YSU) and the students of its branch in Mirny. The students were expected to follow the course together from module to module as each module was available online for every participant according to the following course schedule: (1) a professor from Oxford created the modules and posted them online to the students in Yakutsk and Mirny; (2) within each module, the professor gave directions to the YSU instructors for the face-to-face classroom interactions with the students (in tandem with the online module); (3) The YSU instructors (in Yakutsk and Mirny) were to enhance the online lessons by engaging the students in face-to-face learning and discussion within each module. In addition, the students had different assignments to post material to each other to read online, particularly during the introductory assignments, which allowed them to have some online interaction with each other. They could also post messages online for others to view and send private messages by email. As the instructors in Yakutsk and Mirny were to enhance the online lessons by engaging the students in face-to-face learning and discussion within each module, the course was considered a distant education course with face-to-face enhancements.

In 2009, a team of four teachers from the English Philology Department, Faculty of Foreign Languages participated in a Yakutsk State University project to implement Internet-based educational resources. Our product was an electronic resource package for the Practical Course of English, one of the principal textbooks used by our students. The e-resource was situated within the Moodle learning management system. One of the features of this educational resource is that students can find additional information and materials that they will not be able to find in the textbook. As well, they can practice doing online tests, which prepares them for the progress tests for each unit of the textbook. The e-content includes writing tips, tips for evaluating, 
commenting on, and analyzing texts, and excerpts from contemporary English and American writers' works. The obvious advantage of the e-resource is that it can be used by students in their out-of-class learning activities, which can be easily monitored by their teacher.

In February 2010, Yakutsk University also joined an international wiki project with students from the University of Tromsø, Norway including Academic Writing (www.academicwriting.wikidot.com) and English through Digital Storyline (www.yakutskcity.wikidot.com, http://generation.wikidot.com/start). This project, Net-based Course Development: English through Digital Storyline, was started with the Department of Teacher Education, University of Tromsø, Norway within the University of the Arctic Thematic Network, E-learning and Distant Education. The objectives of the project are as follows: 1) to learn to create the content of an Internet-based course using Web 2.0 technology (blogs, wikis, etc.) and a learning management system; 2) to introduce students to exploring and mastering digital tools, or "to develop their digital competence so that they themselves could discover the pedagogical potential in these tools;” 3) to find ways to incorporate contemporary Internet use and culture into foreign language teaching; 4) to study each others' experience of education through e-learning and Internet-based courses; (5) to establish contact between Russian and Norwegian colleagues for further cooperation, consultation, and exchange; and 6) to develop Internet-based cross-cultural communication networks between students of Arctic universities for a future teaching community.

Storyline is a method for cross-curricular teaching and learning centred on a specific theme. The main objective is to collaborate on a common storyline based on this methodology, entirely realised through so-called Web 2.0 tools (wikis and blogs) and applications (YouTube, Google tools, etc.) (Brox, 2009). A similar project had already been conducted at the University of Tromsø. Now it is intended to expand the storyline to include a wider range of learners.

In Yakutsk, the Storyline project will be integrated into the Practical Course of English for second-year EFL students. The project will be a component of the out-of-class activities of the students and will be evaluated by teachers at the end of the semester. Further plans will involve adapting the project to comply with credit-evaluated modules. In Tromsø, the project has already run through a one-year test period and is now ready to be integrated as a part of the English Didactics component in the one-year English course for third and fourth-year teacher trainees. Further integration is intended as a result of the present redesigning of the university's teacher education program.

The development of Web 2.0 technologies affected significantly the process of creating, circulating, and interpreting the sites' content (textual and graphic) in the Internet community. Depending on the content and address, social network services of the Internet might be divided into different groups: blogs, wikis, or micro-blogs (Syssoev \& Evstigneev, 2009).

A new generation of students can be called a generation of Web 2.0 users. Most of them are active and advanced users of social networking sites (Vkontakte, Facebook, Twitter, etc.) and are able not only to socialize, send and receive e-mails, and browse for information, but also to create 
and maintain sites and blogs by filling them with photos, videos, and hyperlinks. Students can widely collaborate on group projects using wikis and in this way develop not only their digital competence, but also their language skills as well as their imaginative thinking.

In order to practise creating the content of an Internet-based course using Web 2.0 technology, a pilot project, VisitYakutsk.wikidot.com, was started in March, 2010, which involved 10 secondyear EFL students. The activities on the project were divided into three periods.

1. In March after their teacher's short introduction about the content of the work and the final product anticipated, the students independently studied the possibilities that a wiki can provide in their project work. The students were set tasks to collect information and material for the project, which included finding and translating (if necessary) from Russian into English the background information about the history of Yakutsk and its current status and development, about the airport structure and tips for first-time visitors, about hotels, banks, restaurants, cafes, places for sightseeing, and museums in the town centre and on the outskirts, about shopping opportunities and souvenir kiosks, and about the University and its campus. Also, they took photographs of the objects they were going to describe in their project. At this stage the students created documents in MS Word.

2. In April the teachers helped to edit the material created by the students and to correct grammatical, lexical, spelling, and any other mistakes. After editing, the students began designing the wiki site.

3. In May, all the files were placed on the site with simultaneous designing of the material. Further development and maintenance of the site is done by the students at this stage. In order to incorporate the project into the academic course, the project will be a part of the Practical Course of English for second-year students as a component of out-of-class activities to be evaluated by teachers at the end of the semester.

In summary, ICT as tools of e-learning in teaching EFL are becoming more widespread in higher educational institutions and are meeting education quality requirements. E-learning in the academic curriculum allows educators to effectively combine the elements of self-study and distant education through software with the advantages of traditional classroom study and teaching. E-learning provides unlimited opportunities for collaboration in international and crosscultural projects in learning EFL. In this regard, social network services should be actively used in the learning process as they are becoming increasingly popular among the younger generation. 


\section{References}

Access to the Internet: Top-priority national project "Education". www.rost.ru/projects/education/ed2/aed25.shtml

Brumfit, C. (1985). Computers in English language teaching. Oxford: Permagon and the British Council Press.

Brox, H. (2009). Creating learning environments with Web 2.0: Using blogs and wikis in teaching. Seminar in Murmansk.

Moodle. Retrieved from www.wikipedia.org

Storyline. Retrieved from www.wikipedia.org

Syssoev P.V., \& Evstigneev M.N. (2009). Web 2.0 technologies in creating virtual educational environment for learning a foreign language. Foreign Languages at School, 6(3), 4-9.

Syssoev P.V., \& Evstigneev M.N. (2009). Web 2.0 technologies: Social network service of blogs in learning a foreign language. Foreign Languages at School, 6(5), 8-12.

\section{Athabasca University $\mathbf{1}$}

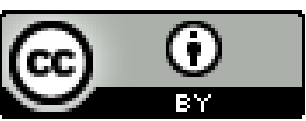




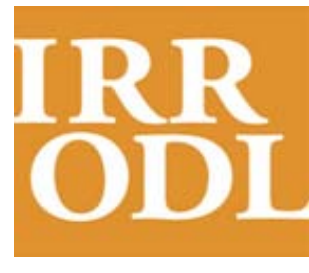

International

Review of

Research in Open

and Distance

Learning

Vol. 12.4

May-2011

\title{
Educating the Citizen of
} Academia Online?

\author{
Mariann Solberg \\ University of Tromso, Norway
}

\begin{abstract}
The Arctic is a vast, sparsely populated area. The demographic situation points to online distance education as a solution to support lifelong learning and to build competence in the region. An overall aim of all university education is what Hans Georg Gadamer calls Bildung, what we in Norwegian call dannelse and what Richard Rorty has called edification. A first problem to be addressed here is that in online distance learning some teachers find that is harder to support the development of the student's voice. Being able to express and position oneself in a scientific community is vital for a well-educated graduate. Another problem in online education has been the extensive use of writing as a means in the student's learning process. Writing is vital to academic education, but in online courses there is in general a danger of overuse. At the University of Tromsø we have tested the web conference tool Elluminate Live. This is a real-time application, integrated in the University's learning management system (LMS), Fronter. The application enables synchronous oral dialogue, simultaneous sharing of texts, and so forth. I present our main experience with the use of Elluminate Live and discuss the extent to which this application has turned out to be helpful in developing the quality of online courses.
\end{abstract}

Keywords: Academic Bildung; web conference; Elluminate Live; synchronous dialogue; Immanuel Kant; sensus communis

\section{Introduction}

A first problem to be addressed here is that in online distance learning some teachers experience that it is harder to support the development of the student's own voice. Being able to express and position oneself in a scientific community is vital for a well-educated graduate. Another problem in online education has been the extensive use of writing as a means in the student's learning process. Writing is vital to academic education, but in online courses there is in general a danger of overuse. Use of synchronous web conference tools for oral discussions is being discussed as a means of overcoming these problems in online studies. 


\section{Two Premises for Choice of Models and Tools for Flexible Education in the High North}

Web conference applications such as Elluminate Live are synchronous tools that are developed for use anywhere on the globe like so many other kinds of virtual learning tools or learning environments. Still, e-learning in the high North is a particularly relevant approach that has to do with demographics. Tromsø has the only university in the region of Northern Norway, a vast and sparsely populated area. ${ }^{1}$ Northern Norway covers an area of $112,946 \mathrm{~km}^{2}$, and this constitutes more than a third of mainland Norway. The area is populated by about 460,000 inhabitants, which is only $10 \%$ of the Norwegian population. It is also an area where this sparse population is quite evenly scattered around and fewer inhabitants than usual live in cities. Thus, the people of Northern Norway are relatively few and live relatively far apart.

The demographic situation of Northern Norway is a very important premise for our choice of models and tools for flexible education or distance education. People will obviously have to travel many hours by car in order to come to Tromsø, 10 hours from Bodø - or Kirkenes. Many would also have to travel far in order to reach their nearest community centre. Still, as the only university in the region, Tromsø is responsible for offering ordinary education to the region, as well as supporting lifelong learning through further and continuous education at the university level. Other institutions provide courses that support the building of competence in the region, but so far there is only one university. The demographic situation leads to a preference for more or less pure online learning solutions for those who cannot come to campus.

The second premise for our choice of models and tools for flexible education is about pedagogy. A main concern in all education, but perhaps particularly in online education, is the question of edification of the students, or what one in Germany would call Bildung. The question is how can we make sure that our students have the possibility of developing their own voice, developing their skills in critical thinking, and becoming knowledgeable in their subjects? Part of our answer is that they have to be able to practice. They must have experience in expressing themselves.

In our experience with blended learning, the worry about Bildung has not been prominent since the use of online resources is always in addition to the activities in the campus classroom. Now, there could of course be every bit as much reason to worry about Bildung in courses on campus, but in this case active participation on the part of the student is not prevented.

\section{Bildung}

Recently, the question of dannelse or Bildung in Norwegian higher education has been revitalized. In 2007 three Norwegian universities formed a standalone committee for examining

\footnotetext{
${ }^{1}$ A population density of 4,1 per $\mathrm{km}^{2}$ versus 14,6 per $\mathrm{km}^{2}$ in all of mainland Norway.
} 
the question of academic dannelse, and in 2009 they delivered a written summary of their work. ${ }^{2}$ Bildung traditionally had two components, an educational dimension where the subjects of the formation make themselves familiar with a scholarly tradition, or a curriculum, and a more existential-ethical dimension that has to do with the personal acquisition of different forms of knowledge. The educational dimension has had various kinds of content, through the ancient educational programs of Paideia to the bourgeoisie "education" in 1800s Germany. Moreover, Bildung has been looked upon as a process where the activity of the subject towards something outside the subject (the world, nature, or culture) has been considered vital. And third, Bildung has been looked upon as relational, a process going on between the subject and other persons. A special category here is the relation between initiated and non-initiated.

\section{Immanuel Kant's Sensus Communis}

I have chosen to base my understanding of Bildung somewhat loosely on Kant's sensus communis. In Kant's Critique of Judgment from 1790 (1987) sensus communis is presented as a general faculty for judgment that all humans have, and where the point is that we relate our own thinking to the potential thinking of others:

...we must [here] take sensus communis to mean the idea of a sense shared [by all of us], i.e., a power to judge that in reflecting takes account (a priori), in our thought, of everyone else's way of presenting [something], in order as it were to compare our own judgment with human reason in general... Now we do this as follows: we compare our judgment not so much with the actual as rather with the merely possible judgments of others, and [thus] put ourselves in the position of everyone else...

(p. 160)

This is similar to what Kant in his article “An Answer to the Question: What is Enlightenment?" calls public use of reason as opposed to private use of reason. And when we put ourselves in the position of everyone else this is for Kant connected to the categorical imperative. The most cited formulation of the categorical imperative is the claim to universality: "Act only according to that maxim whereby you can at the same time will that it should become a universal law." The categorical imperative is by Kant said to have the function of a moral law, situated in each and every human being. It is a law that is categorical; it demands that we follow it always. A maxim is a rule of action and, thus, for any rule of action that we are about to follow, we must see whether we could want others to always follow it. If we could, it is morally permissible that we do as the maxim prescribes. According to Kant humans are autonomous because we have the

\footnotetext{
${ }^{2}$ Kunnskap og dannelse foran et nytt århundre - Innstilling fra Dannelsesutvalget for høyere utdanning. (Knowledge and dannelse - with a new century pending. Recommendation from the committee on dannelse in Norwegian higher education): http://www.uib.no/filearchive/innstilling-dannelsesutvalget.pdf . Their understanding of academic Bildung is, in short: "...critical reflection, insight into scientific mindsets and epistemologies, deepening of understanding, teachings on fairness and objectivity and ethical competence.” (Author's translation)
} 
power of reasoning and because we have the freedom to choose to follow the moral law. But it is only when we choose to follow the law that we express our freedom.

In Kant's Anthropology from a Pragmatic Point of View from 1798 (2000) sensus communis are formulated as three maxims for thinking. The maxims are put forward as guidelines for achieving wisdom:

Wisdom, as the idea of a practical use of reason that conforms perfectly with the law, is no doubt too much to demand of human beings. But also, not even the slightest degree of wisdom can be poured into a man by others; rather he must bring it forth from himself. The precept for reaching it contains three leading maxims: (1) Think for oneself, (2) Think into the place of the other, (3) Always think consistently with oneself. (p. 307)

In focus for Kant here is first the claim of universality in thinking, that we should always judge our own thinking against a universal human standard. This means that when we think for ourselves, we will not only think from our own particular position. Second, the subject's active use of his or her own capacity for thinking is vital; we cannot let others think for us. If we think consistently with ourselves - and this involves both that each of us use his or her own faculty of reason and that each take in the universally human standard - we will be able to think maximally wise. Thus, sensus communis concerns both our theoretical (epistemological) as well as our practical (moral and political) use of reason.

\section{Three Principles for Interacting with a Curriculum}

My slogan for a student's interaction with a curriculum is the following: "Think with, think against and think for yourself.” It is loosely inspired by Kant's sensus communis, and I will explain how I see different forms of interaction with a curriculum in these three forms of thinking.

- Thinking with means to get involved in the tradition and to acquire disciplinary knowledge. The student learns his or her ways in the subject matter such that he or she can see it from the inside (i.e., learns it in such a way as to be able to defend the theories, views, and procedures against criticism).

- Thinking against means being able to take an outside perspective on the tradition; one is able to find good arguments against the various theories and views and raise objections to the procedures that are dominating.

- Think for yourself involves having a distinct voice, in a tradition, and it means being able to formulate new insights.

My division into different modes of thinking is primarily analytical, and the three different forms of thinking, of course, overlap in different ways in practice. It is difficult to imagine that anybody can deliver good counter-arguments (think against) if one does not know the discipline well 
(think with), and also a good defense can be performed better if one is familiar with the objections. To think well on your own without knowing the tradition well, and thus in practice be able to think with and against, is probably not impossible. However, without the background of the tradition it will be difficult to judge whether or not one then really have been thinking well. Also, originality is assessed against a particular background.

The slogan "think with, think against and think for yourself" relates to both an educational dimension and an existential-ethical dimension. That which one is to think with and against is the tradition and subject-matter of the various disciplines. Thinking for yourself have the two other forms of thinking as a necessary basis, but self-thinking is all about settling oneself, as a subject, into the tradition. The development of a personal voice, which is part of the historical and the contemporary academic conversation, is also potentially a fulfillment of the existential-ethical dimension. Dialogue and reflection are two necessary ingredients in the existential-ethical dimension of Bildung at a university, but that which is to be spoken about, reflected upon, and transferred in conversations is primarily the subject-matters of the discipline, the content of the educational dimension.

The educational dimension is necessarily a part of Bildung because this is where our students meet the authoritative interpretation of tradition and history. This is where you meet your masters, meaning the ones you should learn from and be in conversation with, and this is where you first retrieve the contents of your subject. The existential-ethical dimension is likewise necessarily a part of Bildung. The insights supposed to be retrieved from the educational program can not be disclosed and converted unless the student personally acquires them, unless the insights potentially could make a difference in the personal development of the student and his or her self-realization as a citizen of academia. Much of the same applies not only in higher education, of course. The difference for a student at the university is that one is not only expected to be a citizen of the community, but also expected to be able to take full part in a community of scholars and students engaged in education and research.

\section{Sensus Communis and the Curriculum}

Now, Kant's claim to universality in thinking, that we should always include the possible judgment of others, will have a particular interpretation in relation to Bildung in higher education. Also Kant's claim to universality in thinking unifies the two dimensions that I here earlier singled out: the educational dimension and the existential-ethical dimension. The educational program, or the curriculum, will broaden the student's potential for thinking for oneself and it will broaden the potential for thinking into the place of the other. When we put ourselves in the position of others, when we compare our judgments with the possible judgments of others, and thus when it comes to actions let ourselves be guided by the categorical imperative, we adopt maxims for action that we can want others to follow. Self-formation in the existential-ethical dimension is in this sense made on basis of our relation to mankind. 


\section{The Enlightenment Ideal of Autonomy}

If we set ourselves loose a bit from the sensus communis, the more general connection between a project of enlightenment and Bildung seems important. In his 1784 "What is Enlightenment?" (2006) Kant sets out his understanding of enlightenment thus:

Enlightenment is the human being's emancipation from its selfincurred immaturity. Immaturity is the inability to make use of one's own intellect without the direction of another. This immaturity is self-incurred when its cause does not lie in a lack of intellect, but rather in a lack of resolve and courage to make use of one's intellect without the direction of another. "Sapere aude! ${ }^{3}$ Have the courage to make use of your own intellect!" is hence the motto of the enlightenment. (p. 17)

The active use of one's own reason is thus vital in this understanding of what it means to be enlightened. The movement of enlightenment directed itself towards all humans, and the request for independence did not go to any group in particular. However autonomy of thought is considered one of the core elements of the Bildung of students in higher education. Autonomy of thought, as well as being well versed in the curriculum, is what we expect from a student educated from a university. The question now is how we support the development of the student's own voice. How does a student learn to think for him- or herself?

\section{Autonomy of Thought and Interacting with an Authority}

Autonomy is both a presupposition and a goal for Bildung. This has often been coined the pedagogical paradox. ${ }^{4}$ Kant thinks that although all humans are autonomous, just in virtue of being human, we have to learn to be free and self-determined. In the setting of higher education the point is that the students, in order to develop their own voice, need to learn from an expert, the teacher.

Also John Dewey (1902) has been concerned with the seeming opposition between freedom and authority. He notes,

The fundamental factors in the educative process are an immature, undeveloped being; and certain social aims, meanings, values incarnate in the matured experience of the adult. The educative process is the due interaction of these forces. Such a conception of each in relation to the other as facilitates

\footnotetext{
3 “Sapere aude” means, more directly translated into English; “dare to know”, and the phrase is said to stem from Horace.

${ }^{4}$ See e.g., Lars Løvlie in his ”Dannelse og profesjon”, p. 33 in Kunnskap og dannelse foran et nytt århundre - Innstilling fra Dannelsesutvalget for høyere utdanning.
} 
completest and freest interaction is the essence of educational theory. (p. 2)

This picture seems to presuppose that there are some values incarnated in the mature being which we want the immature to develop, values that may be developed only through free interaction. This also means that the teacher and the student necessarily have to interact in order for there to be an educative process according to Dewey.

\section{Bildung and Interaction in Online Courses at the University of Tromsø}

What we want developed in the students is the ability for critical thinking, but not just any critical thinking, we want informed critical thinking. This kind of thinking aims at what we with Plato, especially as we find it in the dialogue Gorgias, could call convictions in the students as opposed to persuasions. We want the students to be autonomous, to freely place themselves within a tradition, and we want them to freely place themselves in relation to other students and to their teachers. In order to do this they will need to formulate their own understanding, and they will obviously need to practice. However, in order to gain from being in a community with other students and scholars, one needs to interact. Actual interaction with other people is thus vital; interaction with only the curriculum (and thus the tradition) will in general not be sufficient for developing your own voice. Now, the question is how well we can take care of this in online education.

At the University of Tromsø a number of purely online courses have been developed since 2005. Earlier our model for distance education was based on gatherings in the region, combined with some work online. An advantage of a model with purely online courses is that these are potentially more flexible than other models and better adjusted to the life situation of people who also work while studying; thus, we have to a large extent run online courses asynchronously. However, several teachers, me included, have noted that online students more readily than oncampus students seem to fall into the reproduction-trap; they reproduce the curriculum rather than rethink it. This means that their written hand-ins more often will be lacking in terms of independence when it comes to the demand of thinking for themselves and when it comes to having the courage to use their own reason. As a first hypothesis as to why, I have guessed that this is so due to fewer comments from others, be it confirmations or corrections of one's own understanding. Scarcity of confirmation and correction means abundance of insecurity.

Lately, we have tested a synchronous tool for web conferences, Elluminate Live. It is a tool integrated in our asynchronous LMS, Fronter. Elluminate Live is a collaborative web conference environment allowing synchronous communication and sharing: the tool allows audio and video broadcast and desktop and document sharing, and it has an interactive whiteboard and a channel for chat. It is possible to transfer the control of the environment to participants and recording of sessions is optional.

Elluminate Live allows real-time classroom teaching online from the teacher's computer to the students on their computers. A teacher can meet up with (in principle) an unlimited number of 
speakers in the Live room, but ordinarily one person (or a few) will speak at a time. A maximum of six people can have their video windows open simultaneously. As the application is integrated in Fronter, anybody in the Fronter-room can start up a Live room and invite others from the same room to join in.

A clear advantage in Elluminate as compared to some of the other web conference systems is that it is possible to see who of the students is speaking in the participant list, who has their camera on, who is drawing on the whiteboard. This information is useful to the teacher, especially in the beginning of a course when one is not yet familiar with the students or if one has a very big class.

Synchronous web conferences are being used in many different ways at the University of Tromsø, but it is in particular a well-functioning tool for seminars, where spontaneous reflection is important. The opportunity to switch between gatherings in plenary (with all the students and the teacher in the same room) and gatherings with a few of the students in separate rooms, in order to work together in smaller groups, is especially useful. Web conferencing enables oral dialogue between teacher and student, directly between the personal computers of those involved. Students can also meet outside of the agreed time for class for working on assignments together, and so on. Web conferencing is used for lectures as well as for seminars, and it is also used for ordinary meetings. The convenience of a live meeting with others is available for anybody who owns a PC or a Mac and a headset with microphones as well as a web camera.

Written discussions in a discussion forum give some specific and very interesting possibilities for development of the student's abilities for critical thinking. The challenge here lies in the teacher's preparations and the kinds of demands that are made to the students concerning form and content, and in order for something of importance to happen, discussion in forums has to be mandatory. The point of using written discussions in online teaching is that the student will get used to seeing his or her own words on the screen, as part of a discussion. Seeing the arguments one has put forward helps in terms of seeing the need for correction and the changes in one's beliefs and opinions. Thus one will have the opportunity to experience any deficiency of the points raised and possibly realize that one has been wrong.

The student's assignments that are being commented upon by the teacher are surely valuable for the student's learning process and his or her development of a personal voice. However, the possibility for oral discussion has always held a special position when it comes to development of abilities for critical thinking and reflection, or at least this is so in the humanities and the social sciences. One of the ideals here has of course been the Socratic dialogue.

Videoconferencing has been and still is an option, and many local communities in the region are equipped with studios. In an educational model relying on videoconferences the students still have to travel, even if the distances are short. The teacher, however, can stay in Tromsø. This model requires somebody to run the studio, to unlock and lock the doors, and so on. And more often, one would want there to be more than one or two students in order to keep the service intact. Now, in the new model with pure online courses, no videoconference is involved. Our question was how can we secure the quality of these courses? And, even more demanding, how 
can we make sure that the students graduating in our online courses are as properly equipped as our students on campus? Critics would say, and in fact often have said, that students in online courses are lacking in the form of Bildung that we typically cheer at the university. It is feared that they will not have gone through the same kind of process of socialization, Bildung, or edification as those on campus.

In philosophy, my subject matter, it has been commonplace to think that one has to get used to hearing one's own voice as one of the voices in an ongoing academic discussion. We like to believe that only the experience and realization of lacunas and errors in one's own belief, arguments, and overall thinking can bring about the kind of reflective and self-reflective abilities that we want in a well-equipped university student. One has to equip oneself with a form and one has to learn how to take a stand on the academically informed and meaningful content that the tradition and the others bring about.

\section{Our Experiences with Elluminate Live}

From our experiences to date, we have to admit that there are some challenges to overcome: There is a high threshold for usage, and technical updates and proper technical testing in advance is required - as well as technical assistance in the beginning. It is important to set up strict requirements for users as concerns the sound equipment (headset with microphones) and camera. And not least, it is important to clear away technical problems concerning connections, connection speed, and various kinds of updates of programs. Elluminate is not easy to use - the user interface is complicated in the beginning. The environment is a bit messy, and users tend to experience the organization of the different tools within the application non-intuitive.

Nonetheless, when all initial problems have been overcome, Elluminate has turned out to be a very useful tool for synchronous tutoring and dialogue, for sharing text and illustrations, and for cooperative learning. Experienced users are enthusiastic about the variety of ways of working and learning with others.

We will continue to extend our use of Elluminate as integrated in Fronter. It is a very useful tool for cooperative learning and in general for real time interaction, on top of a basic "knowledge package," consisting of a well-structured plan for the semester, streamed lectures, reading of textbooks and other kinds of literature, written assignments, discussions in forums, self-tests, and so on, which the students find in their digital classroom. This means that we think one should supply an array of approaches for learning.

We believe that the introduction of Elluminate into several of our online courses will mark a difference in teaching and learning quality as one of the most problematic traits of our purely online courses until now has been too little spontaneous feedback from the teacher and too little interaction between the students. Too little participation on the side of the students has in online courses in general been threatening the student's development of edification, or Bildung. This problem can now - at least to some extent - be overcome. 


\section{Power, Democracy, Internet, and Academia}

There might be certain aspects concerning the social interplay in the academic community that any online student will miss. The power relations between the professors, the body language, and other information that tells about who and what merits attention, information that otherwise would be vital for understanding the values of the community, will not reach the online student. Thus, some information that can be vital for your interpretation of others and for your own behavior in such communities will be missing. This means that the online student lacks parts of the socialization process. As many online teachers report, online students are often less submissive in their communication with the teacher than campus students are. They also seem to be more demanding when it comes to practical concerns, such as requesting delays in handing in assignments. On the one hand, this might suggest that we in online education come closer to an ideal communication with less strict power structures than we see in campus studies. On the other hand, as we have been discussing here, the process of self-formation for the students often seems to be less supported in these courses than is desirable.

For the general citizen the Internet has radically expanded the possibilities for taking part in the public sphere. This means that Kant's idea of the global citizen, the cosmopolitan, could be closer to realization than ever before. Due to online learning more people than before can now also take part in the process of academic Bildung.

\section{Summary}

On the basis of our experiences one might wonder what to think of the future when it comes to virtual learning environments. How can educational technology support the kind of learning and development that we wish for in our online students? What kinds of tools are important? While it is important to note that we need a diversity of approaches and that many virtual environments can support the students in their processes of learning, it is also obvious that not all can support the process of Bildung equally well. We thus will continue to use asynchronous as well as synchronous technologies, but the point is first and foremost that we have to ensure academically based interaction between the students and the teacher as a group, and also between the students, and between the teacher and the individual student. The student must have several opportunities to try out his or her own voice, as a voice among other voices, where some are equal and at least one is an expert. This is how we can reach the kind of Bildung - as well as knowledge, competence, and skills - that we take to be an essential feature for the educated students of higher education. 


\section{References}

Dewey, J. (1902). The child and the curriculum. Retrieved from http://www.munseys.com/diskeight/chid.pdf

Kant, I. (1987). Critique of judgment. Hackett, Indianapolis.

Kant, I. (2006). An answer to the question: What is enlightenment? In P. Kleingeld (Ed.), Immanuel Kant. Toward perpetual peace and other writings on politics, peace, and history. New Haven and London: Yale University Press.

Kant, I. (2007). Anthropology from a pragmatic point of view. In Anthropology, history and education. Cambridge: Cambridge University Press.

Løvlie, L. (2009). “Dannelse og profesjon”, in Kunnskap og dannelse foran et nytt århundre Innstilling fra Dannelsesutvalget for høyere utdanning. (Knowledge and dannelse when a new century is pending. Recommendation from the committee on dannelse in Norwegian higher education): http://www.uib.no/filearchive/innstilling-dannelsesutvalget.pdf

\section{Athabasca University $\mathbf{A}$}




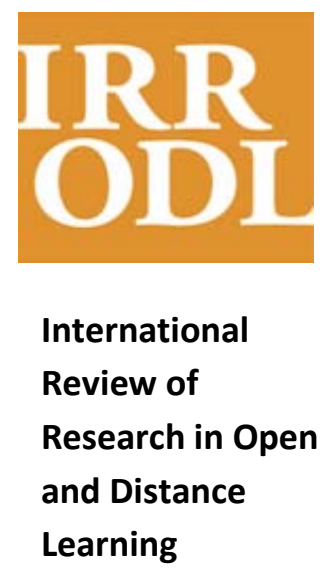

Vol. 12.4

May - 2011

\section{Re-Thinking Sustainable Education Systems in Iceland: The Net-University Project}

\author{
Frank Rennie \\ Lews Castle College UHI, UK \\ Sigurbjörg Jóhannesdóttir \\ Icelandic Ministry of Education, Science and Culture, Iceland \\ Stefania Kristinsdottir \\ The East Iceland Knowledge Network, Iceland
}

\begin{abstract}
The recent economic crisis in Iceland has raised issues of the sustainability of Icelandic higher education to new levels of importance. A key strategy in relation to this economic crisis is to consider the merger of the four public universities in Iceland and to introduce a much higher enegagement with online and open delivery methods of higher education.The Net-University Project was an EU Leonardo-funded initiative to compare approaches to open and distance education in Iceland, Sweden, and Scotland, with additional lessons from Atlantic Canada. In particular, it sought to focus on the transfer of innovation in continuing university education, with particular emphasis on the development and delivery of online higher education courses throughout rural Iceland (i.e., outside of Reykjavik). The partners concentrated on how knowledge and experience about distributed and distance learning models could be transferred between the partner countries and how such models can be integrated into the education system to better support higher education and lifelong learning. There was a particular interest in the practical use of open educational resources (OER) for course design and in the sharing of these course modules among university partners. Some good practice and lessons from OER use in course creation are listed.
\end{abstract}

Keywords: Distance education; open educational resources; knowledge transfer

\title{
Introduction: The Icelandic Context
}

Iceland has a total area of 103,000 square kilometres with a population of approximately 320,000. Nearly half of the national population is located in the dense capital area. Altogether, there are 78 municipalities in Iceland (Statistics Iceland, 2009). The educational system in Iceland is administered by the Ministry of Education, Science and Culture. The fundamental principle of the system is that everyone should have equal opportunities to acquire an education, irrespective of 
economic status, residential location, gender, religion, handicap, and cultural or social background (Ministry of Education, Science and Culture in Iceland, 2005).

Education in Iceland is traditionally within the public sector. There are very few private schools in Iceland and almost all of them receive public funding. The Icelandic educational system is divided into four levels: pre-school, compulsory school, upper-secondary school, and higher education. There are 7 universities, 32 upper-secondary schools, 10 knowledge centres, 31 learning centres, as well as 7 research centres from the University of Iceland (UI) and 2 university centres in the Western-Fjords and in South Iceland that focus on developing and supporting university education (Figure 1).

In addition to the research and learning centres shown in Figure 1, about 100 knowledge centres operate around the country, including regional nature-institutions, development centres, and cultural institutions, some of them involved in university education. In 2009, the Ministry of Education and Culture appointed a group with the role of mapping and investigating the potential for collaboration between research and development services and cultural centres or institutions in Iceland.

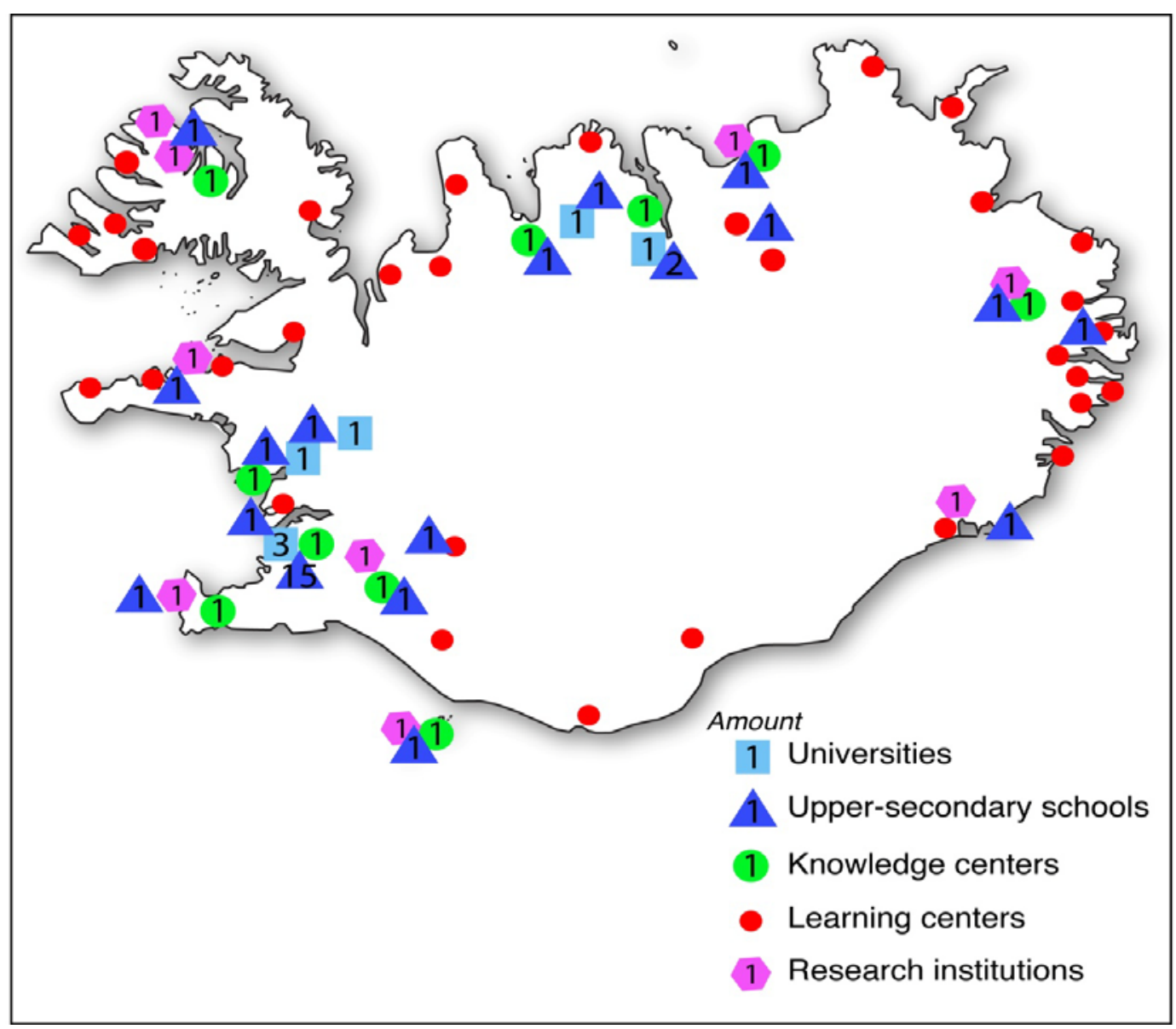

Figure 1. Knowledge centres, learning centres, universities, and upper-secondary schools in Iceland, 2010. 
Most study programmes offered at the university level are only available in the capital area as face-to-face study, but some distance provision is delivered (Table 1. Note: some students in blended study are counted by more than one mode). Only a few study programmes are available in distance or distributed mode, and there is almost no cooperation between universities about what programmes are offered by such methods. At the upper-secondary level, eight hosts offer some programmes in distance teaching, while other programmes are only offered in face-to-face teaching. Iceland is committed to the fundamental principle that everyone should have equal opportunities to acquire an education, regardless of their location, and this has prompted a realisation of the need to collaborate more efficiently between the universities, as well as between higher education institutions and schools or local learning centres.

Table 1

Total Students at University Level in Iceland

\begin{tabular}{|l|rrrrr|}
\hline Universities & $\mathbf{2 0 0 2}$ & $\mathbf{2 0 0 4}$ & $\mathbf{2 0 0 6}$ & $\mathbf{2 0 0 8}$ & $\mathbf{2 0 0 9}$ \\
\hline Total students & 13,900 & 16,096 & 16,738 & 18,104 & 18,226 \\
Day courses & 11,807 & 13,089 & 14,536 & 14,514 & 14,592 \\
Evening courses & 456 & 437 & 196 & 157 & 369 \\
Distance learning & 1,936 & 2,751 & 2,439 & 3,340 & 4,047 \\
\hline
\end{tabular}

Distance education was established to make education accessible and thereby create opportunities for studies that are independent of where people live and what their financial status or personal circumstances are (e.g., a disability). Distance education in Iceland has also grown over the last decade, with a strong indication of continuing growth (Figure 2). In the past decades, an emphasis has been placed on developing the technical aspects of distance education, but now an increased emphasis on pedagogical research may lead to improved education. Finally, there is an emphasis on making distance education more economical by further developing the number of students involved in distance education and by extending the range of courses. 


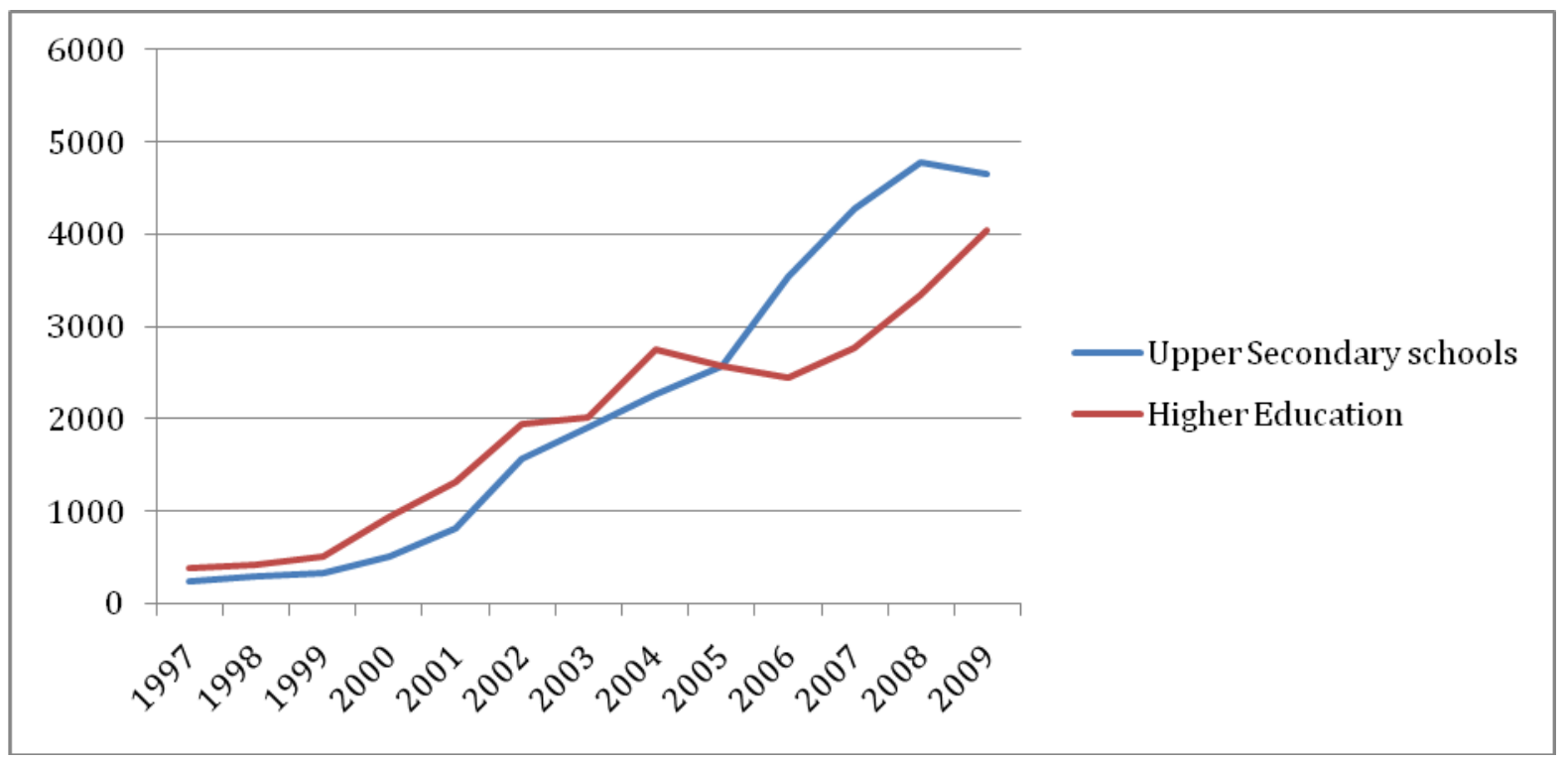

Figure 2. Total number of students participating in distributed learning (Source: Statistics Iceland, 2009).

Distance and distributed education is regulated in the same manner as traditional education; however, no conscious policy for common platform(s) for distributed education is followed and overall no formal collaboration network for distance or distributed education exists. The responsibility for the execution of distance teaching is carried out by several parties within Iceland's upper-secondary schools and universities. The maturity and form of distance education depends on which school is involved and even what type of distance studies are being offered. The development of distance education is practiced separately within each school and university (and can even be very different between departments).

The suggestion from this project, together with the conclusions of the previous study (Thórsteinsdóttir et al., 2007), is that distance education at upper-secondary and university levels in Iceland would benefit hugely from joint collaboration between schools and universities, for example, through sharing facilities, infrastructure, and staff. Lifelong learning and educational centres are working with the universities in Iceland, but it has been suggested that a more formal setting should be formed for broad-scope discussions on distributed education. University representatives are also looking towards more cooperation with overseas countries. It is clear that a policy for distance and distributed education is needed within each of the universities and upper-secondary schools in Iceland, as well as a more holistic policy for the country's overall education system.

Kvasir, the association of education and lifelong learning centres in Iceland, works with the universities and upper-secondary schools. Its main goal is to increase the availability of lifelong learning and distance learning at these levels. Educational levels in Iceland are generally lower in the rural areas than in the densely populated capital area, and this undermines the importance of demonstrating equal opportunities for education on a national basis. 


\section{The Net-University Project}

The Net-University Project was funded to compare approaches to open and distance education in Iceland, Sweden, and Scotland, with additional lessons from Atlantic Canada. The project ran from 2008-2010, co-ordinated by the East Iceland Knowledge Network, with academic partners from Lews Castle College (UHI Millennium Institute, Scotland) and Jönköping University (Sweden). Also involved in the project as contractors were the University of Akureyri (Iceland) and Smart Labrador (for the province of Newfoundland and Labrador in Canada).

There were five clear objectives of the Net-University project:

1. to open universities to the public as an essential part of continued vocational training and lifelong learning;

2. to make university education more accessible to adults and inhabitants of rural areas, including students undertaking self-directed learning;

3. to create a platform for cooperation, between universities and continuing education centres in Iceland and abroad, in developing new courses and degrees;

4. to create a platform for continuing education centres and institutions in rural areas to develop university-level courses related to vocational educational needs;

5. to develop methodologies and support for students in distance education.

Although the idea of an Icelandic university network has been developing for several years, a similar concept for secondary education has not emerged to the same extent. In 2005, the Ministry of Education established a policy group on distance university education that produced two reports: one on distance education in Iceland (Thórsteinsdóttir, 2006) and another on the organisation of online or distance university education in Sweden, Scotland, Canada, and France (Thórsteinsdóttir et. al, 2007). Following up this work, Kvasir, the association of education centres around the country, nominated The East Iceland Knowledge Network (TEIKN) to work further on the development of the Icelandic Netháskóli or Distance University. Based on this nomination, a preparatory group for the Distance University was formed in 2007 within the Ministry of Education, in cooperation with TEIKN. The Ministry supported the group to deliver two outputs:

1. A demonstration model and framework for a Distance University of Iceland, presenting the necessary information, a site map, and ways in which the model could be further developed. At this point the group was only focusing on a Web site listing content related to distance education in Iceland (Jóhannesdóttir, 2007).

2. A report, including a needs analysis and system definition, on how content related to distance education could be transferred from universities’ IT systems and categorised into a centralised database. Issues such as possible services to distance students were also addressed, for example how can learning centres work better with universities in servicing their students' needs and in sharing access to students' calendars, information on exams, and contact information to be able to inform students of local facilities and services? (Jóhannesdóttir, 2008). 
The first report was presented at a conference in the autumn of 2007, where representatives from the universities, the Ministry, and the education centres met to discuss ways to further develop the Distance University concept. Prior to the conference, representatives from TEIKN and the Ministry visited all the universities in Iceland to introduce the idea of the Distance University and discuss their possible involvement in the project.

The second report was a follow-up on the conference and the meetings with the universities. It was developed in cooperation with university representatives (different ones than in the first round) from IT and distance education departments. The report was handed to the Ministry in January 2009, with suggestions on next steps, a draft of a project, and a financial plan for implementation. During the project, the idea for a Distance University was changed from a plan to simply include information on courses and services for distance students to the concept of a holistic and categorized database on university education in Iceland. This database would include categorised information on distance education, courses in English, and short courses as part of lifelong learning, and so forth.

The construction of this holistic database supports the ongoing work of the Ministry to reconstruct the Icelandic university education system and to save money without decreasing services. A similar situation applies to the upper-secondary level, and therefore it would seem sensible to coordinate these networks into one system of lifelong learning, covering both uppersecondary and higher education in Iceland. From this position, the Net-University project serves to provide potential guidelines for the Ministry of Education and Culture's policy development and for collaborative work among the universities and upper-secondary schools in Iceland.

\section{Conceptual Framework}

In the Icelandic context, where a number of universities, research institutions, and higher education learning centres are scattered around the country but the vast majority of students are located in the capital city, there is a strong desire to develop networked solutions for educational delivery. From a broad range of options (Thórsteinsdóttir et al., 2007; Mason \& Rennie, 2008), early investigation by Icelandic institutions identified open and flexible delivery through the existing network of regional centres to have strong similarities with the developing model in Scotland (Hills \& Lingard, 2003; Rennie, 2008).

An earlier study of networked learning gave broad definitions of the terminology and pedagogy and listed among its advantages that network learning "is appropriate for learning situations where the participants cannot gather in a classroom because they are dispersed geographically or have tight schedules, but would benefit from learning together" (Haughey \& Anderson, 1998, p. 8). The current project considered better networking of educational provision within Iceland (particularly using ICT solutions) as a means to share resources, avoid inefficient overlap, and improve quality learning experiences for students. This thinking led to 1) detailed discussions of opportunities for networking within Iceland; 2) consideration of opportunities for international networking; and 3) the improved use of open educational resources (OER) as a basis for 
curriculum development. The latter point was specifically influenced by the frameworks for OER development and use proposed by Gurell and Wiley (2010) and the Commonwealth of Learning (2005). A subsidiary consideration was the assumption that the costs of collaborative sharing of open-access educational materials by a network of Icelandic institutions would be more favourably received by government in the midst of the current financial crisis. The realisation of the need for a substantial step change from the current educational situation, in the face of acute financial cutbacks, has prompted a greater awareness of the possibility of sharing courses between existing universities by utilising online education.This is new thinking in the Icelandic educational system and it would mean re-thinking the funding system that is currently built on face-to-face teaching. Advantages are not just in cost savings and labour efficiency but also in investing in (decentralised) rural areas and driving up quality by networking the best resources. Challenging these idealised opportunities are the elements of the "real" system, as summarized by Davis (2004, p. 98), in which he notes that

any or all of the following deviations from the ideal occur: limited resources, legacy systems that have loyal advocates, key staff who must be retrained, unworkable policies and practices that you never knew existed, inadequate governance processes, [and] administrative systems that might or might not be made to work with the new systems.

All of these components can be recognized as being relevant to the current Icelandic context.

\section{Knowledge Transfer}

Several models of good practice were identified and documented in a report to the Ministry of Education in Iceland (Thórsteinsdóttir et al., 2009). In Scotland, the UHI Millennium Institute (UHI) is a network of 13 academic partners - colleges, research institutions, and 50 plus local learning centres - located throughout the Highlands and Islands of Scotland. Depending on the course, students may be taught face-to-face at one academic site or have access to a distributed course that is taught by staff from multiple campus sites. The latter may be delivered fully online or through a blended approach (e.g., including face-to-face or some video conference tuition.) The UHI has an internal formula to reward the different elements of student engagement, with elements of institutional funding being allocated for tuition, for "hosting" the student (i.e., the provision of classrooms, computer room, libraries, etc.), and for student enrolment (i.e., recruiting the student to the UHI and processing associated paperwork). Each element may be carried out by a different partner in the network.

In Newfoundland and Labrador, we noted that the entire school-college-university system uses a common online platform to link with learners and this has distinct advantages in terms of lifelong learning provision and community education.

In Sweden, local learning centres are owned by the municipality, not the university, and are regarded in much the same light as public libraries and public recreation centres. 
The partner institutions in Scotland, Canada, and Sweden all have a specific locus in the engagement of higher education provision in the sustainable development of their own geographical regions.

A natural development during this project was to investigate a methodology that would utilise open educational resources in the construction of higher education courses that could be adapted to the different educational contexts and cultural nuances of the different institutional partners. A pilot module on environmental issues was developed, using OER to test this methodology in practice, and following positive feedback from the partners, this will be the basis of future collaboration.

\section{The Adoption of OER in Course Design}

At an early stage in the Net-University project, it became apparent that for the academic partners to gain the maximum benefit from a more flexible approach to educational provision, the digital resources and supporting software should be free or extremely inexpensive. This led naturally to a consideration of only open access materials, freeware, open source software, open access journals, and other open educational resources (OER). The study was informed by a recent OECD report in which it was recognised that although the standard definition of OER is "digitised materials offered freely and openly for educators, students and self-learners to use and reuse for teaching, learning and research” (OECD, 2007, p.10), in practice this covers a very wide area. This very broad definition of OER was adopted to include any digital materials that are able to be easily accessed, shareable, and freely available for reuse within the very broad constraints of Creative Commons licensing for use in the construction of educational "lessons."

In the academic literature, there is an ongoing debate between "big OER" (institutionally supported, top-down) and "small OER" (created by individual users on the fly, bottom-up) (Weller, 2010a). Downes (2006), among others, distinguishes between OER systems by funding models, technical models, and content models and attributes very different functions and requirements to these different structures. In the case of this study, we limited ourselves to the coproduction model, that is, the consideration of OER reuse that was essentially the repurposing of open access educational resources that were co-produced, decentralised, and low-cost in the belief that these would be more sustainable in the current Icelandic situation (Wiley, 2007; Guthrie, Griffiths, \& Maron, 2008). It soon became apparent that while there are many thousands of open educational resources available via the Internet (e.g., SideCAP, 2010; Rennie \& Weller, 2010), there are significantly fewer good examples of the systematic reuse of OER to construct open access courses at the higher education level. It was therefore decided that the best way to illustrate the process and the value of OER in course design was to create actual exemplars and document the process. Preference was given to non-institutional, open-access software for the creation or manipulation of educational resources, for example, Jing for screencasts, Picasa and Flickr for images, Wetpaint or PBwiki for hosting wikis, and Moodle for the online learning platform. 


\section{Process}

In order to demonstrate the generic value of the idea, it was decided to create a general course on a subject area with a very broad appeal. Accordingly (and purely as a vehicle to experiment with the pedagogic process), due to the Icelandic interest in generating a course relating to National Park management, the topic People and Nature was selected on the grounds that this specific subject area is an important issue in environmental and societal sustainability and affects all people directly or indirectly.

1. The first step was to identify the main headings for the structure of the course content. These should be the key topics for discussion with students and the most important points around which tutors would like to see learning occur.

2. Using Internet browsers, the next stage was to search and identify relevant digital resources that matched the main headings of our course structure. Priority was given to the identification of open educational resources, as defined above, that could be used and recombined with other resources to produce systematic educational activities of a high quality. Initially, no real distinction was made whether these resources were digital photographs, diagrams, maps, video or audio clips, journal articles, or other materials.

3. The resources were then grouped according to their match with the main headlines of the course structure, and a storyboard was created to link the most relevant OER in a sequential manner to construct a lesson plan or educational activity.

4. The course team then created some wrap-around text to link these OER and to place them in an appropriate educational context with respect to the level and learning objectives of the course. This enabled the team to structure the course materials in a manner that was pedagogically sound and which they considered to be educationally relevant and interesting.

5. It was at this stage that the course team stood back to review the entire scope and contents of the course and its educational resources. As was to be expected, several gaps were identified in the range of these resources. After another brief but unsuccessful attempt to locate relevant OER to fill these gaps, it was decided to create our own OER which we could add to the course and then to contribute these new OER to the global pool of open educational resources with a Creative Commons licence. As a result, web photograph albums (with explanatory captions), screencasts, and a video clip were added. Consideration is being given to web streaming of two or more lecture presentations to be recorded on relevant topics.

6. We now had to make a decision about the media that we wanted to use to deliver the course and the OER that we had selected. In this case, because the exercise was undertaken as a pilot example to demonstrate the process, we decided to host the course in four media formats: 
a. on a publicly accessible wiki (open to Internet view; write-restricted to trusted editors) ${ }^{1}$;

b. as a simple MS Word document for printing and distribution in situations of restricted Internet access;

c. as a simple Open Office document (free and open) for people in the same situation but without access to MS Word;

d. as a single document on a CD (for those without any online access).

7. The next stage was to license the course using the Creative Commons protocols, make the pilot course available for students, and invite review and or further refinements of the course contents and resources. This process is summarised in Figure 3.

In general, we sought open access resources that would have a relevance to northern Europe and that were in English (this being the common project language, as well as the fact that both Iceland and Sweden occasionally teach higher education courses in English). The selection of material was made for an introductory level course, although in reality multiple levels would need to be considered. The project also discussed the idea of providing podcasts in other languages (e.g., Swedish, Icelandic, and Gaelic) to give a wider cultural setting to the resources, but in the end this was not completed due to lack of time.

\section{Difficulties/Challenges}

There have been three main challenges to this operational process. Firstly, it was very timeconsuming in the initial stage to search and identify suitable OER (this was particularly true for relevant academic papers published in open access journals). Although there are many tens of thousands of OER available, they are not necessarily tagged in an appropriate manner to suit the context of each personal search, so a lot of time was spent at the start simply searching and browsing a diverse array of OER sources, using different but related search terms. Considerable Internet skills and some lateral thinking were useful in hunting down appropriate OER, but as with other procedural tasks, these abilities are likely to improve with constant practice.

Secondly, when the assemblage of open educational resources was collected, it was apparent that there is a diversity of quality between the individual OER. The resources also vary in length and in the academic level of complexity, but together this facilitates the inclusion of the OER in different functional roles within the completed course, that is as exemplars of introductory concepts, learning activities, and/or components of further reading.

Thirdly, there were inevitably some gap areas where appropriate OER were not identified or were not considered to be of sufficient quality to be reused (e.g., perhaps too specific or too generic in its context.) In these cases, the challenge was to generate new and relevant OER from personal resources or from those of the institution and then to license and include these in the global OER

\footnotetext{
${ }^{1}$ http://netuniversity.wetpaint.com/page/People+and+Nature+course
} 
pool. While initially a matter of minor apprehensiveness, after some assistance and some practice, a range of very good still images, audio clips, screencasts, and other digital OER were successfully created for addition to the course pool. These were added to Picasa, Flickr, and so forth and then linked to the structure of the course on the course wiki. It goes without saying that starting completely from scratch to produce new OER can at first be rather daunting, but as more are created by the course team and by the institution, and as experience is gained, a large pool of contextually appropriate OER can be generated for teaching and learning support.

From the student perspective, three key challenges were identified by our user group. Firstly, the need to download and install external (independent of the institution) software (e.g., iTunes) may be difficult for users with basic computer literacy. There may also be an issue with obtaining download permissions when students are using a computer terminal at work or in a public learning centre or library. Secondly (and related), it may occasionally be required for users to register with service providers in order to access relevant software, and though the process itself may be relatively simple, there may be an ethical barrier on the part of some users to share their private profile data with corporate providers. When educational resources remain hosted on the university online platform, the contract of confidentiality is solely between the student and the institution; this is extended into multi-party agreements with potentially less control of security when the user makes agreements with providers not subject to control by the university. Thirdly and more generally, the issues of credibility and the status of digital scholarship are in transition, heavily influenced by three new characteristics of academic practice: the fact that educational resources are becoming more digital, networked, and open (Weller, 2010b). For end users, there is a growing requirement to be able to identify "good" (i.e., high-quality) and "bad" (i.e., inaccurate, biased, or low quality) Internet-based resources, and although this issue concerns more than just OER, the openness of OER has tended to encourage students to forage on the Internet in areas without the ability of the lecturer to pre-select relevant resources at a suitable level. Learners frequently feel that they need to be specifically trained to locate and recognize good materials on the Internet.

In the pilot online course, the choice of a free wiki provider (Wetpaint) meant that commercial advertisements were included in marginal frames of the wiki, and this non-educational clutter may have proved to be confusing or annoying to student users. In fact, this software provider offers a facility to have advertising removed from their wikis which have an educational purpose, but the project did not seek to make use of the facility due to the short timeframe and temporary nature of the pilot. A more serious concern relates to the ethical and long-term planning issues of hosting the educational materials of an institution through an external service provider. In the case of this project, the ethical issues are considered to be minimal as students were not being asked to give their information to a third party in order to view the course (only university-based editors were granted write-permissions; read-access is available to all). Secondly, the issues of backup and ensuring access to the information on the external site were not regarded as a problem, again due to the temporary nature of the wiki. In the longer timeframe, there is a wider discussion to be had about balancing the advantages of an internal wiki (university-hosted) that ensures data security, backup services, and so forth versus the greater diversity, versatility, and speed of change provided by external (commercial) software suppliers. This is part of a wider 
discussion that balances the closed-but-secure services provided by universities' ICT against the more popular but open facilities through, for example, WordPress, Facebook, and YouTube.

\section{Perceived Advantages}

A major advantage is the speed with which it is possible to construct high quality courses, using digital OER that have been created by other trusted sources. An estimation of the time taken to construct a course in this way will vary enormously, but it has taken as little as 3-4 weeks rather than many months of the conventional design structure, where each piece of text and teaching resource is generated anew from scratch. Another advantage, then, is the ease of collaboration with others in the generation of new educational perspectives without having to reinvent the wheel. This encourages a good teamwork approach. In addition, the OER method of course construction has the effect of lowering the costs of course production while at the same time generating publicity and inter-institutional collaboration. From a wider perspective, it is a strong, positive feature that the creation and reuse of OER adds value to the global community of learners and scholars, not simply in our own institutions or those of our co-workers. It also brings potential benefits to learners in less developed countries where proprietary software or resources are effectively inaccessible. Lastly, the procedure of using a Creative Commons licence to reuse, share, and develop derivative resources is rewarded by the requirement to share the new OER in appropriate digital repositories, thus benefiting everyone with the improvements and/or contextual changes.

From the perspective of the student, there are two reported advantages to the use of OER materials in course construction. The primary advantage is to enable easy access by learners to alternative ways of learning about a subject/topic than is covered in the course of their studiesto revise, to delve more deeply, or simply to have the same material explained in a different manner by another scholar. Although the initial advantage is mainly direct access to high-quality OER that tutors have drawn to their students' attention, many students are quick to identify such repositories (e.g., Academic Earth, iTunes, Creative Commons, Flickr) as valuable resources that they can explore for themselves. This is encouraged by the seal of approval given to trusted sources indicated by their tutor. A secondary advantage for learners is the speed of course construction facilitated by OER use as this enables tutors to augment the resources on the course as they are discovered on more or less a real-time basis. Unlike conventional courses that are based on textbooks and lectures, the addition of digital educational resources can be added to the web links of a course if, for example an article or video becomes open for circulation, even after it has been covered in the course schedule; students like the freshness and topicality of this facility.

\section{Lessons Learned}

1) Have a clear idea what subjects/concepts you want the course to cover in general, but remain flexible over the specific teaching content. 
2) Some sources of OER are more useful and reliable than others and usually come from trusted "brands" (such as esteemed universities), although many of the smaller OER that are generated by less well-known individuals can be of equally high quality. (We suspect that this issue of "big OER" versus "small OER" will become a highly contested area for education in the near future.)

3) Be flexible and patient in your initial searches for OER sources and courses - different keywords will generate different searches, and it may take time and ingenuity to locate and recognise exactly what you are looking for.

4) The process itself helps to clarify the educational objectives and the desired outcomes of the course to be constructed. Openness to the availability and reuse of OER encourages pedagogical innovation in the incorporation of educational technology.

5) It is best to save the completed course in a variety of formats to enable the widest possible access for learners.

6) The creation of new OER to fill perceived gaps, which can then be added to the global OER pool, may initially be intimidating, but this is quickly superseded by the realisation that the benefits outweigh the time invested.

\section{Conclusions}

The practical experimentation in the project led to the conclusion that while it is relatively easy to find open access resources for educational reuse, it is much more difficult to locate precise OER for specific purposes within even a loosely pre-arranged course structure. There are several immediate reasons for this: firstly, the difficulties in locating relevant resources easily, due to inadequate Internet search skills and or poor tagging of resources (although both of these should improve with use); secondly, many OER are too large (e.g., video clips longer than 15 minutes) to drop into a course structure without skewing the proposed course structure in a manner that was not intended; thirdly (and partly in relation to the second point), some OER cover a wider range of topics than is being sought, and course constructors may be reluctant to edit these OER, even if this is permissible; fourthly, access to some digital resources may require taking steps that are unavailable or unfamiliar to the person searching and therefore discourage exploration; fifthly, some specifically sought resources (e.g., particular academic journals) are not yet available as open resources (although this too may change with time).

From the perspective of the educator attempting to pull together a new course, there is clearly a balancing point where the skills and time needed to locate relevant OER that can be reused in a course is counterbalanced by the skills and time required to generate new educational resources from scratch. The responses to this may largely be governed by the subject matter and level of the course, for example, good quality photographs for an introductory geography course may be readily available on Creative Commons Flickr, whereas comparable quality images for specific medical or engineering subject matter may not. Partly, too, the use of OER may be determined by 
their educational function within the new course, that is are they intended to cover need-to-know areas of the curriculum, or are they intended to cover nice-to-know areas, where students might be encouraged to watch/listen to the views of other scholars (even contrary views to provoke discussion)? With the former, the size and exact relevance of the OER is a crucial issue, requiring short, specific resources, for example, a good diagram, a succinct explanation of a conceptual point, or an illustration with an appropriate example. With reference to the nice-to-know additional educational resources, these may be deployed simply to provide extra layers of perspective for learners seeking a deeper subject understanding.

We found the institutional attitudes to the wider adoption of OER constraining in two areas. On the one hand, there is often a reluctance to reuse resources that appear to be too heavily branded by another institution, perhaps indicating an apprehension that this may be seen as an admission of being in the shadow, or otherwise inferior, to the branded institution. On the other hand, there is also an uncertainty among many academic staff as to whether they as individuals, their institutional employers, or the world at large should be the owners of the intellectual property that they create. To some extent this confusion is being addressed by open access educational initiatives such as OpenLearn (2010) and OpenCourseWare (2010), but these are relatively small cutting-edge initiatives within a large sea of higher education curriculum materials. Apart from a few instances where institutions have taken a strategic lead (and even here), the OER "movement” has largely progressed by the work of individual early adopters.

From the perspective of the learner, the incorporation of OER into course delivery may be relatively discrete (as in images included within an explanatory text) or blatantly obvious (as in the situation where students are referred to external, branded sites such as YouTube, iTunes, and Academic Earth). In neither case did our pilot group of users voice any objections to using OER; rather, the main concern was whether the sites were considered to be reliable educational resources, and in this they were largely reassured due to the fact that their "lecturers" (i.e., the course designers) were seen to be recommending these resources to the students and pre-selecting the OER to be included in the course. The two minor areas of concern that were raised related to the need for students to register with external service providers and to the technical confidence of the students to download and install any necessary software. As with other aspects of online education, dealing with these issues at a comprehensive student induction at the start of the course may dispel these initial concerns.

In conclusion, the experiment to locate and reuse OER in the construction of complete higher education courses was a qualified success. Two areas of proposed further investigation are the skill sets required by academics to locate, identify, and recombine OER into their course materials and the experience of learners in using these hybrid course resources (OER plus contextual original materials) for their own study (especially to what extent they are tempted to continue to explore identified trustworthy sources for their own self-motivated study activities). 


\section{Using OER in Course Design}
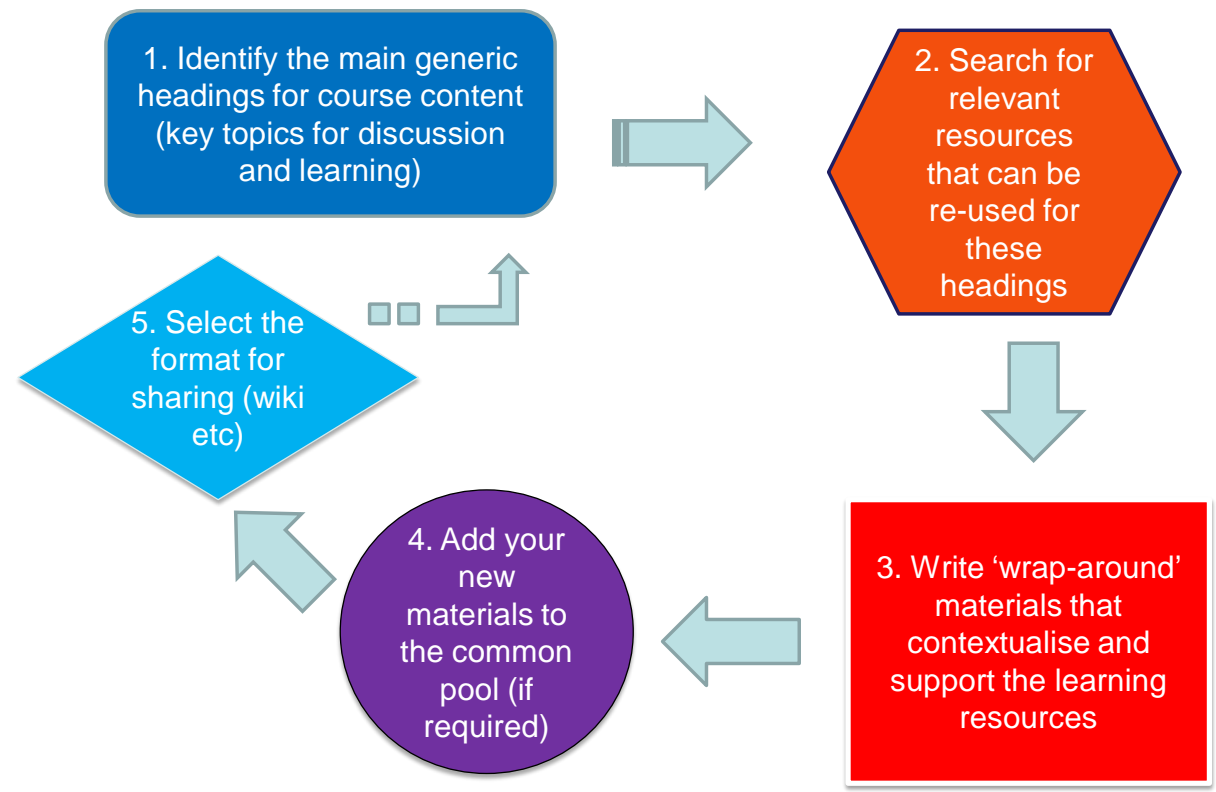

Figure 3. Summary of course design process using OER. 


\section{References}

Commonwealth of Learning (2005). Creating learning materials for open and distance learning: A handbook for authors and instructional designers. Retrieved from http://www.col.org/SiteCollectionDocuments/odlinstdesignHB2.pdf

Davis, A. (2004). Developing an infrastructure for online learning. In T. Anderson \& F. Elloumi, (Eds.), Theory and practice of online learning (Chapter 4). Athabasca, AB: Athabasca University Press. Retrieved from http://cde.athabascau.ca/online_book/

Downes, S. (2006). Models for sustainable open educational resources. National Research Council of Canada. Retrieved from www.oecd.org/document/32/0,2340,en_2649_33723_36224352_1_1_1_1,00.html

Gurell S., \& Wiley, D. (2010). Open educational resources handbook 1.0 for educators. Retrieved from http://wikieducator.org/OER_Handbook/educator_version_one

Guthrie, K., Griffiths, R., \& Maron, N. (2008). Sustainability and revenue models for online academic resources. Retrieved from http://www.jisc.ac.uk/publications/programmerelated/2008/scaithakasustainability.aspx

Haughey, M., \& Anderson, T. (1998). Networked learning: The pedagogy of the Internet. Toronto, ON: Cheneliere/McGraw-Hill.

Hills, G., \& Lingard, R. (2003). UHI: The making of a university. Ediburgh: Dunedin Academic Press.

Jóhannesdóttir, S. (2007). Samstarfsnet háskóla og símenntunarmiðstöðva Demó. Report to the Ministry of Education, Science and Culture in Iceland. Reykjavík.

Jóhannesdóttir, S. (2008). Netháskólinn, skýrsla byggð á viðtölum við samstarfsháskóla. Report to the Ministry of Education, Science and Culture in Iceland. Reykjavík.

Mason, R., \& Rennie, F. (2008). Social implications of three different models of distributed learning. In T. Kidd \& I. Chen (Eds.), Social information technology: Connecting society and cultural issues (Chapter 21). IGI Global.

Ministry of Education, Science and Culture. (2005). Ministry of education, science and culture in Iceland. Publication No. 18. Reykjavík: Ministry of Education, Science and Culture.

OECD. (2007). Giving knowledge for free: The emergence of open educational resources. Retrieved from www.sourceoecd.org/education/9789264031746 
OpenCourseWare. (2010). The landing page of the MIT Open Courseware initiative. Retrieved from http://ocw.mit.edu/OcwWeb/web/home/home/index.htm

OpenLearn. (2010). The learning space of the UK open university open courseware initiative. Retrieved from http://openlearn.open.ac.uk

Rennie, F. (2008). Flexible delivery in action: the case of the University of the Highlands and Islands. In M. Weaver (Ed.), Transformative learning support models in higher education: Educating the whole student (Chapter 7). London: Facet Publishing.

Rennie, F., \& Weller, M. (Eds.). (2010). Open to all: Designing digital courses using open educational resources. Blurb Publishing. Retrieved from http://www.blurb.com/bookstore/detail/1267854

SideCAP. (2010). Project documentation of the "Staff Innovation in Distributed Education in the Caribbean, African, and Pacific countries” project. See especially the resources pages. Retrieved from www.sidecap.wetpaint.com

Statistics Iceland. (2009). Retrieved from http://www.hagstofa.is

Thórsteinsdóttir, G. R. (2006). Fjarnám erlendis: Skipulag fjarnáms á háskólastigi í Frakklandi, Kanada, Skotlandi og Svípjóð. Skýrsla unnin fyrir Menntamálaráðuneytið. RHA. (38 $\quad$ s.) Retrieved from http://www.rha.is/?mod=sidur\&mod2=view\&id=18

Thórsteinsdóttir, G. R., et al. (2007). Fjarnám við íslenska háskóla: úttekt og stöðugreining. Reykjavík: Ministry of Education, Science and Culture. Retrieved from http://www.rha.is/skrar/File/Rannsoknir/2007/fjarnam_isl_hask_lokask.pdf

Thórsteinsdóttir, G. R., Kristinsdóttir, S., Jóelsdóttir, S. S., Rennie, F., \& Hultman, S., \& Downes, S. (2009). Transfer of innovation in continuing university education: The best practice report. $\quad$ Retrieved from http://www.leonardodavinciprojekte.org/adam/project/view.htm?prj=5095

Weller, M. (2010a). Let's play OER roulette. Retrieved from http://nogoodreason.typepad.co.uk/no_good_reason/2010/11/lets-play-oer-roulette.html

Weller, M. (2010b). Every day I write the book. Retrieved from http://nogoodreason.typepad.co.uk/no good reason/2010/09/everyday-i-write-thebook.html

Wiley, D. (2007). On the sustainability of open educational resource initiatives in higher education. Retrieved from the OECD Centre for Educational Research and Innovation/CERI: http://www.oecd.org/edu/oer 


\section{Athabasca University $\mathbf{A}$}

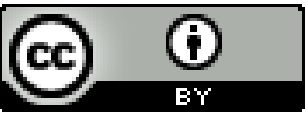

